\title{
USE OF FIBER BRAG GATING SENSORS IN CIVIL ENGINEERING APPLICATIONS \\ By
}

Zahra Yazdizadeh

B.Sc. (Bachelor of Civil Engineering)

Ryerson University, 2009

\author{
A Thesis \\ Presented to Ryerson University \\ in partial fulfilment of the \\ requirements for the degree of \\ Master of Applied Science \\ In the program of \\ Civil Engineering
}

Toronto, Ontario, Canada, 2014

(C)(Zahra Yazdizadeh), 2014 


\section{Author's Declaration}

\section{AUTHOR'S DECLARATION FOR ELECTRONIC SUBMISSION OF A THESIS}

I hereby declare that I am the sole author of this thesis. This is a true copy of the thesis, including any required final revisions, as accepted by my examiners.

I authorize Ryerson University to lend this thesis to other institutions or individuals for the purpose of scholarly research.

I further authorize Ryerson University to reproduce this thesis by photocopying or by other means, in total or in part, at the request of other institutions or individuals for the purpose of scholarly research.

I understand that my thesis may be made electronically available to the public. 


\section{ABSTRACT}

This research presents an overview of development and application of Fiber Bragg Grating sensors (FBG) technology in civil engineering applications. The primary focus of this research is the use of FBGs to investigate two most important time-dependent properties of concrete namely: creep strain and shrinkage strain. The first phase of this investigation is focused on using FBG sensors to measure the concrete strains in unreinforced concrete beams and cylinders to determine modulus of elasticity, the modulus of rapture and fracture energy of concrete. The second phase of this research is designed to investigate the creep and shrinkage using FBG sensors. Normal strength concrete (NC), High performance concrete (HPC) and ultra-high performance (UHPC) specimens' are used to measure creep and shrinkage strains and to compare the values with typical prediction models. The measured creep and shrinkage strains are compared to four different models to determine which model is the most accurate. 


\section{Acknowledgements}

I would like to express my gratitude and appreciation to my graduate supervisor, Dr. Hesham Marzouk, department of civil engineering, for his support, guidance and trust in my personal work and innovation. Without his enthusiasm, inspiration and his invaluable guidance, my academic perspective would not be possible.

Special thanks to the Program Director, Dr. Ahmed El-Rabbany, Department of Civil Engineering, who gave me a chance to further my pursue education.

I would like to thank Lafarge North America for providing UHPC for this project.

I would like to thank Ryerson Civil Engineering Concrete Laboratory staff for their cooperation. Special thanks to Mr. Nidal Jaalouk the Civil Engineering lab director for his cooperation and accommodation to assist me in setting up, running and recording results of this test.

I would like to thank my husband for his support and assistance in reviewing the dissertation. Finally, my love and sincere thanks to my parents for their unconditional support, constant love, and encouragement during my studies and specially for taking care of little one while I was away to complete my studies. I would not be able to complete my graduate studies without their support. 


\section{Table of Contents}

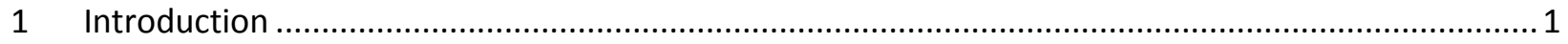

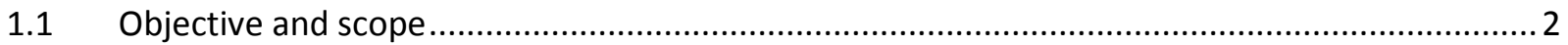

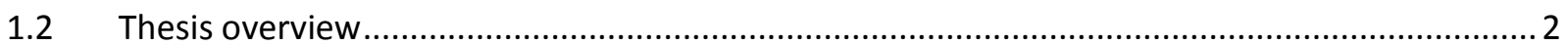

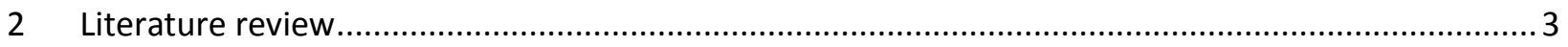

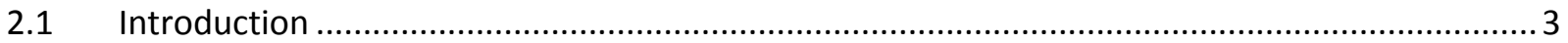

2.2 Structural Health Monitoring System (SHM) …............................................................... 3

2.3 Introduction to Fiber-Optic Technology …..................................................................... 5

2.3.1 Fiber optic sensors in structural health monitoring ..................................................... 6

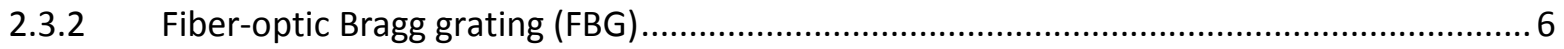

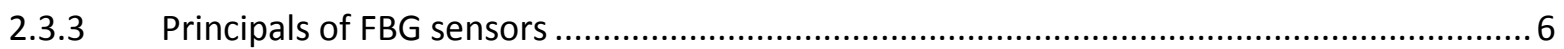

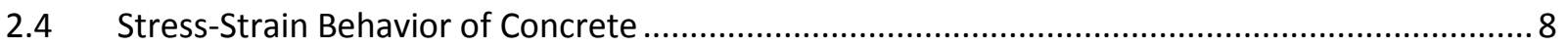

2.5 Stress-strain relationship and modulus of elasticity of concrete............................................ 9

2.6 Modulus of Elasticity of Concrete in Compression (ASTM- C 469) .......................................... 10

2.7 Factors Affecting Modulus of Elasticity of Concrete ............................................................. 11

2.7.1 Effects of moisture condition ...................................................................................... 11

2.7.2 Effects of Aggregate properties …............................................................................ 12

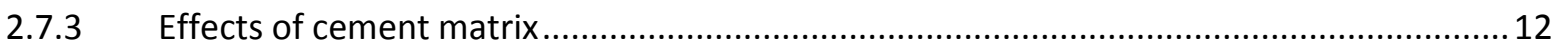

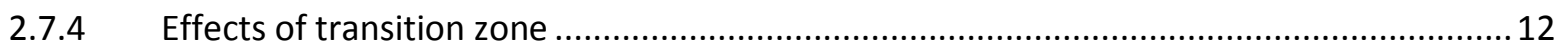

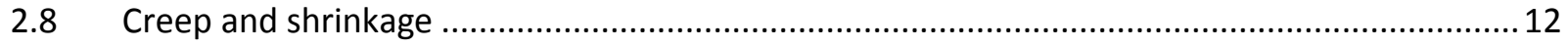

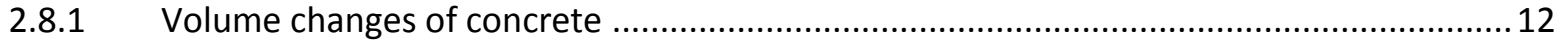

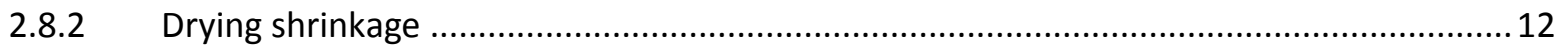

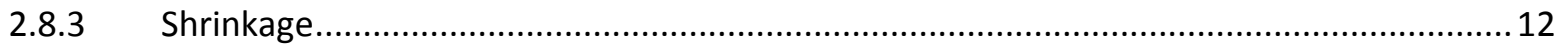

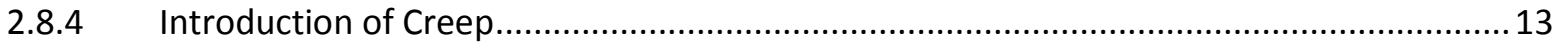

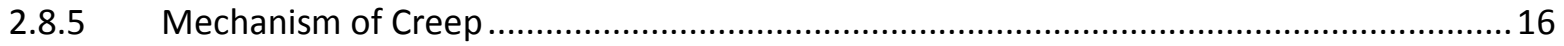

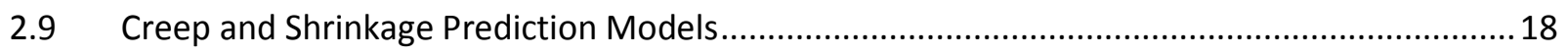

2.9.1 Basic assumptions for development of predictive models ............................................. 18

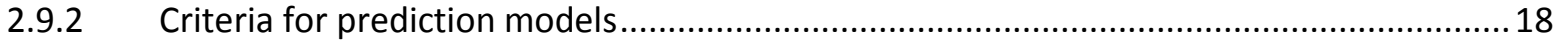

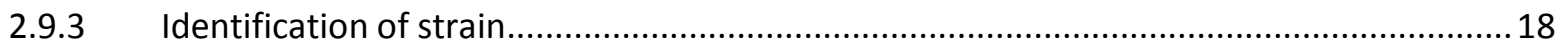

2.9.1 Models for Predication of Shrinkage and Creep of concrete.......................................... 19 


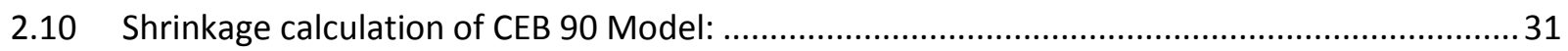

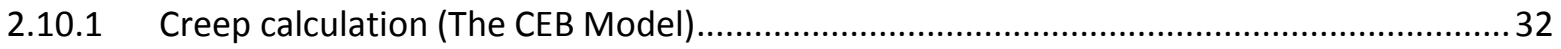

2.10.2 Total strain based on short term experimental data ......................................................... 34

2.10.3 Long -term shrinkage prediction base on experimental result ....................................... 35

2.10.4 Creep and shrinkage measurement for Ultra-High Performance Concrete .......................36

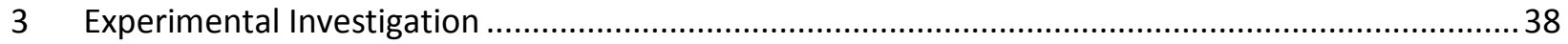

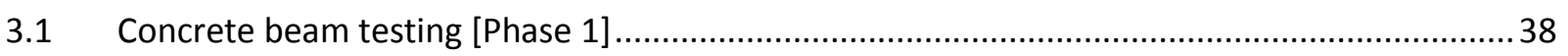

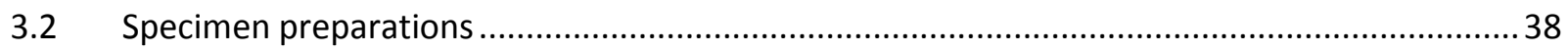

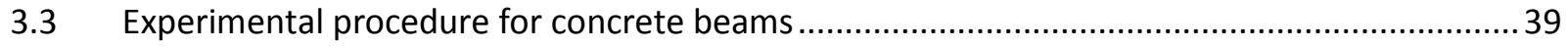

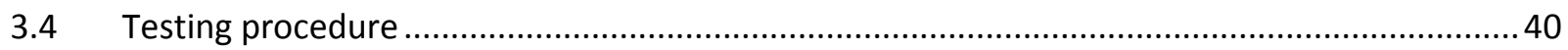

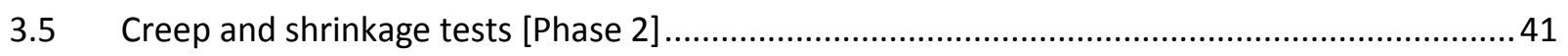

3.6 Concrete Mix Design for Creep Investigation ..................................................................... 42

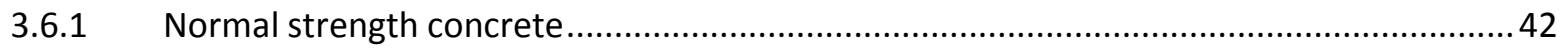

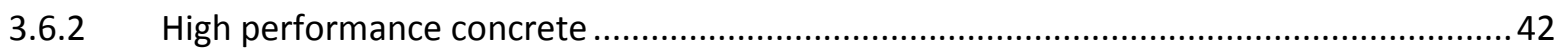

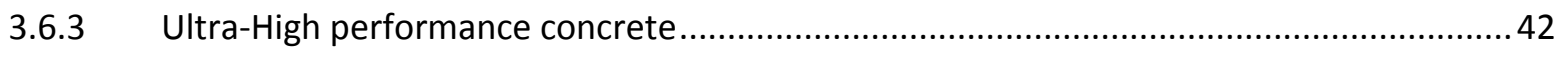

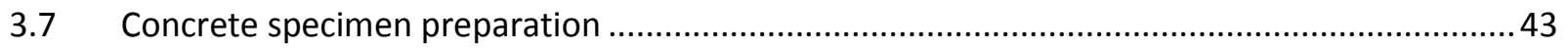

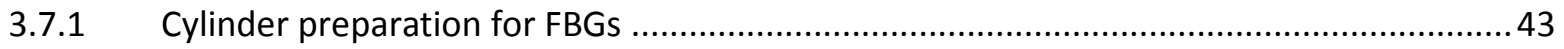

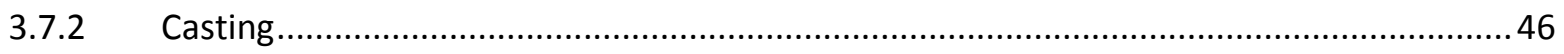

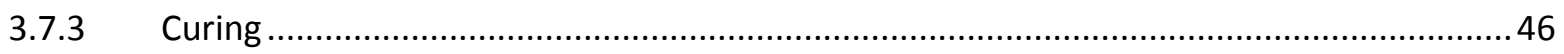

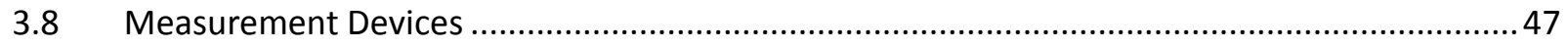

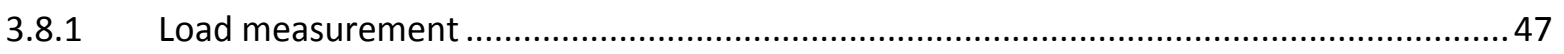

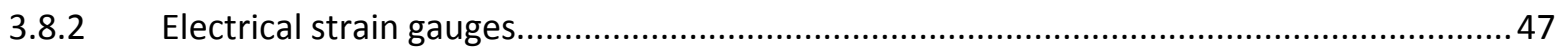

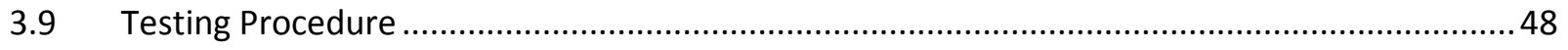

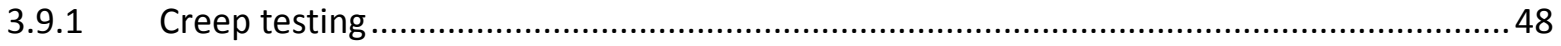

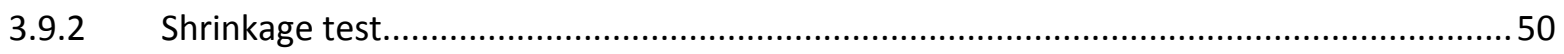

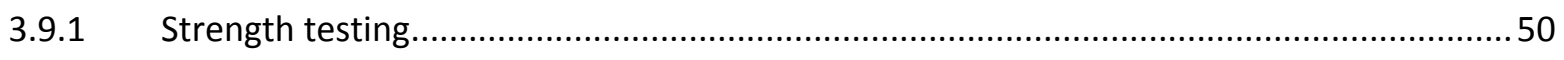

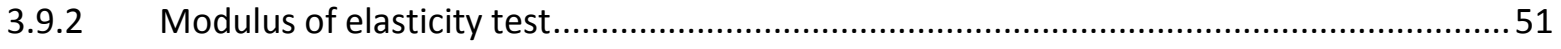

4 Assembling and fabrication of FBG sensors for civil applications .................................................. 53

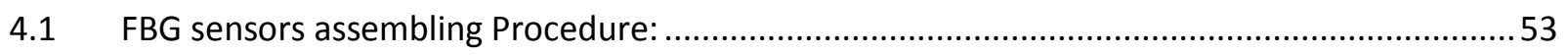

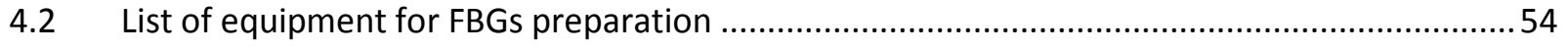

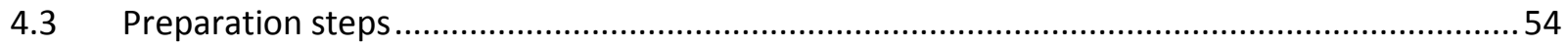

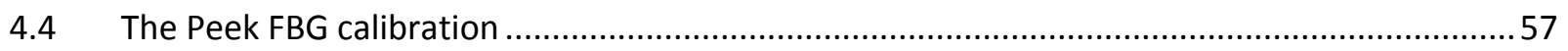




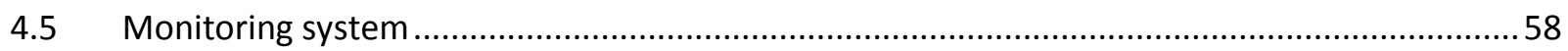

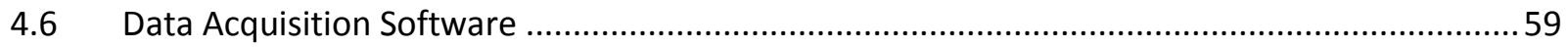

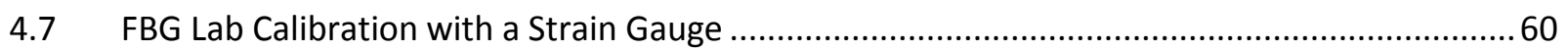

4.7.1 Fiber Bragg Grating (FBG) sensors Results............................................................... 60

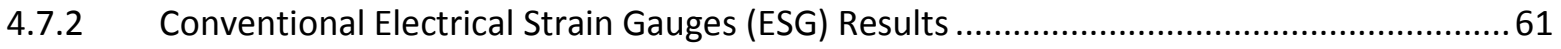

4.7.3 Comparison between Fiber Bragg Grating (FBG) and Conventional Electrical Strain Gauges

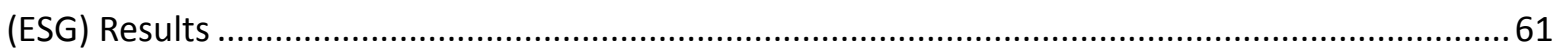

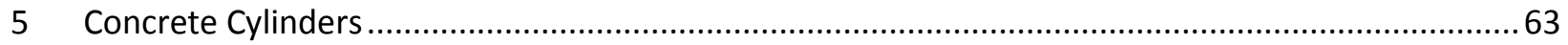

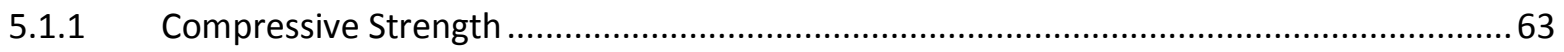

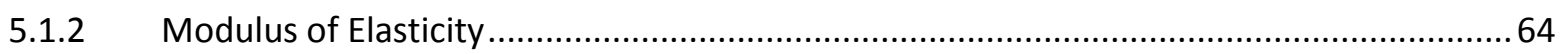

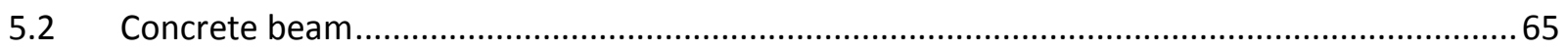

5.2.1 Effect of the loading rate on normal strength concrete .................................................65

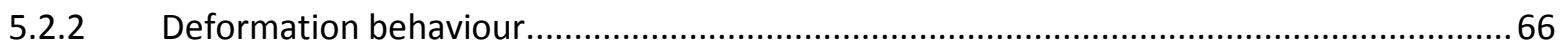

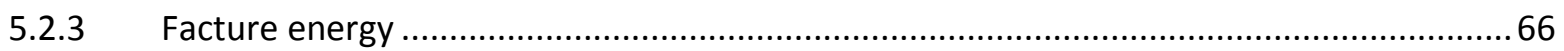

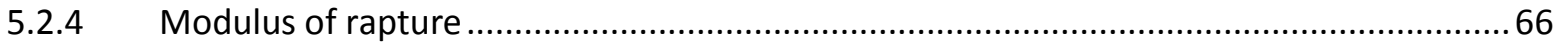

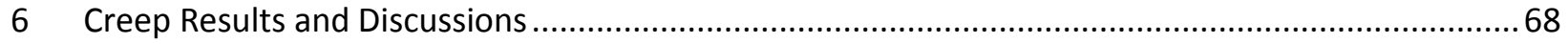

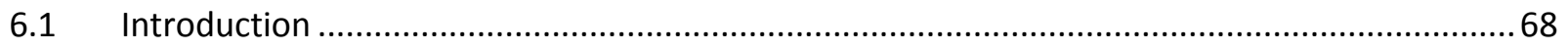

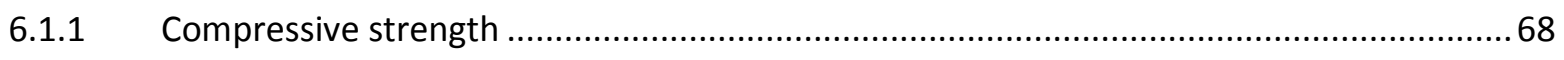

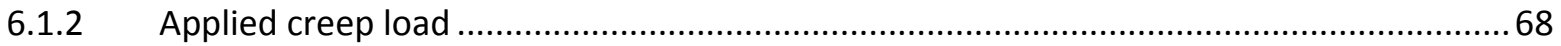

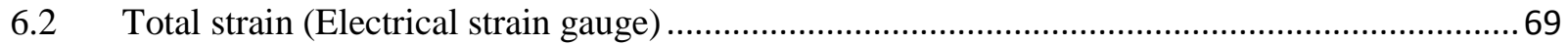

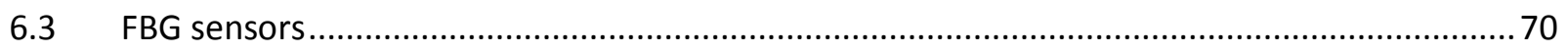

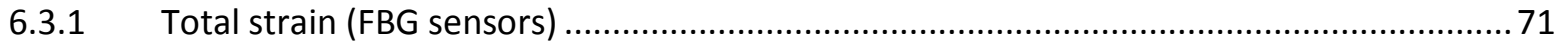

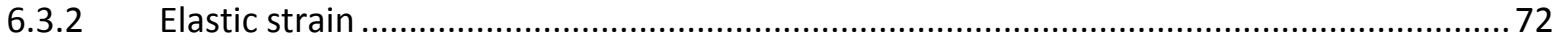

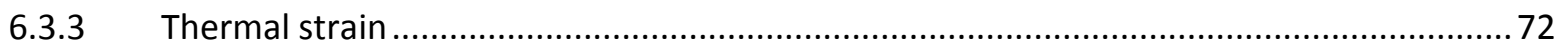

6.4 Total displacement up to required load applied................................................................ 72

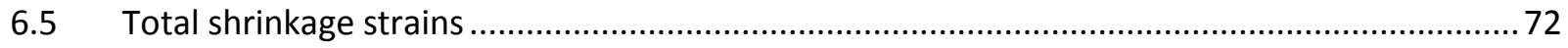

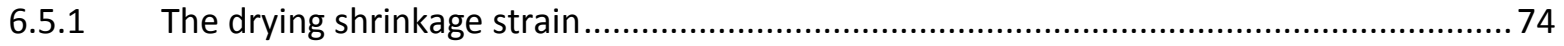

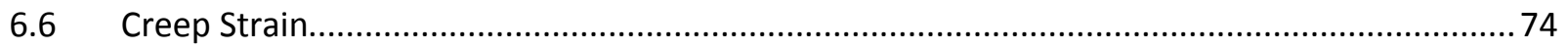

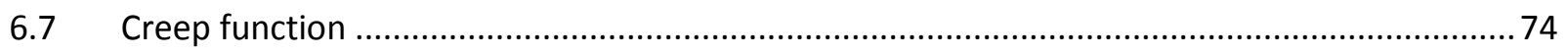

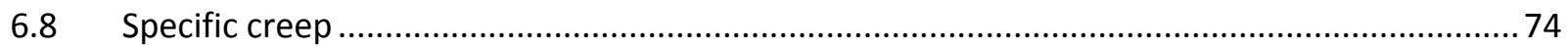

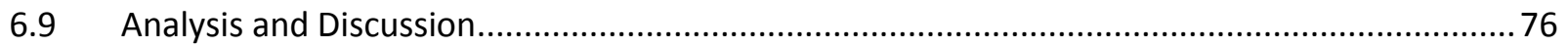

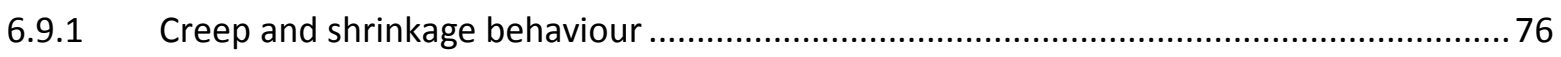




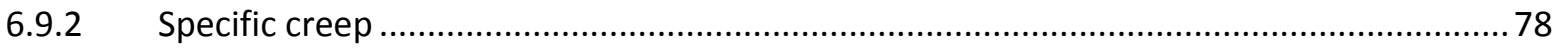

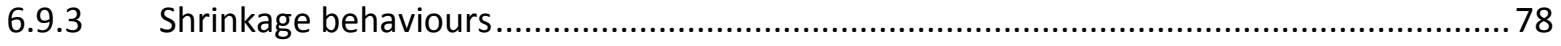

6.9.4 Long -term creep prediction base on experimental result 28 days ................................. 79

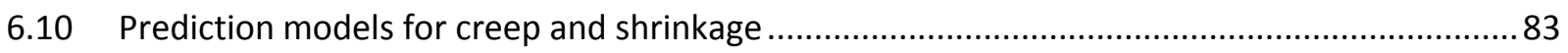

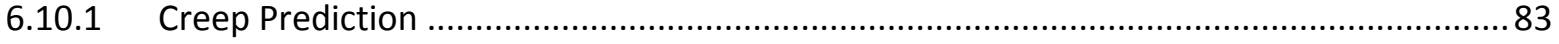

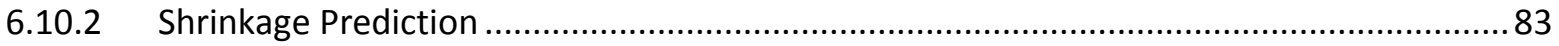

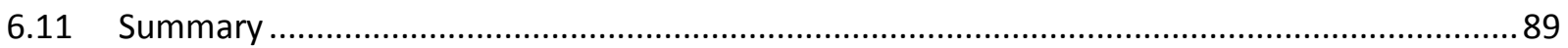




\section{List of Tables}

Table 2-1 Parameters most frequently monitored (Branko \& Daniele, 2007) .......................................... 5

Table 2-2 Parameter ranges for each model ( (ACl Committe 209, 2004) ..............................................20

Table 2-3 B and C values for model (Hossein \& AL-Maraseer, 2005) ........................................................23

Table 2-4 Required parameter for creep and shrinkage (Hossein \& AL-Maraseer, 2005) ....................... 25

Table 2-5 $\boldsymbol{\beta}$ s Coefficient (Hossein \& AL-Maraseer, 2005)...................................................................... 31

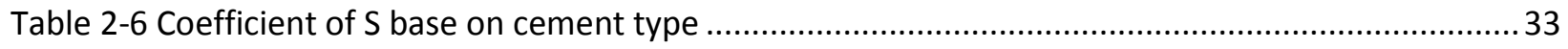

Table 3-1 Mix Properties of three graded concrete ........................................................................... 43

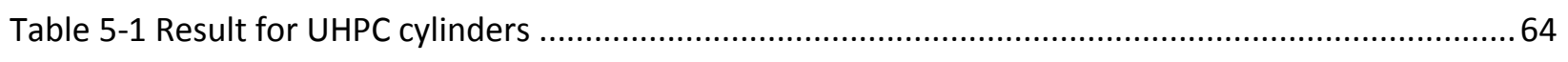

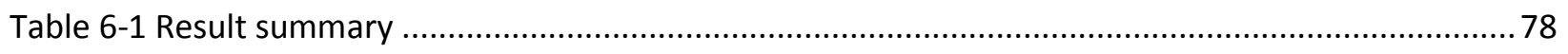




\section{List of Figures}

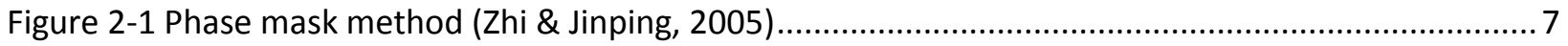

Figure 2-2 FBG strain measuring system (Kin-tak, et al., 2001) ............................................................ 7

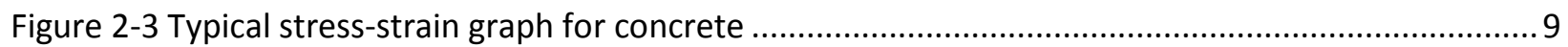

Figure 2-4 Stress-strain relationship in concrete (Neville, 2002)......................................................... 10

Figure 2-5 Time-dependent deformations in concrete subjected to a sustained load (Neville, 2002) ...... 15

Figure 3-1 Beam with embedded FBG sensors, (a) FBG installation,(b) Frame preparation for Beam, (c)

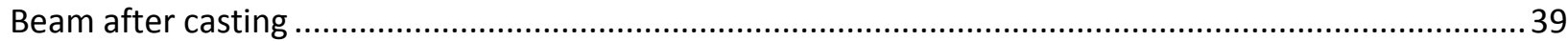

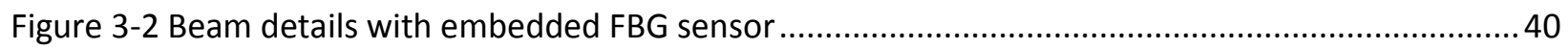

Figure 3-3 Typical beam under two point loading …....................................................................... 41

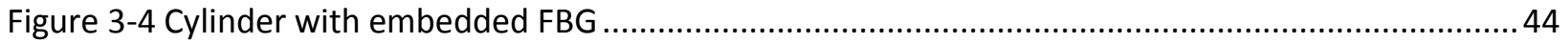

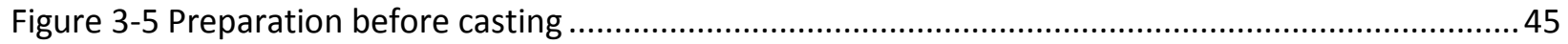

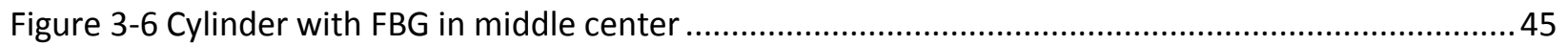

Figure 3-7 Cylinders after pouring concrete with embedded FBG sensor............................................. 46

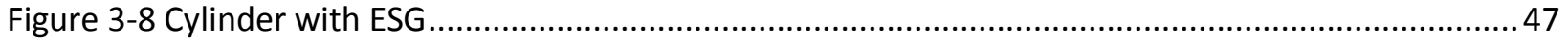

Figure 3-9 Experimental set up for creep test .............................................................................. 49

Figure 3-10 Cylinders under constant load with (a) FBG embedded (b) ESG on surface .........................49

Figure 3-11 Shrinkage Test- Cylinder with embedded FBG .................................................................50

Figure $3-12$ Grinder machine while grinding cylinders ..................................................................... 51

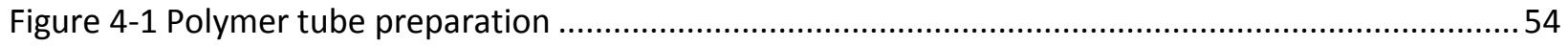

Figure 4-2 Gauge length marked before packaging ......................................................................... 55

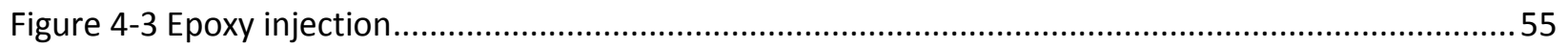

Figure 4-4 FBG and epoxy bonding location at the polymer tube ........................................................55

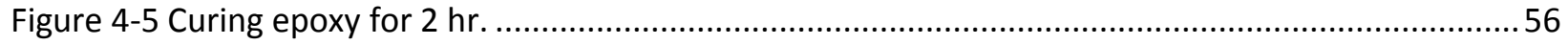

Figure 4-6 Bond stainless steel tubing with polymer tube (Pu, 2010) .................................................56

Figure 4-7 Fiber splicing spot steel tubing protection (Pu, 2010) ...........................................................57

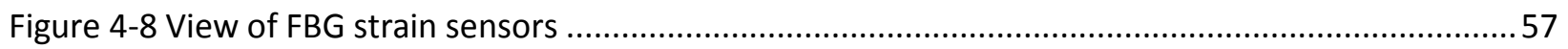

Figure 4-9 View of a device for wavelength measurement with different load ....................................5 58

Figure 4-10 Peak FBG calibration result for three different sensors ….................................................58

Figure 4-11 Fiber Bragg grating wavelength sensing system (Rizk, et al., 2012) ....................................59 
Figure 4-12 Time-strain relationship of the concrete and steel FBG sensor .........................................60

Figure 4-13 Load- average strain relationship of the reinforcement using ESG ....................................61

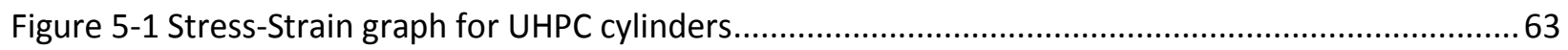

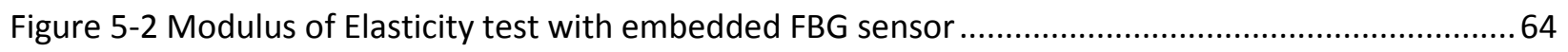

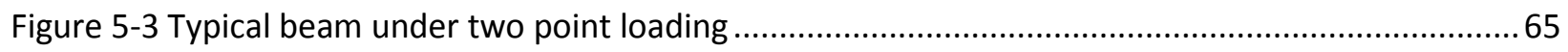

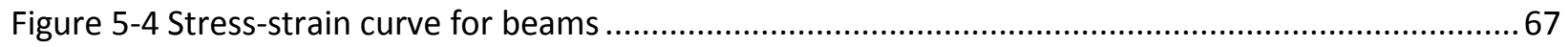

Figure 6-1 Displacement after Load kept constant for 28 days ............................................................69

Figure 6-2 Strain calculated from cylinder displacement of 28 days ..................................................... 70

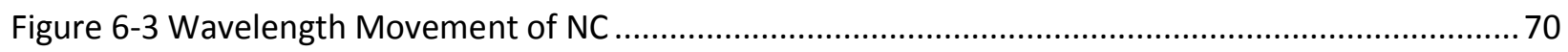

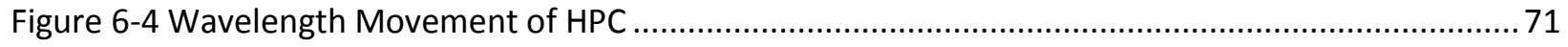

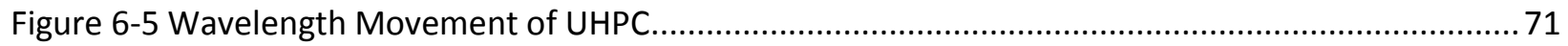

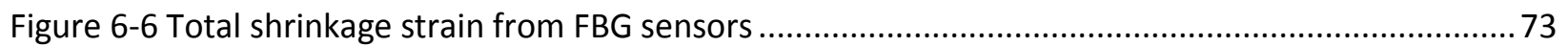

Figure 6-7 Drying shrinkage starting at 28 days after casting from FBG sensors ...................................73

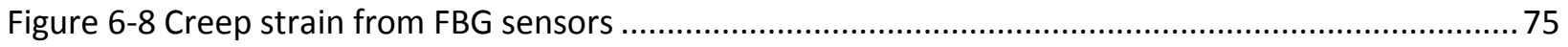

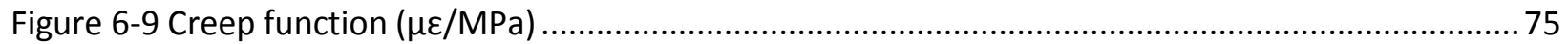

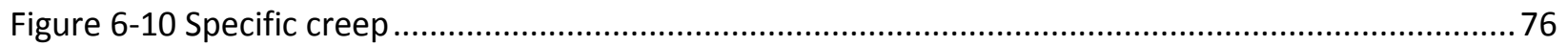

Figure $6-11$ Creep strain regression lines base on 28 days results ..................................................... 80

Figure 6-12 Prediction model result based on 28 days experiment results for normal NC .....................81

Figure 6-13 Prediction model result based on 28 days experiment results for HPC ............................... 81

Figure 6-14 Prediction model results based on 28 days experiment results for UHPC ........................... 82

Figure 6-15 Prediction model results based on 28 days experiment results for, NC, HPC, UHPC............. 82

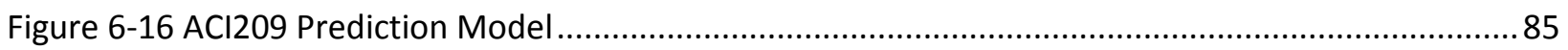

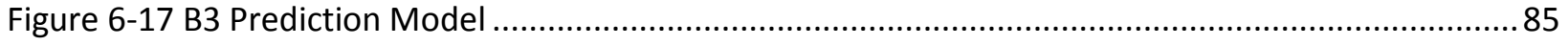

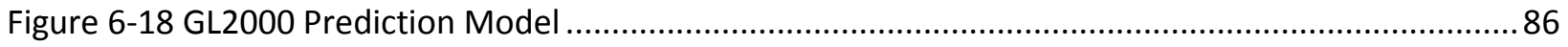

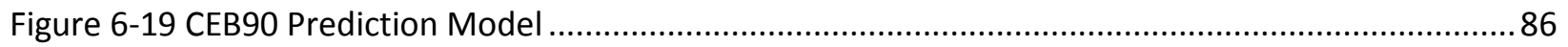

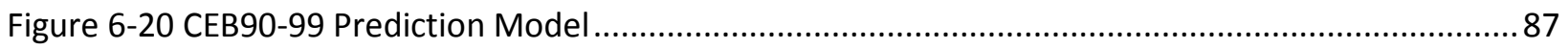




\section{Chapter 1}

\section{Introduction}

Fiber brag grating (FBG) sensors are the preferred type of strain sensors to monitor structures in order to improve safety and optimize maintenance of structures. FBG systems play a key role in measuring structure response to live loading and environmental change such as stress, strain and temperature continuously or periodically in civil structures. There is a need to develop a technique for minimizing the problem of handling and installation of bare fiber to resist the harsh environment of construction industry in FBG sensors. An ideal sensor should be designed to be sensitive to one specific parameter; strain in this research.

All concrete structures experience time-dependent deformation known as creep and shrinkage creep which is described as the deformation of a viscoelastic material under sustained stress over time. Shrinkage is the time-dependent strain measured in unloaded concrete specimen. Therefore, the total strain of concrete specimens at any time is the combination of its initial elastic strain, creep and shrinkage. In this research, creep and shrinkage of different types of concrete with compressive strain of $30 \mathrm{MPa}$ for Normal concrete (NC), $60 \mathrm{MPa}$ for High performance concrete (HPC) and $140 \mathrm{MPa}$ for ultra-high performance (UHPC) are measured with FBG sensors. Creep and shrinkage are identically affected by factors such as hydration of cement paste, amount of water content or water cement ratio (w/c) and silica fume in high and ultra-high performance concrete. The current research uses the latest sensor technique (FBG sensors) to measure creep and shrinkage to compare the results with conventional electrical and mechanical methods.

Conventional and electrical methods have been used for many years for the investigation of creep and shrinkage of concrete. However, these methods use point sensors which are installed on the surface of concrete and are difficult for laboratory use and suffer from long-term instability and fluctuation due to environment effects and temperature changes. Also, they are not suitable for usage under moist conditions and because of this fresh concrete damage these types of strain gauges. FBG sensors have some unique advantages over traditional sensing methods such as good strain resolution, long term stability, immunity to moisture condition, 
capability of continuous strain measurement, and capability of embedded monitoring. Because of all these advantages, FBG sensors are good candidates for investigation of long-term properties of concrete.

\subsection{Objective and scope}

The objectives of this research are (1) to present the application of FBG sensors in civil structures and discuss packaging and installation of these sensors for different applications to measure strain in beam and cylinders; (2) to present shrinkage and creep characteristics of normal, high, and ultra-high performance concrete and factors which affect these two timedependent properties. There is not much research on creep of ultra high performance concrete (UHPC), rapid development of UHPC in construction industry requires more attention to be paid to creep and shrinkage determination of this type of concrete. (3) to examine laboratory observed creep and shrinkage deformation especially for UHPC concrete and (4) to study current prediction models and determine the long-term prediction based on experimental measurements over 28 days

\subsection{Thesis overview}

Chapter 2 reviews fundamentals and development history of fiber optic sensors in civil applications. Additionally, the behaviour of concrete in different stress levels as well as the factors that affect modulus of elasticity of concrete are discussed. Thereafter, creep and shrinkage characteristics of concrete as well as creep and shrinkage prediction models for concrete are presented. Chapter 3 explains the experimental program, which contains two phases namely; 1) cylinders and beam casting with embedded FBG sensors to test with different strain rates and 2) experimental program preparation for creep and shrinkage. Chapter 4 explains the overall results for beam and cylinder tests with embedded FBGs. Chapter 5 is assigned to experimental results for creep and shrinkage as well as results from prediction models. 


\section{Chapter2}

\section{Literature review}

\subsection{Introduction}

This research presents an overview of current study and development in the field of structural health monitoring (SHM). SHM technology, which is a mixture of advanced sensor technology, data processing, damage analysis and condition assessment techniques, is now a key element for the safety and cost-effective management of infrastructures. Among different sensor technologies that are used in SHM, fiber optic sensing is recognized as a reliable technique which offers a viable sensing approach with a number of advantages over traditional sensors. Immunity to electromagnetic interference, light weight, small size, multiplexing capacities, ease of installation and durability are some of the benefits of fiber optic sensing technique. Fiber Bragg Gating (FBG) is a type of optic sensing which is recognized as an in-situ, non-destructive technique for monitoring, diagnosis and control in civil structures.

\subsection{Structural Health Monitoring System (SHM)}

In every society, regardless of geographical location, religion, culture and economical development, Civil and important infrastructure structures exist. It is almost impossible to imagine a civilization without buildings, bridges, roads, power plants, tunnels, dams, railways etc. In every civilization, structures play the main role in human, social, ecological and cultural aspects of society. The gross internal product of each society is associated with all these aspects in structure industry. Therefore, structural engineering ambitions are good design, construction quality, durable and safe operation of structures in each society. Any non-functional civil structure can have irreparable and serious consequences in human life. The human life is the most valuable one which is not returnable. Also, if infrastructures partially or completely go out of service the whole society face complication. The collapse of some critical structures such as nuclear power plant or pipelines can provoke serious ecological pollution as well.

Structural deficiency impacts on the economy are either direct or indirect. The direct impact is cost of reconstruction, while the indirect impact involves losses in other branches of economy. 
Monitoring and measuring have a critical role in well managed structures. Well maintained structures are mostly safer and durable in civil and industrial structures. Collected data from a monitoring program help to optimize the operation, maintenance, repair and replacement of a structure.

Now, there is no exact measurement for structural safety. In many cases, the structures were tested after signs of damage become obvious and damages already impaired the system's reliability. Unfortunately, in many cases structures already collapse or on the verge of collapse which there is no time to prevent and stop the tragedy. Therefore, constant visual inspection is mandatory to prevent any damage in advance in important structures. For instance, USA Federal Highway Administration survey showed that at most $68 \%$ of cases, inspectors couldn't find any interior deficiencies and condition of the structure was reported to be good despite the fact that deficiencies actually existed. To prevent accident or warning imminent irregular states at an early stage to avoid losses as well as giving maintenance and habitation advice, there is a need to use of in-situ, continuous measurement and data analysis of structures under operating condition (Hong-Nan, et al., 2004)

Structural health monitoring (SHM) is a system to provide accurate and in-time data and information to examine performance and condition of a structure at any time. There is no time limitation for monitoring. Ability of long time, short time, continuous and periodic monitoring are the main parameters of SHM. All collected data and information from monitoring can help obtain a plan and design maintenance, increase safety and reduce uncertainty in structures. Importance of structural health monitoring is gradually widespread in society. However, in order to have maximum performance and a successful monitoring process, lots of delicate phase and appropriate and detailed planning of each step are necessary (Branko \& Daniele, 2007)

In the best manner, the process of SHM consists of permanent, continuous or periodically continuous recording of data and information which reflects the performance of the structure. (SHM can be executed in the short term (up to a few days), midterm (few days to a few months), long term (few months to a few years) and during the whole life span depends on the type and conditions of projects and structures (Branko \& Daniele, 2007). Parameters that are selected to be monitored depend on many things, such as the type and the function of a structure, expected loads, construction materials, predictable degradation and environmental conditions. In general, 
SHM can monitor physical, chemical and mechanical properties. Table 2-1 presents the most frequently monitored parameters. This research mainly focuses on monitoring mechanical parameters of structures using fiber optic sensors.

Table 2-1 Parameters most frequently monitored (Branko \& Daniele, 2007)

\begin{tabular}{|l|l|}
\hline Mechanical & Strain, deformation, displacement, cracks opening, stress, load \\
\hline Physical & Temperature, humidity, pore pressure \\
\hline Chemical & $\begin{array}{l}\text { Chloride penetration, sulfate penetration, } \mathrm{pH}, \text { carbonation penetration, } \\
\text { rebar oxidation, steel oxidation, timber }\end{array}$ \\
\hline
\end{tabular}

A typical SHM system has three main parts: a sensor system, a data processing system which includes data acquisition, transmission and storage, and a health evaluation system.

The Commodore Barry Bridge, Benica Martinez bridge of US and the Akashi Kaikyo Bridge in Japan are important examples of SHM. The majority of the conventional sensors used in these structures are based on transmission of electric signals. Limitations of theses sensors are becoming more obvious during the time. These sensors are not small enough to be embedded in structures to measure interior properties. It can measure properties in only one location and cannot be easily multiplexed. Signal problem is another issue for these sensors due to electrical or magnetic interference (EMI). Also, different demodulation methods are required for different sensors. All these increases the inconvenience of conventional sensors in structural health monitoring systems. Fiber optic sensors (FOSs) can be a promising option for sending in structural health monitoring system.

\subsection{Introduction to Fiber-Optic Technology}

Fiber-optic sensors are the primary candidates for complete sensing sensors and have many advantages over other electrical sensors. Field of fiber optic sensors has grown very rapidly in the past 20 years and attracted an intense worldwide attention for research and development. 


\subsubsection{Fiber optic sensors in structural health monitoring}

Delta Rocket in 1987 invented a closed-up fiber gyro to replace mechanical gyros that were the first fiber optic sensor. Such Fiber Optic Sensor (FOS) s are originated from fiber optic communications (Hong-Nan, et al., 2004).Due to different environmental perturbations while transmitting light from one location to another, optical fiber experiences geometrical and optical changes. Geometrical changes are considered as the size and shape of sensors and optical changes are related to reflective index and mode conversion.

\subsubsection{Fiber-optic Bragg grating (FBG)}

Fiber-optic Bragg Grating (FBG) sensors are the most common types of fiber optic sensors used for structural applications. The sensors have been known as a non-destructive evaluation (NDT) technique for all structural applications. FBG specialty is strain sensing locally with high resolution and accuracy. Also, the physical size of optical fiber is very small compared with other strain measuring components and it qualifies to be fixed into structures for determining the strain distribution without manipulating the mechanical properties of the original materials (Kin-tak, et al., 2001)

\subsubsection{Principals of FBG sensors}

\subsubsection{Strain measurement}

In 1987, FBG technology has been discovered by Hill et al. In general, the FBG system includes optical fiber with prewritten grating sensors, a broadband source (light emission device), coupler and optical spectrum analyzers (OSA). For strain measurement in concrete structures, load is transferred directly from host materials to the fiber core of the grating region by the action of shear. This causes the length of the grating area to be changed and reflective result of the core section to be different consequently.

Currently, grating is written with two methods namely: holographic method and phase mask method (Zhi, et al, 2004). Provided grating from Electrical Lab of Ryerson University uses mask method which exposes fiber to a pair of strong Ultra-violet (UV) interference signal. This creates the grating in the core of the optical fiber, those performs fundamentally as a wavelength selective mirror. Figure 2-1 shows a phase mask method which is to write the grating in the optical fiber for strain and temperature measurement. 


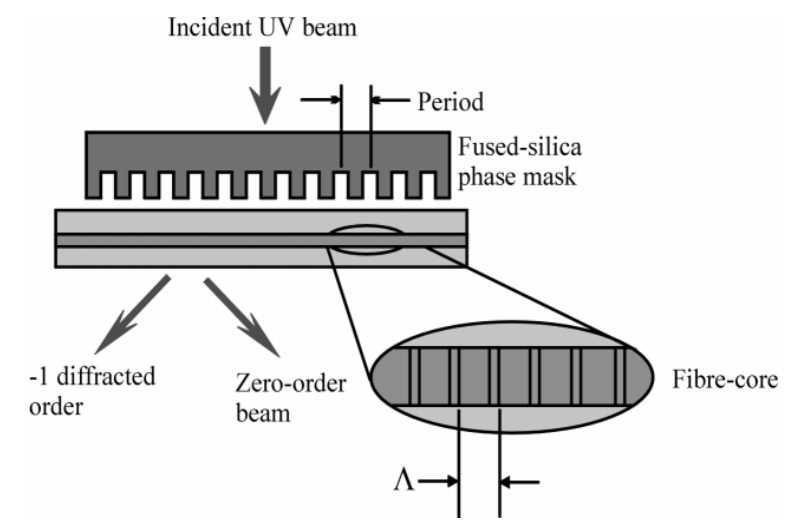

Figure 2-1 Phase mask method (Zhi \& Jinping, 2005)

Figure 2-2 shows a schematic illustration of FBG system for strain measurement. Measuring the reflected wavelength change from the system would show the mechanical properties of the structure.

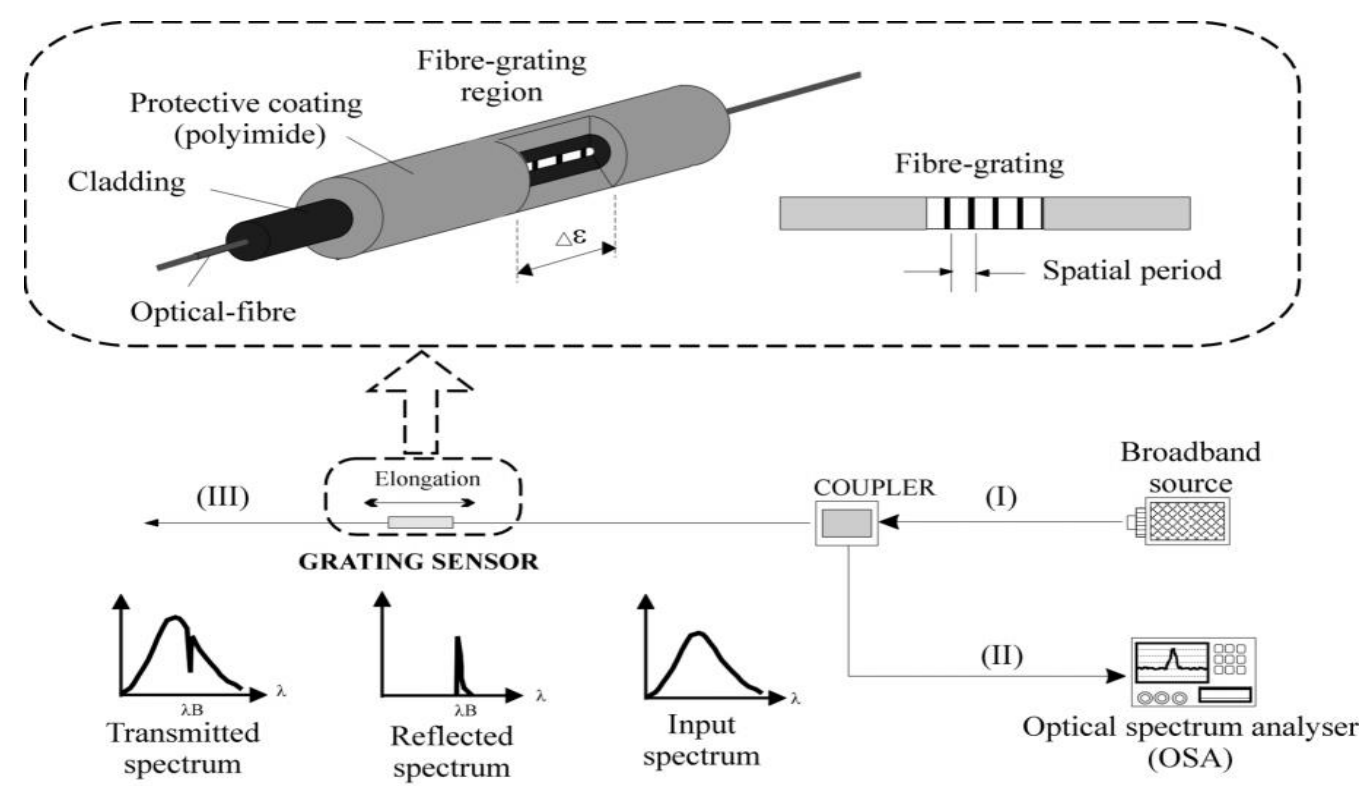

(III)

(II)

(I)

Figure 2-2 FBG strain measuring system (Kin-tak, et al., 2001)

Light is illuminated from the broadband source via a coupler, and then part of the light is reflected back to the coupler. The part of light which is reflected back to the coupler and the reflected-wavelength are detected by the OSA. The common sensing region or grating length is about 5-20 mm. Therefore, in large-scale structures, the FBG can measure as point sensors similar to electrical strain gauges (Allan, et al., 2006) 
Reflected wavelength shift from the sensors shows the strain variation in the grating area in fiber. According to Bragg's law, the reflective wave length can be defined as $\lambda \mathrm{B}=2 n_{\mathrm{eff}} \Lambda$ where $n_{\text {eff }}$ is effective reflective index and $\Lambda$ is grating period. Strain $\Delta \varepsilon$ and temperature $\Delta \mathrm{T}$ have an effect on the shift in Bragg wavelength which is given by:

$\Delta \boldsymbol{\lambda} \mathrm{B}=(\mathbf{1}-\mathbf{p e}) \boldsymbol{\lambda B} \boldsymbol{\Delta} \boldsymbol{\varepsilon}+(\boldsymbol{\alpha}+\xi) \lambda \mathrm{B} \Delta \mathrm{T}$

Equation 2-1

Where $\mathrm{Pe}$ is the effective photo-elastic coefficient which is around 0.22 and is given by:

$\mathrm{Pe}=\left(\frac{\mathrm{n}^{2}}{2}\right)\left[\mathrm{P}_{12}-\mu\left(\mathrm{P}_{12}+\mathrm{P}_{11}\right)\right]$

Equation 2-2

Where $\mathrm{P}_{\mathrm{ij}}$ are the Pockels coefficients of the strain-optic sensor and $\mu$ is the Poisson ratio. The $\alpha$ is the coefficient of thermal expansion which given by $\alpha=(d \Lambda / d T) / \Lambda$ and thermal-optic coefficient is $\xi$ and given by $\xi=\left(d n_{\text {eff }} / d T\right) /$ neff .

It is obvious that both strain and thermal changes of the sensing region will effect on Bragg grating wavelength shift. It is assumed that the deboning and slippages at interface between concrete specimen and optical fiber is negligible (Allan, et al., 2007).

\subsection{Stress-Strain Behavior of Concrete}

The evaluation and definition of stress-strain relationship are necessary to do sectional analysis in concrete structures. A large number of expressions is available but it might not be possible to define a direct relationship between stress and strain to present actual concrete behaviour in ascending and descending portion of stress-strain graph under different test conditions (Mohammed, et al., 1990).

The specimen can be loaded in two extreme slow and rapid rates. The apparent strength of concrete decreases under the slow loading rate which is also called static or quasi-static and it increases under rapid or impact rate. The following graph is a typical stress-strain graph. 


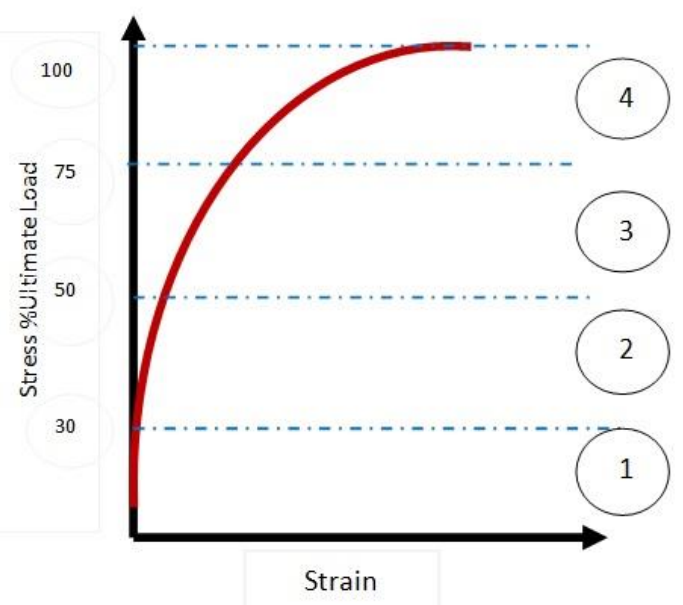

Figure 2-3 Typical stress-strain graph for concrete

(1) The stress-strain graph is linear at stresses less than $30 \%$ of ultimate load

(2) The stress-strain graph becomes non-liner at stresses between $30 \%$ to $50 \%$ of ultimate value due to increasing length and width numbers of micro-cracking's.

(3) The stress-strain curve bends toward horizontal at $50 \%$ to $60 \%$ of ultimate stress

(4) Usually concrete specimen fails at $75 \%$ to $85 \%$ of ultimate value due to the fact that stress reaches a critical stress level for natural crack growth under a sustained stress.

\subsection{Stress-strain relationship and modulus of elasticity of concrete}

Figure 2-4 shows stress-strain relation for a loaded and unloaded concrete specimen in compression or tension before ultimate stress. In compression tests, because of the final preexisting fine shrinkage cracks, there is a small concave up part of the stress - strain relation for a concrete specimen graph at the beginning of loading. Young's modulus of elasticity can be applied to the straight part of the stress - strain curve but when there is no straight portion it can be applied to the tangent to the curve at the origin which is the initial tangent modulus (Neville, 2002).

Recorded strain will decrease when load is applied extremely fast such as 0.01 second; therefore the curvature of the stress-strain curve becomes very small. When loading the specimen increases from 5 seconds to 2 minutes, the strain will increase about $15 \%$. 


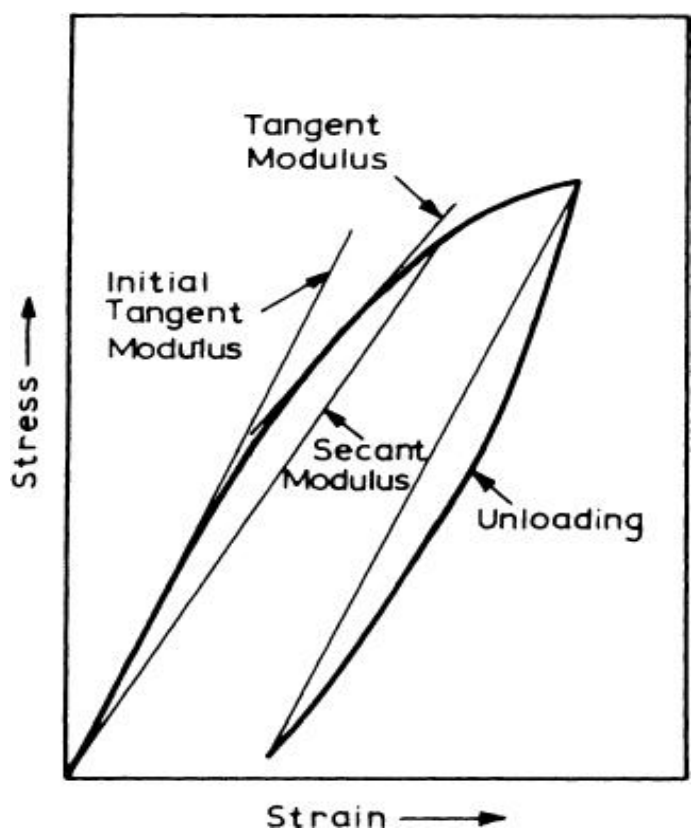

Figure 2-4 Stress-strain relationship in concrete (Neville, 2002)

Due to creep of concrete, the strain will increase when load is applied. However, due to the dependency of instantaneous strain on the speed of loading the differentiation between elastic and creep strains is difficult. Therefore, a random difference is made for practical purposes; the deformation during loading is measured, as elastic, and the following increase in strain is considered as creep. The modulus of elasticity satisfying this requirement is the secant modulus also referred as chord modulus in Figure 2-4. The secant modulus is determined from an experimental stress-strain relation on test cylinder, therefore it is considered as static modulus (Neville, 2002).

Due to decrease in secant modulus with an increase in stress for determination of modulus, the stress must be stated (Neville, 2002). For the same reason, the maximum stress applied is selected as a fixed amount of ultimate strength. This amount was reported as 33\% in (BS, 1983)and as 40\% in (ASTMC469, 2002) .

\subsection{Modulus of Elasticity of Concrete in Compression (ASTM- C 469)}

Modulus of elasticity increases with an increase in compressive strength of concrete but there is no agreed upon form of relationship (Neville, 2002). 
Since concrete is a nonlinear material, four methods are used to determine its modulus of elasticity as follows.

1. Tangent modulus: the slope of the stress-strain curve at any particular stress or strain points.

2. Initial tangent modulus $\left(\mathrm{E}_{\mathrm{it}}\right)$ : the slope of the stress-strain curve at the origin

3. Chord modulus $\left(\mathrm{E}_{\mathrm{c}}\right)$ : the slope of a line drawn between two specified points on the stressstrain curve, with the initial point corresponding to a strain of 50 micro strains.

4. Secant modulus: the slope of a line drawn from origin to any specified point on the stressstrain curve

According to (ACI 318-11, 2002) the modulus is proportional to the strength raised to the power of 0.5 . For normal weight concrete, the secant of elasticity of concrete for structural calculations is calculated a

$\mathrm{E}_{\mathrm{c}}=4.73\left(\mathrm{f}_{\mathrm{c}}\right)^{0.5}$

Equation 2-3

Where;

$$
\begin{aligned}
& E_{C}=\text { modulus of elasticity in } \mathrm{GPa} \\
& \mathrm{f}_{\mathrm{c}}{ }^{\prime}=\text { strength of concrete in } \mathrm{MPa}
\end{aligned}
$$

The modulus of elasticity of for high performance concrete up to $83 \mathrm{MPa}$ according to ACI 36392 is as follows:

$E_{c}=3.23\left(f_{c}\right)^{0.5}+6.9$

Equation 2-4

According to (Neville, 2002) the $\mathrm{E}_{\mathrm{c}}$ is expressed in the range of 80 to $140 \mathrm{GPa}$ compressive strength as following:

$E_{\mathrm{C}}=3.65\left(f^{\prime}\right)^{0.5}$

Equation 2-5

\subsection{Factors Affecting Modulus of Elasticity of Concrete}

\subsubsection{Effects of moisture condition}

Specimens tested in dry condition show about $15 \%$ decreases in elastic modulus as compared to wet specimens. This is explained by the fact that drying produces more micro-cracks in the 
transition zone, which affects the stress-strain behavior of concrete. This is in opposite to its effects on compressive strength. The compressive strength is increased by about $15 \%$ when tested dry compared with wet tested specimens.

\subsubsection{Effects of Aggregate properties}

Porosity of aggregate has the most effect on the elastic modulus of concrete. An aggregate with a low porosity has a high modulus of elasticity. The elastic modulus of concrete is affected by the volume fraction of the aggregate as well as the elastic modulus of the aggregate (Neville, 2002).

\subsubsection{Effects of cement matrix}

The lower the porosity of the cement paste, the higher the elastic modulus of the cement paste. The higher the elastic modulus of the cement paste, the higher the elastic modulus of the concreteas repoted by (Neville, 2002).

\subsubsection{Effects of transition zone}

Void spaces and micro-cracks in the transition zone play a major role in affecting the stressstrain behavior of concrete. The transition zone characteristics affect the elastic modulus more than it affects the compressive strength of concrete (Neville, 2002).

\subsection{Creep and shrinkage}

\subsubsection{Volume changes of concrete}

The volume of concrete will change during hardening. It will shrink by losing of moisture or it will expand if it is hardening in water. The reason of volume change in concrete can be due to applied loads, changes in chemical reaction of the cement with the water, changes in water content and changes in moisture content.

\subsubsection{Drying shrinkage}

Leaving of water from concrete stored in unsaturated air causes drying shrinkage. This moisture movement is irreversible and should be distinguished from the reversible moisture movement. Reversible and irreversible moisture movements are caused by alternating storage under wet and dry conditions.

\subsubsection{Shrinkage}

The amount of changes in the volume of hardening concrete is not equal to the volume of water evaporated. The evaporation of free water causes small or even no shrinkage (Neville, 
1970). When concrete continues to dry, water evaporates and the volume of the restrained cement paste changes and therefore concrete shrinks.

Many factors cause the shrinkage of concrete which is related to changes in moisture condition of concrete.

1. Water and cement content. The shrinkage increases by more water content in the concrete mix.

2. Composition and fineness of cement. High-early strength cement illustrates more shrinkage than normal Portland cement. The finer the cement the greater the expansion under moisture condition (Pickett, 1956)

3. Type, amount, and gradation of aggregate. Shrinkage increases by the smaller size of aggregate particles. Shrinkage reduces by the larger aggregate content. (Hassoun \& ALMaraseer, 2005)

4. Ambient conditions, moisture and temperature. Moist condition causes concrete specimen undergoes an expansion of 200 to 300 microstrain, but concrete specimen shrinks if it dries in the air. High temperature increases shrinkage because higher temperature speeds up evaporation. (Hassoun \& AL-Maraseer, 2005)

5. Size and shape of specimen. Water evaporation in concrete specimen depends on the size and shape of the specimen and consequently the shrinkage changes with the size and shape of the specimen; shrinkage decreases with an increase in the size of the specimen. Shrinkage can be expressed as a function of the volume/surface ratio of specimen.

\subsubsection{Introduction of Creep}

The relation between stress and strain for concrete is a function of time. Creep can be defined as the increase in strain under a sustained stress (Figure 2-5). Because of extreme increase in strain when loading, creep is important in structures. Also, creep is important in stressed concrete which is subjected to constant strain because of a progressive decrease in stress with time. Figure $2-5$ shows this form of relaxation. 
Recorded strain depends on the speed of loading, elastic strain and creep. It is hard to distinguish exactly between the immediate elastic strain and early creep, but it is not practically important as long as the total strain induced by the application of load is measured.

Concrete starts developing plastic and elastic strain upon application of small stresses. The plastic deformation increases under sustained load and it will continue over the years. Plastic deformation increases at a high rate during the first 4 months after applied load (Hassoun \& ALMaraseer, 2005). The immediate strain depends on the speed of applied load under normal condition of loading and it is not only an elastic strain but some creep. It is difficult to distinguish precisely between the immediate elastic strain and early creep, but the total strain induced by applied load is important in practice (Neville, 2002).

Modulus of elasticity of concrete will increase with age whereas elastic deformation decreases slowly with time. Creep is measured as strain in the excess of elastic strain a long time. When the modulus of elasticity is not determined at different times, creep measured as an increase in strain above initial elastic strain which is shown in Figure 2-5. 


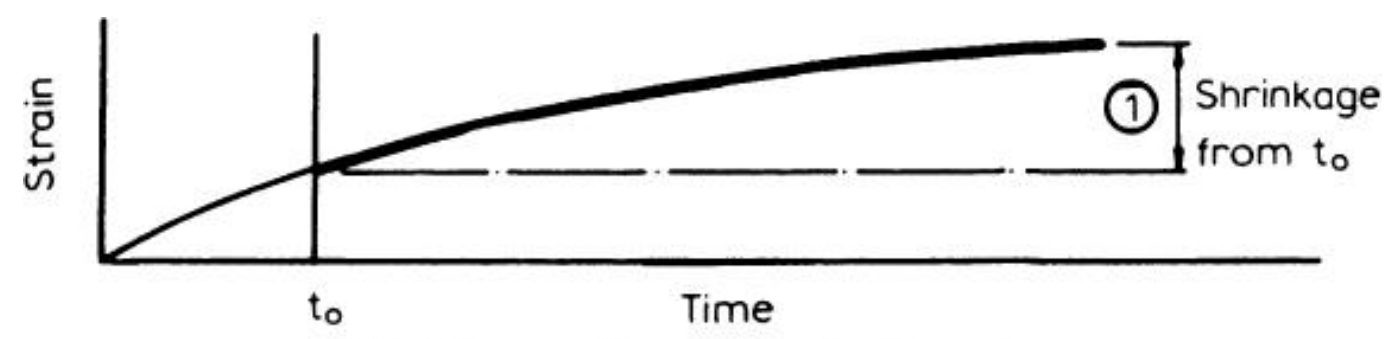

a) Shrinkage of an Unloaded Specimen
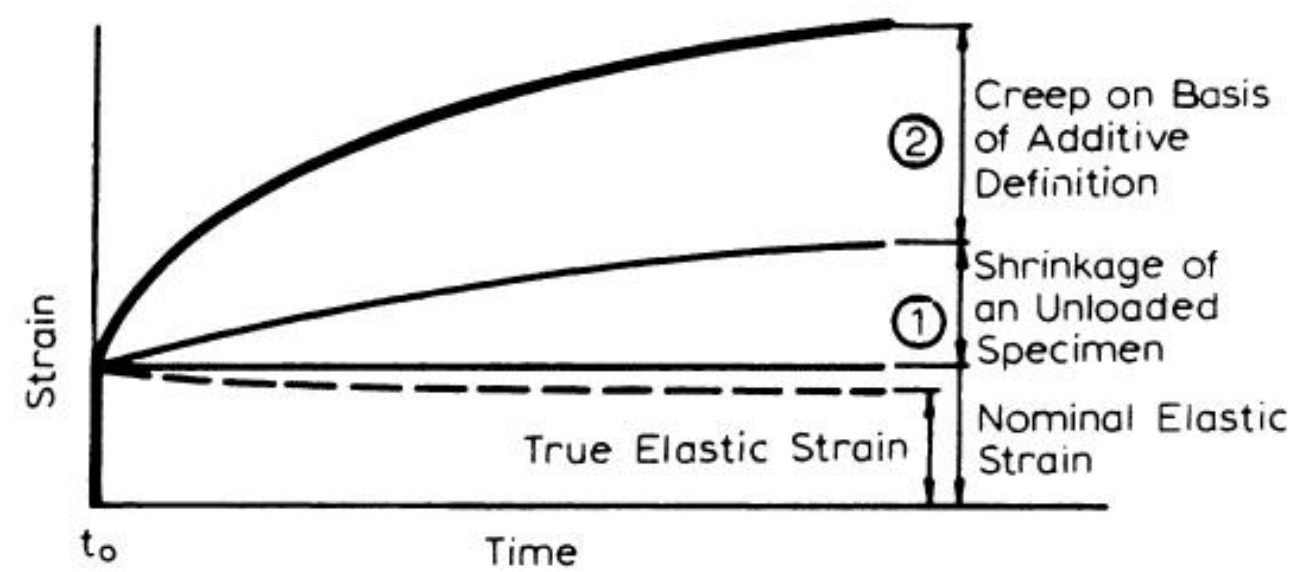

b) Change in Strain of Loaded and Drying Specimen

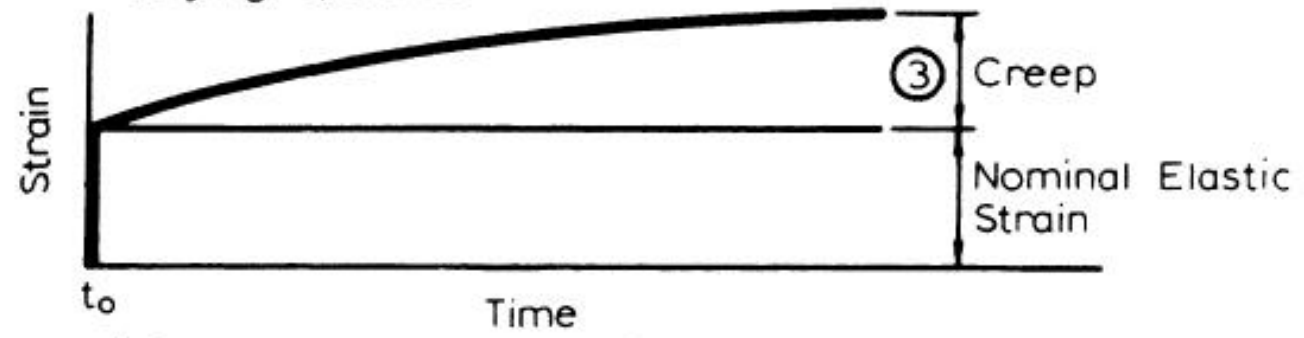

c) Creep of a Loaded Specimen in Hygral Equilibrium with the Ambient Medium

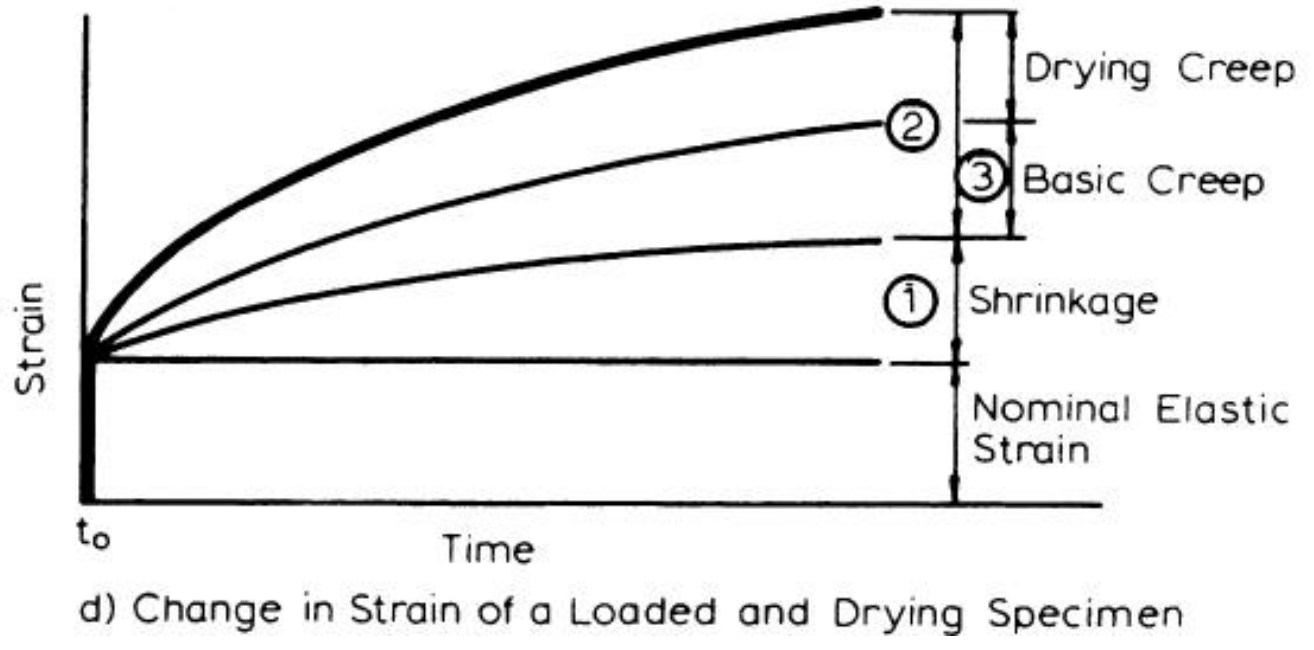

Figure 2-5 Time-dependent deformations in concrete subjected to a sustained load (Neville, 2002) 
In order to eliminate the shrinkage and swelling from creep measurement the concrete specimens should be in drying condition under load, creep is calculated as the difference between the totaldeformation of loaded specimen and shrinkage of a similar unloaded specimen in the same period under the same condition. Shrinkage and creep in the specimen are not independent phenomena; therefore in fact the shrinkage on creep would increase the magnitude of creep.

\subsubsection{Mechanism of Creep}

There is no comprehensive theory to explain all factors affecting the mechanism of creep and able to fully explain experimental results.

Different mechanisms of creep that may explain the mechanism of creep are discussed in the following, namely: mechanical deformation theory, viscous and plastic flow, seepage of gel water, delayed elasticity, and microcracking.

\subsubsection{Mechanical deformation theory}

At first Freyssinet as early as 1936 believed that creep is completely irreversible but after more investigations he found out that creep consists of two parts (Neville, 1970):

1) Irrecoverable: due to the tendency of the hydrated cement paste toward maximum stability under a sustained load

2) Reversible: elastic deformation deferred by the wetness of the concrete due to pressure

The mechanical theory is not accepted by most scholars due to insufficient experimental evidence to support it and deficiency to explain the influence of other factors on creep.

\subsubsection{Plastic theories}

Vogt in 1953 observed that in short-term tests on concrete, after a period under a sustained load, additional load results in a small raise of strain till the stress-strain curve approaches asymptotically to the virgin curve (Neville, 1970).

Some form of plasticity may enter the deformation behavior of concrete at stresses nearing a failure but this is not of great significance to the creep behavior under normal loads. 


\subsubsection{Viscous and viscous flow theories}

Viscous flow theories contribute to creep of concrete; as the hydrated cement paste is a highly viscous liquid whose viscosity increases with time as a result of chemical changes within the structure such as crystallization and aging.

According to the ACI committee 209 many factors influence creep of concrete that can be summarized by follows:

1. Level of stress; Creep in specimen with same type of concrete and load increases by same duration of time.

2. Water-cement ratio; with increases in the water cement ratio, creep increases.

3. Strength and age of concrete; when the stress is applied, creep appears to be smaller if specimen loaded at a late age.

4. Rate of loading; creep increases with and increases in rate of loading for long period of time.

5. Duration of loading; creep increases with loading period. Almost, $80 \%$ of the creep happens in first 4 months and $90 \%$ occurs after 2 years.

6. Ambient condition; creep decreases as the humidity of the ambient air increases.

7. Size of concrete specimen; creep reduces with smaller size of tested specimen.

8. Type and content of cement; the amount of cement significantly affect creep, cement creeps about 15 times as much as concrete

9. Type and grading aggregate; denser concrete with well-graded aggregate decreases creep.

10. Type of curing; high-temperature steam curing of the specimen decreases the total creep due to improved properties of concrete. 


\subsection{Creep and Shrinkage Prediction Models}

\subsubsection{Basic assumptions for development of predictive models}

Many testing conditions have been well-known to standardize the measurement of shrinkage and creep. Some assumptions have been simplified by ACI committee report towards the development of prediction models.

\subsubsection{Criteria for prediction models}

Over the past decades, many models have been suggested for prediction of drying shrinkage and creep under constant load. All these models compromise between precision and convenience. ACI committee 209 recommended that the model or models have to be accessible to engineers with little specialized knowledge of shrinkage and creep. Also, the committee considers the following major issues however are not limited to (ACI Committe 209, 2004):

- Models should be suitable and explain what input information is needed

- What data are needed to evaluate the models

- How intimately the models would represent physical phenomena

- What statistical methods are suitable for evaluating a model

The mechanical properties of concrete at the time of design or mixture proportions should be sufficient to calculate the time-dependent properties of concrete. However, the committee required that shrinkage and creep models should contain the following information: The strength or modulus of elasticity of concrete, ambient relative humidity, age of concrete at loading, duration of drying, duration of loading and specimen size.

The Committee described that, the stiffness of aggregate significantly affect the shrinkage and creep of concrete. Some models explain the effect of aggregate type by assuming that the effect of aggregate is related to its density or concrete elastic modulus. Therefore, models that use concrete strength can be considered as a measured modulus of elasticity to account for aggregate properties (ACI committee 209, 2004).

\subsubsection{Identification of strain}

The total and shrinkage strain is measured in a creep and shrinkage experimental program as of which the compliance is determined. It is not easy to separate early-age creep from elastic strain. 
Consequently, the unspecified elastic strain is dependent on the time at which the strain measurement is made and early creep would be ignored. Basic creep and drying creep are determined from the compliance by subtracting the elastic strain (ACI committee 209, 2004). The following equations describe the strain and compliance:

Total strain $=$ shrinkage strain + compliance $\times$ stress

Compliance $=($ elastic strain + basic creep + drying creep $) /$ stress

\subsubsection{Shrinkage and creep}

Two identical sets of concrete specimen are prepared and stored in the same environment and curing conditions. One set is loaded from 20 to $40 \%$ of concrete compressive strength while the other identical set is not loaded and kept in the same environment as loaded specimen to determine shrinkage. The measured shrinkage strains on the unloaded specimen are subtracted from strain measured on the loaded specimen to determine load induced strains. As a result, it is assumed that the shrinkage and creep are independent of each other. (ACI committee 209, 2004)

\subsubsection{Liner aging model for creep}

Experimental research shows that creep can be considered approximately proportional to stress which suggests that the applied stress should be less than $40 \%$ of concrete compressive strength.

\subsubsection{Stress induced during the curing phase}

Most of the test programs assume the measurement of strains from the start of drying (ACI committee 209, 2004). It is assumed that restrained stress related to swelling and autogenous shrinkage is negligible due to large creep strains and stress relaxation of the concrete at early ages.

Table 2-3 shows the individual model's appropriate range for different input variables (AlManasser \& Lam, 2005). As reported in (ACI committee 209, 2004), comparison of models with experimental data is difficult because of the lack of agreement on selection of suitable data and on the methods used to compare the correlation.

\subsubsection{Models for Predication of Shrinkage and Creep of concrete}

\subsubsection{The ACI 2009 Model}


The ACI 209 model was used for prediction of creep and shrinkage in concrete structure for a long time. For the first time Branson and Christianson developed this model in 1970. Also, the American Concrete Institute recommended the ACI model (ACI Committe 209, 2004). This model is easy to use for creep and shrinkage prediction however; it is not very accurate (Hassoun \& AL-Maraseer, 2005). The model reported the following advantages for this model (ACI committee 209, 2004):

It is simple to use and doesn't need strong mathematical background knowledge.

It is easy to adjust to match short-term test data simply by modifying ultimate shrinkage or creep to produce the best fit data.

The disadvantages of the according model are:

It doesn't model shrinkage or creep phenomena because it has a practical base.

It has limited accuracy.

Table 2-2 Parameter ranges for each model (ACI Committe 209, 2004)

\begin{tabular}{|c|c|c|c|c|c|}
\hline \multirow[b]{2}{*}{ Input variables } & \multicolumn{5}{|c|}{ Prediction Model } \\
\hline & ACI 209R-92 & $\begin{array}{c}\text { Baz ant-Bawja } \\
\text { B3 }\end{array}$ & CEB MC90 & CEB MC90-99 & GL2000 \\
\hline$f_{\mathrm{cm} 28} M P a$ & - & 17 to 70 & 20 to 90 & 15 to 120 & 16 to 82 \\
\hline$a / c$ & - & 2.50 to 13.50 & - & - & - \\
\hline $\begin{array}{l}\text { Cement content, } \\
\qquad \mathrm{Kg} / \mathrm{m} 3\end{array}$ & 279 to 446 & 160 to 720 & - & - & - \\
\hline$w / c$ & - & 0.35 to 0.85 & - & - & 0.40 to 0.60 \\
\hline Relative humidity \% & 40 to 100 & 40 to 100 & 40 to 100 & 40 to 100 & 20 to 100 \\
\hline Type of cement, & $\overline{A S T M}(I$ or $I I I)$ & $\operatorname{ASTM}(I, I I, I I I)$ & $\operatorname{ASTM}(I, I I, I I I)$ & $\operatorname{ASTM}(I, I I, I I I)$ & $\operatorname{ASTM}(I, I I, I I I)$ \\
\hline $\mathbf{t}_{\mathrm{c}}(\mathrm{moist}$ cured $)$ & $\geq 1$ day & $\geq 1$ day & $<14$ days & $<14$ days & $\geq 1$ day \\
\hline $\mathbf{t}_{\mathrm{c}}(\mathrm{steam}$ cured $)$ & 1 to 3 days & - & - & - & - \\
\hline $\mathbf{t}_{\mathbf{0}}$ & $\geq 7$ days & $\mathrm{t}_{0} \geq \mathrm{t}_{\mathrm{c}}$ & $\geq 1$ day & $\geq 1$ day & $\mathrm{t}_{0} \geq \mathrm{t}_{\mathrm{c}} \geq 1$ day \\
\hline
\end{tabular}




\subsubsection{ACI Shrinkage calculation Model:}

The following factors are required for shrinkage calculation:

- Curing method (stem-cured, moist-cured concrete)

- Type of cement

- Relative humidity $(\mathrm{H})$

- Ultimate shrinkage strain $\left(\varepsilon_{\text {shu }}\right)$

- Age of concrete after casting ( $\mathrm{t}$ )

- Specimen shape

- Age at the end of moist curing $\left(\mathrm{t}_{\mathrm{c}}\right)$

The shrinkage strain is described as follows:

$\boldsymbol{\varepsilon}_{\mathrm{s}}(\boldsymbol{t})=\frac{\boldsymbol{t}-\boldsymbol{t}_{\mathrm{c}}}{\boldsymbol{b}+\left(\boldsymbol{t}-\boldsymbol{t}_{\mathrm{c}}\right)} \boldsymbol{K}_{\mathrm{ss}} \boldsymbol{K}_{\mathrm{sh}} \boldsymbol{\varepsilon}_{\mathrm{shu}}$

Equation 2-5

Where,

$$
\begin{aligned}
& t=\text { Age of concrete after casting (days) } \\
& t_{\mathrm{c}}=\text { Age of concrete drying commenced } \\
& b=\text { Constant in determining shrinkage strain, depends on curing method } \\
& K_{\text {sh }}=\text { Relative humidity correction factor for shrinkage } \\
& \varepsilon_{\text {shu }}=\text { ultimate shrinkage strain }=780 \times 10^{-6}(\mathrm{~mm} / \mathrm{mm}) \text { (for moist-and steam cured) }
\end{aligned}
$$

Shape and size correction factor for shrinkage is calculated according to:

$K_{\mathrm{ss}}=1.14-0.0035\left(\frac{V}{s}\right)$

Where,

$$
\begin{aligned}
& \mathrm{V}=\text { Volume of specimen }\left(\mathrm{mm}^{3}\right) \\
& S=\text { Surface of specimen }\left(\mathrm{mm}^{2}\right)
\end{aligned}
$$


Relative humidity correction factor for shrinkage with relative humidity between ( $40 \% \leq H \leq$ $80 \%$ ) is $1.4-0.01 H$ and with relative humidity between( $81 \% \leq H \leq 100 \%)$ is $3-0.03 H$.

\subsubsection{Creep calculation (The ACI 209 Model)}

This model calculates the creep coefficient rather than compliance, which may cause problems according to assumed value for elastic modulus. According to (ACI committee 209, 2004) the committee overestimates measured shrinkage at low shrinkage values and underestimates it at high shrinkage value. This shows the limitation of the model's equation used to predict shrinkage.

The total-load dependent strain at time $t, \varepsilon_{\text {ic }}\left(\mathrm{t}, \mathrm{t}_{0}\right)$ for a concrete member uniaxial loaded at $t_{0}$ with a constant stress is defined as:

$\varepsilon_{\mathrm{ic}}\left(\boldsymbol{t}, \boldsymbol{t}_{0}\right)=\varepsilon_{\mathrm{i}}\left(\boldsymbol{t}_{0}\right)+\varepsilon_{\mathrm{c}}\left(\boldsymbol{t}, \boldsymbol{t}_{0}\right)$

Equation 2-7

Where,

$$
\begin{aligned}
& \varepsilon_{\mathrm{i}}\left(t_{0}\right)=\text { The initial elastic strain at loading } \\
& \qquad \varepsilon_{\mathrm{i}}\left(t_{0}\right)=\frac{\sigma}{e_{\mathrm{cmt} 0}} \\
& \varepsilon_{\mathrm{c}}\left(t, t_{0}\right)=\text { The creep strain at time } t \geq t_{0} \\
& \varepsilon_{\mathrm{ic}}\left(t, t_{0}\right)=\frac{\sigma}{E_{\mathrm{cmt} 0}} \mathrm{C}_{\mathrm{c}}(\mathrm{t})
\end{aligned}
$$

Where,

$$
E_{\mathrm{cmt} 0}=\text { Modulus of elasticity at age of loading }(\mathrm{MPa})
$$

The total load dependent strain is presented with compliance function which is called the creep function, $J\left(t, t_{0}\right)$. Creep function corresponds to the total load dependent strain at time $\mathrm{t}$ produced by a unit constant stress that has been acting since time $\mathrm{t}_{0}$.

$\boldsymbol{J}\left(\boldsymbol{t}, \boldsymbol{t}_{0}\right)=\mathbf{1}+\frac{\mathrm{C}_{\mathrm{c}(\mathrm{t})}}{\boldsymbol{E}_{\mathrm{cm} t 0}}$

$$
E_{\mathrm{cmt} 0}=0.043(\gamma)^{\frac{3}{2}} \sqrt{\sqrt{f_{\mathrm{c}}\left(t_{0}\right)}}
$$


Where,

$\gamma=$ Concrete unit weight $\left(\mathrm{kg} / \mathrm{m}^{3}\right)$

$f_{\mathrm{c}}\left(t_{0}\right)=$ Mean concrete unit compressive strength at age of loading (MPa)

$\boldsymbol{f}_{\mathrm{c}}\left(\boldsymbol{t}_{0}\right)=\boldsymbol{f}_{\mathrm{cm} 28} \frac{\boldsymbol{t}_{0}}{\boldsymbol{b}+\boldsymbol{c t} \boldsymbol{t}_{0}}$

Equation 2-9

Where

$f_{\mathrm{cm} 28}=$ Average 28-day concrete compressive strength $(\mathrm{MPa})$

$\mathrm{b}$ and $\mathrm{c}$ are constants and their values depend on the type of cement according to the table below:

Table 2-3 B and C values for model (Hassoun \& AL-Maraseer, 2005)

\begin{tabular}{|l|c|c|c|c|}
\hline \multirow{2}{*}{ Type of cement } & \multicolumn{2}{|c|}{ Moist-cured Concrete } & \multicolumn{2}{c|}{ Steam-cured Concrete } \\
\cline { 2 - 5 } & B & C & b & \\
\hline ASTM Type I & 4.00 & 0.85 & 1.00 & 0.95 \\
\hline ASTM Type III & 2.30 & 0.92 & 0.70 & 0.98 \\
\hline
\end{tabular}

$C_{\mathrm{c}}(t)$ is creep coefficient which is defined according to :

$\boldsymbol{C}_{\mathrm{c}}(\boldsymbol{t})=\frac{\boldsymbol{t}^{\mathbf{0 . 0 6 0}}}{\mathbf{1 0 + \boldsymbol { t } ^ { \mathbf { 0 . 0 6 } }}} \boldsymbol{C}_{\mathrm{cu}} \boldsymbol{K}_{\mathrm{ch}} \boldsymbol{K}_{\mathrm{ca}} \boldsymbol{K}_{\mathrm{cs}}$

Equation 2-10

Where,

$C_{\mathrm{cu}}=$ Ultimate creep coefficient $=2.35$

$K_{\mathrm{ch}}=$ Relative humidity correction factor for creep

$K_{\mathrm{ca}}=$ Age at loading correction factor

$K_{\mathrm{cs}}=$ Shape and size correction factor for creep 


\subsubsection{The Bazant- Baweja B3 Model}

The B3 model was developed in 1970 by Bazant and Baweja. This model is based on mathematical descriptions of over 10 physical phenomena affecting creep and shrinkage (Zdenek, et al., 2001). This model is functional for simple and complex structures and uses the compliance function. The compliance function reduces the risk of errors due to inaccurate values of elastic modulus. The B3 model separates basic and drying creep (ACI committee 209, 2004). Bazant-Bawja B3 model requires some data which may not available at the time of design, such as specific concrete properties and concrete mean compressive strength for prediction of both shrinkage and creep. In this model some default values of the input parameter automatically considered if they are not available. Also authors suggested that if the compressive strength at 28 days is the only known parameter for design, the water-cement ratio can be calculated using the following equation and the typical values of cement content and aggregate cement ratio will be assumed.

$\frac{\mathrm{w}}{\mathrm{c}}=\left[\left(\frac{\mathrm{f}_{\mathrm{cm} 28}}{22.8}\right)+0.535\right]^{-1}$

Equation 2-11

The following parameters are needed to calculate shrinkage with B3 model: Compressive strength at day 28 , curing condition, cement type, relative humidity, water content in concrete and specimen shape.

The shrinkage strain $\varepsilon_{\mathrm{s}}(t)$ can be calculated using the following equation:

$\boldsymbol{\varepsilon}_{\mathrm{s}}(\boldsymbol{t})=\left(\boldsymbol{\varepsilon}_{\mathrm{shu}}\right)\left(\boldsymbol{K}_{\mathrm{h}}\right) \boldsymbol{S}(\boldsymbol{t})$

Equation 2-12

Where,

$\varepsilon_{\text {shu }}=$ Ultimate shrinkage strain according to equation 2-13

$K_{\mathrm{h}}=$ Humidity function according to table 2-4

$S(t)=$ Time function for shrinkage according to equation 2-14

Ultimate shrinkage stain is determined with the following equation: 
Where,

$\alpha_{1}=$ Type of cement correction factor

$\alpha_{2}=$ Curing condition correction factor

$w=$ Water content $\left(\mathrm{kg} / \mathrm{m}^{3}\right)$

$f_{\mathrm{cm} 28}=$ Mean compressive concrete strength at day $28(\mathrm{MPa})$

Table 2-4 Required parameter for creep and shrinkage (Hassoun \& AL-Maraseer, 2005)

\begin{tabular}{|l|l|l|l|l|l|}
\hline $\begin{array}{l}\text { Curing } \\
\text { method }\end{array}$ & $t_{0}$ (days) & $\mathrm{H}$ & $\mathrm{K}_{\mathrm{ca}}$ & $\mathrm{k}_{\mathrm{ch}}$ & $\mathrm{k}_{\mathrm{ca}}$ \\
\hline \multirow{2}{*}{ Moist Cured } & $\geq 1$ days & $\geq 40 \%$ & N/A & N/A & N/A \\
\cline { 2 - 6 } & $\geq 7$ days & $\geq 40 \%$ & $1.25\left(t_{0}\right)^{-0.118}$ & $1.27-0.0067 \mathrm{H}$ & $\begin{array}{l}1.14- \\
0.0035(\mathrm{~V} / \mathrm{S})\end{array}$ \\
\hline \multirow{2}{*}{ Steam Cured } & $\geq 1$ days & $\geq 40 \%$ & $1.13\left(t_{0}\right)^{-0.095}$ & $1.27-0.0067 \mathrm{H}$ & $\begin{array}{l}1.14- \\
0.0035(\mathrm{~V} / \mathrm{S})\end{array}$ \\
\cline { 2 - 6 } & & & & N/A & N/A \\
\hline
\end{tabular}

The correction factor $\left(\alpha_{1}\right)$ for cement type $I, I I, I I I$, is $1.00,0.85$ and 1.10 respectively. Also the correction factor $\left(\alpha_{2}\right)$ for stem cure concrete, water cured $(100 \% \mathrm{H})$ and sealed during curing is $0.75,1.0$ and 1.2.

The humidity function for shrinkage $\left(\mathrm{K}_{\mathrm{h}}\right)$ is :

$$
\begin{aligned}
& (\text { Humidity } \leq 98 \%)=1-\left(\frac{H}{100}\right)^{3} \\
& \text { Humidity }=100 \%=0.2 \\
& 98 \% \leq \mathrm{H} \leq 100 \%=\text { Liner interpolation }
\end{aligned}
$$

$S(t)$ is time function for shrinkage and calculated according to the following equation: 
$S(t)=\tanh \sqrt{\frac{t-t_{\mathrm{c}}}{T_{\mathrm{sh}}}}$

Equation 2-14

Where,

$\mathrm{t}=$ Age of concrete after casting (days)

$\mathrm{t}_{\mathrm{c}}=$ Age of the concrete drying commenced (days)

$\mathrm{T}_{\mathrm{sh}}=$ Shrinkage half-time (days) according to the equation 2-15

$\mathrm{Ks}=1$ (for not identified members)

$T_{\mathrm{sh}}=0.085\left(t_{\mathrm{c}}\right)^{-0.08}\left(f_{\mathrm{cm} 28}\right)^{-0.025}\left[2 K_{\mathrm{s}}\left(\frac{v}{s}\right)\right]^{2}$

Equation 2-15

\subsubsection{Creep calculation (The Bazant- Baweja B3 Model)}

Creep function or creep compliance $J\left(t, t_{0}\right)$ is calculated from the following equation:

$J\left(t, t_{0}\right)=q_{1}+C_{0}\left(t, t_{0}\right)+C_{\mathrm{d}}\left(t, t_{0}, t_{\mathrm{c}}\right)$

Equation 2-16

Where,

$q_{1}=$ The instantaneous strain

$C_{0}\left(t, t_{0}\right)=$ The compliance function for basic creep

$C_{\mathrm{d}}\left(t, t_{0}, t_{\mathrm{c}}\right)=$ The compliance for drying creep

$\boldsymbol{q}_{1}=\frac{\mathbf{0 . 6}}{\boldsymbol{E}_{\mathrm{cm} 28}}$

Equation 2-17

Where

$E_{\mathrm{cm} 28}=4735 \sqrt{f_{\mathrm{cm} 28}}$

The compliance function for basic creep is calculated as follows: 


$$
C_{0}\left(t, t_{0}\right)=q_{2} Q\left(t, t_{0}\right)+q_{3} \ln \left[1+\left(t-t_{0}\right)^{0.1}\right]+q_{4} \ln \left(\frac{t}{t_{0}}\right)
$$

Where,

$\mathrm{q} 2$ = Aging viscoelastic creep factor

$$
\begin{gathered}
\qquad q_{2}=185.4(c)^{0.5}\left(f_{\mathrm{cm} 28}\right)^{0.9} \times 10^{-6} \\
c=\text { Cement content }\left(\frac{K g}{m^{3}}\right) \\
Q\left(t, t_{0}\right)=\text { The binomial integral } \\
q_{3}=\text { Nonaging viscoelastic creep function } \\
q_{4}=\text { follow creep parameter } \\
t_{0}=\text { Age of concrete at loading (days) } \\
\boldsymbol{Q}\left(\boldsymbol{t}, \boldsymbol{t}_{0}\right)=\boldsymbol{Q}_{\mathrm{f}}\left(\boldsymbol{t}_{0}\right)\left[\mathbf{1}+\frac{\boldsymbol{Q}_{\mathrm{f}}\left(\boldsymbol{t}_{0}\right) r^{r\left(t_{0}\right)}}{Z\left(t, t_{0}\right)^{r\left(t_{0}\right)}}\right]^{-\mathbf{1} / r\left(t_{0}\right)}
\end{gathered}
$$

Where,

$$
\begin{gathered}
Q_{\mathrm{f}}\left(t_{0}\right)=\frac{1}{0.086\left(t_{0}\right)^{2 / 9}+1.21(t 0)^{4 / 9}} \\
Z\left(t, t_{0}\right)=\ln \left[1+\left(t-t_{0}\right)^{0.1} / \sqrt{ } t_{0}\right. \\
r\left(t_{0}\right)=1.7\left(t_{0}\right)^{0.12}+8 \\
q_{3}=0.29 q_{2}\left(\frac{w}{c}\right)^{4} \\
q 4=20.3\left(\frac{a}{c}\right)^{-0.7} \times 10^{-6}
\end{gathered}
$$

The creep function for drying creep, $C_{\mathrm{d}}\left(t, t_{0}, t_{\mathrm{c}}\right)$ would be calculated as follows: 
Where,

$q_{5}=$ Drying creep compliance function that would be calculated as follows:

$\mathbf{q}_{5}=\frac{0.757\left|\varepsilon_{\mathrm{shu}} \times 10^{6}\right|^{-0.6}}{\mathbf{f}_{\mathrm{cm} 28}}$

Equation 2-21

$H(t)$ and $H\left(t_{0}\right)$ are spatial average of pore relative humidity that is calculated as follows:

$\left.H(t)=1-\left(1-\frac{H}{100}\right) S(t)\right]$

Equation 2-22

$\left.H\left(t_{0}\right)=1-\left(1-\frac{H}{100}\right) S\left(t_{0}\right)\right]$

Equation 2-23

$S\left(t_{0}\right)=\tanh \sqrt{\frac{t_{0}-t_{\mathrm{c}}}{T_{\mathrm{sh}}}}$

Equation 2-24

\subsubsection{The GL2000 Model}

The GL2000 model was developed by Gardner and Lockman with small modification which applied to Gardner (Gardner \& Lockman, 2001) . This model is a modification of the GZ Atlanta 97 model to confirm ACI209 model guideline. The GL2000 model only needs input data which were available to engineers at the time of design, except for the concrete compressive strength. (ACI committee 209, 2004). GL2000 requires the following data for prediction of creep and shrinkage: Concrete means compressive strength at day 28 , age of concrete when drying starts, age of concrete at loading, relative humidity, volume-surface ratio and type of cement

\subsubsection{Shrinkage calculation for GL2000 model}

The following equation can be used to calculate strain shrinkage of concrete:

$\varepsilon_{\mathrm{s}}(t)=\varepsilon_{\text {shu }} \beta(h) \beta(t)$

Equation 2-25

$\varepsilon_{\mathrm{s}}(t)=$ Ultimate shrinkage strain 
$\beta(h)=$ Correction term for effect of humidity

$\beta(t)=$ Correction term for effect of time

Where,

$\varepsilon_{\text {shu }}=(900) K\left(\frac{30}{f_{\mathrm{cm} 28}}\right)^{\frac{1}{2}} \times 10^{-6}$

Equation 2-26

$\beta(h)=1-1.18\left(\frac{H}{100}\right)^{4}$

Equation 2-27

$\beta(t)=\left(t-\frac{t_{c}}{t-t_{c}+0.12\left(\frac{v}{s}\right)^{2}}\right)^{1 / 2}$

Equation 2-28

Where,

$$
\begin{aligned}
& t=\text { Age of concrete after casting (days) } \\
& t_{c}=\text { Age of concrete at the beginning of shrinkage (days) } \\
& V / S=\text { Volume to surface area ratio }
\end{aligned}
$$

\subsubsection{Creep calculation for GL2000 model:}

The creep strain is combination of the elastic strain and the creep strain according to following equation (Hassoun \& AL-Maraseer, 2005):

$\boldsymbol{J}\left(\boldsymbol{t}, \boldsymbol{t}_{\mathbf{0}}\right)=\frac{\mathbf{1}}{\boldsymbol{E}_{\mathrm{cm} t 0}}+\frac{\phi\left(\boldsymbol{t}, \boldsymbol{t}_{\mathbf{0}}\right)}{\boldsymbol{E}_{\mathrm{cm} 28}}$

Equation 2-29

Where,

$E_{\mathrm{cmt} 0}=$ Modulus of elasticity of concrete at loading (MPa)

$\Phi\left(t, t_{0}\right)=$ Creep coefficient

$E_{\mathrm{cm} 28}=\mathbf{3 5 0 0}+\mathbf{4 3 0 0} \sqrt{\boldsymbol{f}_{\mathrm{cm} 28}}$

Equation 2-30

$f_{\mathrm{cmt} 0}=$ Concrete mean compressive strength at loading (MPa) 
Where,

$$
\begin{aligned}
& \boldsymbol{f}_{\mathrm{cmt} 0}=\boldsymbol{f}_{c m 28} \frac{\boldsymbol{t}^{\frac{3}{4}}}{a+b t^{\frac{3}{4}}} \\
& \Phi\left(\boldsymbol{t}, \boldsymbol{t}_{0}\right)=\phi\left(\boldsymbol{t}_{\mathrm{c}}\right)\left[2\left(\frac{\left(t-t_{0}\right)^{0.3}}{\left(t-\boldsymbol{t}_{0}\right)^{0.3}+14}\right)+\left(\frac{7}{\boldsymbol{t}_{0}}\right)^{0.5}\left(\frac{t-\boldsymbol{t}_{0}}{t-t_{0}+7}\right)^{0.5}+2.5\left(1-1.086 h^{2}\right)\left(\frac{t-\boldsymbol{t}_{0}}{t-\boldsymbol{t}_{0}+\mathbf{0 . 1 2}\left(\frac{V}{S}\right)^{2}}\right)^{0.5}\right]
\end{aligned}
$$

Equation 2-32

If $t_{0}=t_{\mathrm{c}}$ then $\quad \phi\left(t_{\mathrm{c}}\right)=1$

If $t_{0}>t_{\mathrm{c}}$ then $\phi\left(t_{c}\right)=\left[1-\left(\frac{t-t 0}{t_{0}-t_{\mathrm{c}}+0.12\left(\frac{v}{s}\right)^{2}}\right)^{0.5}\right]^{0.5}$

\subsubsection{The CEB Model}

Muller and Hilsdorf presented CEB model for the prediction of shrinkage and creep of concrete in 1990 (CEB, 1999). Also, this model was modified in 1999 to include normal and high performance concretes and to divide the total shrinkage into its autogenous and drying shrinkage mechanism. The revised model is called CEB 90-99, while the revised model is closely related to the approach in CEB (ACI committee 209, 2004; CEB, 1999). This model was accepted by some engineers as a preferable approach over ACI model for prediction of creep and shrinkage of sensitive structures (Branson \& Christiason, 1971; ACI Committe 209, 2004). The CEB model (CEB, 1999)do not need any information about the duration of curing or curing condition. However, the duration of drying could have a direct impact on shrinkage and creep of concrete, and should not be ignored when predicting the shrinkage and creep. In this model, the correction term used for relative humidity in the creep equation is very sensitive to any difference in relative humidity. As reported in ACI committee, the CEB model usually underestimates the shrinkage of North American concrete and significantly underestimates the shrinkage of concrete containing basalt aggregate found in Hawaii, Australia and New Zealand. (McDonald \& Roper, 1993; ACI Committe 209, 2004). The CEB shrinkage model dose not responded well to early-age concrete shrinkage. (ACI Committe 209, 2004). The model requires the following data: age of concrete at loading (age at the end of moist curing), age of concrete at 
loading, relative humidity expressed as a decimal, concrete mean compressive strength at day 28 , volume -surface ratio, and cement type,

\subsection{Shrinkage calculation of CEB 90 Model:}

The strain due to shrinkage can be calculated as:

$\boldsymbol{\varepsilon}_{\mathrm{s}}\left(\boldsymbol{t}, \boldsymbol{t}_{\mathrm{c}}\right)=\boldsymbol{\varepsilon}_{\mathrm{cs} 0} \boldsymbol{\beta} \mathrm{s}\left(\boldsymbol{t}, \boldsymbol{t}_{\mathrm{c}}\right)$

Equation 2-33

Where,

$\varepsilon_{\mathrm{cs} 0}=$ Notional shrinkage confident

$\beta \mathrm{s}\left(t, t_{\mathrm{c}}\right)=$ Coefficient of shrinkage

$\boldsymbol{\varepsilon}_{\mathrm{cs} 0}=\boldsymbol{\varepsilon}_{\mathrm{s}}\left(\boldsymbol{f}_{\mathrm{cm} 28}\right) \beta_{\mathrm{RH}}$

Equation 2-34

$\varepsilon_{\mathrm{s}}\left(f_{\mathrm{cm} 28}\right)=$ Concrete strength factor for shrinkage

$\varepsilon_{\mathrm{s}}\left(f_{\mathrm{cm} 28}\right)=\left[160+10\left(\beta_{\mathrm{sc}}\right)\left(9-\frac{f_{\mathrm{cm} 28}}{10}\right)\right] \times 10^{-6}$

Equation 2-35

$\beta_{\mathrm{sc}}=$ Coefficient that depends on the type of cement according to the following table:

Table 2-5 $\beta$ s Coefficient (Hassoun \& AL-Maraseer, 2005)

\begin{tabular}{|c|c|c|c|}
\hline Type of Cement & European Type & American Type & $\boldsymbol{\beta s}$ \\
\hline Slow Hardening & SL & II & 4 \\
\hline $\begin{array}{c}\text { Normal/Rapid } \\
\text { Hardening }\end{array}$ & R & I & \\
\hline $\begin{array}{c}\text { Rapid Hardening, } \\
\text { High performance }\end{array}$ & RS & III & 8 \\
\hline
\end{tabular}

The development of shrinkage with time is calculated as following: 


$$
\begin{gathered}
\boldsymbol{\beta}_{\mathrm{sc}}\left(\boldsymbol{t}-\boldsymbol{t}_{\mathrm{c}}\right)=\sqrt{\frac{\left(\boldsymbol{t}-\boldsymbol{t}_{\mathrm{c}}\right)}{\mathbf{0 . 5 6}\left(\frac{\boldsymbol{h}_{\mathrm{e}}}{\mathbf{4}}\right)^{2}+\left(\boldsymbol{t}-\boldsymbol{t}_{\mathrm{c}}\right)}} \\
t=\text { Age of concrete } \\
t c=\text { Age of concrete at the beginning of shrinkage (days) } \\
h_{\mathrm{e}}=\text { Effective thickness (volume/surface ratio)(mm) } \\
\boldsymbol{h}_{\mathrm{e}}=\mathbf{2} \boldsymbol{A}_{\mathrm{c}} / \boldsymbol{u}
\end{gathered}
$$

Equation 2-37

Where,

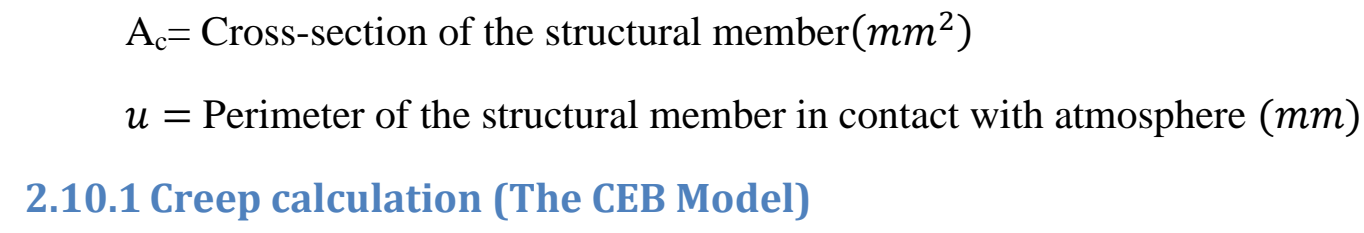

\subsubsection{Creep calculation (The CEB Model)}

Creep compliance represents the total stress dependent strain per unit stress and calculated as following ( (Hassoun \& AL-Maraseer, 2005)

$J\left(t, t_{0}\right)=\frac{1}{E_{\mathrm{cmt} 0}}+\frac{\phi\left(t, t_{0}\right)}{E_{\mathrm{cm} 28}}$

Equation 2-38

Where:

$E_{\mathrm{cmt}}=$ Modulus of elasticity at age of loading $(\mathrm{MPa})$

$E_{\mathrm{cm} 28}=$ Modulus of elasticity at day $28(\mathrm{MPa})$

$\phi\left(t, t_{0}\right)=$ Creep coefficient

$\boldsymbol{E}_{\mathrm{cmt} 0}=\boldsymbol{E}_{\mathrm{cm} 28} \exp \left[\mathbf{0 . 5 S}\left(1-\sqrt{\frac{28}{t}}\right)\right]$

Equation 2-39

S=Coefficient which depends on cement factor and calculated according to the following table: 
Table 2-6 Coefficient of S base on cement type

\begin{tabular}{|c|c|c|c|}
\hline Type of Cement & European Type & American Type & $\boldsymbol{S}$ \\
\hline Slow Hardening & SL & II & 0.38 \\
\hline $\begin{array}{c}\text { Normal/Rapid } \\
\text { Hardening }\end{array}$ & R & I & 0.25 \\
\hline $\begin{array}{c}\text { Rapid Hardening, } \\
\text { High performance }\end{array}$ & RS & III & 0.20 \\
\hline
\end{tabular}

$E_{\mathrm{cm} 28}=21500 \sqrt[3]{\frac{f_{c m 28}}{10}}$

Equation 2-39

$\Phi\left(\mathrm{t}, \mathrm{t}_{0}\right)=$ Creep coefficient

$\Phi\left(\mathbf{t}, \mathbf{t}_{0}\right)=\phi_{0} \boldsymbol{\beta}\left(\boldsymbol{t}, \boldsymbol{t}_{0}\right)$

Equation 2-40

$\phi_{0}=$ Notional creep coefficient

$\beta\left(t, t_{0}\right)=$ expression of creep development with time after loading

$\phi_{0}=\phi_{\mathrm{RH}} \boldsymbol{\beta}\left(\mathbf{f}_{\mathrm{cm} 28}\right) \boldsymbol{\beta}\left(\mathbf{t}_{0}\right)$

Equation 2-41

Where,

$$
\phi_{\mathrm{RH}}=1+\frac{1-\left(\frac{H}{100}\right)}{0.16 \sqrt[3]{\frac{h_{\mathrm{e}}}{4}}}
$$

$\beta\left(f_{\mathrm{cm} 28}\right)=$ Concrete strength factor on national creep coefficient:

$\beta\left(f_{\mathrm{cm} 28}\right)=\frac{5.3}{\sqrt{\frac{f_{\mathrm{cm} 28}}{10}}}$

Equation 2-42

$\beta\left(t_{0}\right)=$ Age of concrete at loading factor on the national creep coefficient: 
$\boldsymbol{\beta}\left(\boldsymbol{t}_{0}\right)=\frac{1}{0.1+t_{0} 0.2}$

Equation 2-43

$\beta_{c}\left(t, t_{0}\right)=$ Development of creep with time after loading:

$\boldsymbol{\beta c}\left(\mathbf{t}, \mathbf{t}_{0}\right)=\left(\frac{\mathbf{t}-\mathbf{t}_{0}}{\boldsymbol{\beta}_{\mathrm{H}}+\mathbf{t}-\mathbf{t}_{0}}\right)^{0.3}$

Equation 2-44

$\beta_{\mathrm{H}}=1.5 h_{\mathrm{e}}\left[1+(0.012 H)^{18}\right]+250 \leq 1500$ days

The prediction capabilities of the four shrinkage and creep models were evaluated by comparing measured results with the experimental program. Fibers Bragg gratings were installed to measure creep and shrinkage in three types of concrete. All results are explained and shown in the following chapters.

\subsubsection{Total strain based on short term experimental data}

Gilbert provided an equation for total strain in 1983 (Teng, 2007) for a concrete specimen under a constant and sustained axial compressive load. (Gilbert, 1983),

$\boldsymbol{\varepsilon}_{\mathrm{T}}=\boldsymbol{\varepsilon}_{\mathrm{ins}}+\boldsymbol{\varepsilon}_{\mathrm{crp}}+\boldsymbol{\varepsilon}_{\mathrm{shr}}+\boldsymbol{\varepsilon}_{\mathrm{thm}}$

Equation 2-45

Where,

$\varepsilon_{\text {ins }}=$ instantaneous elastic strain

$\varepsilon_{\text {crp }}=$ the creep strain

$\varepsilon_{\text {thm }}=$ thermal strain

The gross strain measured from the loaded specimen is total strain. Total strain measurement starts exactly from starting point of loading specimen (Teng, 2007). The equation assumed that each part of strain element can be calculated individually (Teng, 2007) but, it is not easy to separate the creep from other strain component (Neville \& Brooks, 1983). However, in experimental measurements, all components are considered as separate element to calculate creep in specimen.. Base on this assumption, each component calculated as following (Teng, 2007): 
1) The instantaneous elastic strain is determined by measuring the strain instantly after applied load

2) The creep strain measured from loaded specimen without the instantaneous elastic strain and shrinkage strains

3) The shrinkage strain measured from unloaded specimen in same environment of loading.

4) The thermal strain neglected if the temperature kept constant

\subsubsection{Long -term shrinkage prediction base on experimental result}

As mentioned and introduced in pervious section, several creep-time expression used to predict the long-term creep strain .To determine the creep strain prediction in $(\mu \varepsilon / \mathrm{MPa})$ on the shortterm experimental data ASTM provided the following equation base on logarithmic expression (ASTM, 2009).

$C_{\mathrm{t}}=\left(\frac{1}{E}\right)+F(k) \ln (t+1)$

Equation 2-46

Where,

$\mathrm{E}=$ the instantaneous elastic modulus $(\mu \varepsilon / \mathrm{MPa})$

$\mathrm{F}(\mathrm{k})=$ the creep rate $(\mu \varepsilon / \mathrm{MPa} /$ days $)$

$\mathrm{t}=$ time after loading (days)

The accuracy of the above equation principally depends on the length of recorded data in shortterm experiment (Teng, 2007). Teng reported that about $88 \%$ of the total stain was recorded in the first 120 days as a percentage of the value in 1 year. The literature indicated that after about 4 months, the creep deformation would increase in very small rate. Also, the accuracy of creep prediction after 1 year in 120 days experimental data is about 11 (Neville \& Brooks, 1983).Thus, Teng repoted that the predictaed value for creep were cloase to maesued data (about $4 \%$ ) which was more accurate from repoted accurancy in 1983 by Neville et al.

In addition, Brooks and Neviel in 1978 were suggested a satisfactory method to predict the creep of concrete in short-term (28 days) tests and estimate at a later age by etrapolation using the following equation (Domone \& Illston, 2010) 
Where,

$C_{28}=$ measured specific creep at 28 days

$\mathrm{C}_{\mathrm{t}}=$ spesific creep at $\mathrm{t}$ days $(\mu \varepsilon / \mathrm{MPa})$

$\mathrm{t}=$ age after 28 days (days)

Some emprical methods with varying degree of complexicity for estimation of crrep and shrinkage such as ACI, B3,GL200,CB99 are available, when short-term tests are not practical for measuremnt of creep and shrinkage .

\subsubsection{Creep and shrinkage measurement for Ultra-High Performance Concrete}

\subsubsection{Long-term creep testing}

The U.S department of transportation reported a long-term compressive testing of Ultra High Performance Concrete UHPC. Four cylinders $100 \mathrm{~mm}$ diameter by $200 \mathrm{~mm}$ long were cast. The test performed by using hydraulically actuated load frames as shown in Figure 2-6, Which is typical set up for creep loading measurements. A Whittemore gauge typically uses to measure changes in length between the gage points over time. Strains were calculated by dividing the change in length by the original gage length. In order to calculate creep strain, loaded cylinders were paired with unloaded cylinders by relative magnitudes of deformation. The load level applied to each set of cylinders was $77 \mathrm{MPa}$ (11.2 ksi), which were 40 percent of $193 \mathrm{MPa}$ (28 ksi), the anticipated compressive strength of a steam-treated cylinder. 


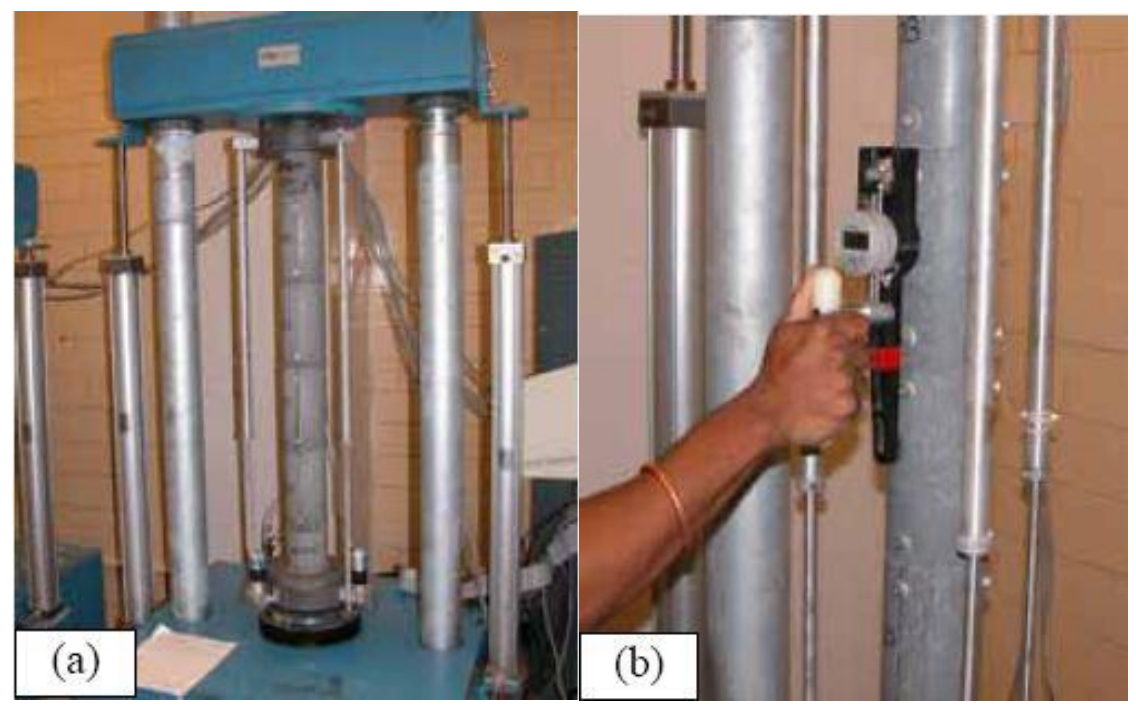

Figure 2-6 (a) Creep cylinders in load frame, (b) measurement of creep (Federal Highway Adminstration, 2006)

The result indicated that, the shrinkage strain was subtracted from the creep strain for two reasons.

1) Some of the measured creep strain was necessarily due to shrinkage.

2) The overall shrinkage strains were small or nonexistent,

Therefore the total error applied was negligible. If the shrinkage strain were not subtracted from the creep strain for the untreated and tempered steam-treated specimens, the creep coefficients would have been less than 10 percent higher.

It was reported the creep coefficients for concrete typically is the range of 1.5 to 3.0 and specific creep values usually range from 35 to 145 ( $\mu \varepsilon / \mathrm{MPa}$ ) (Federal Highway Adminstration, 2006) and (Domone \& Illston, 2010). 


\section{Chapter3}

\section{Experimental Investigation}

\subsection{Concrete beam testing [Phase 1]}

In the first part of the investigation, FBG sensors were used to measure the concrete strains for un-reinforced normal strength concrete beams loaded at three different load-displacement rates. The main objective of this experiment was to evaluate the performance of FBG sensors in measuring strains and also show a simple procedure for installing FBG sensors in concrete structure. Another goal of these experiments was to determine the limitations and resistance of FBGs with specific packaging in concrete structure.

\subsection{Specimen preparations}

A total of three beams were constructed in the test; each $1000 \mathrm{~mm}$ long $300 \mathrm{~mm}$ deep and 200 mm wide. Each beam was instrumented with one FBG strain sensors in bottom with $30 \mathrm{~mm}$ clear space. The FBG were attached to tiny steel wire with diameter of less than $1 \mathrm{~mm}$ along with the beam and fixed with plastic band as shown in Figure 3-1. Since the diameter of the steel wire and FBG cable were relatively small compared to the concrete structure, it was assumed that the mechanical properties of structure would not be influenced by these tiny embedded wire and cable. The beams were simply supported with compressive strength of $35 \mathrm{MPa}$ after 28 days. All FBG sensors survived concrete pouring and compaction. 


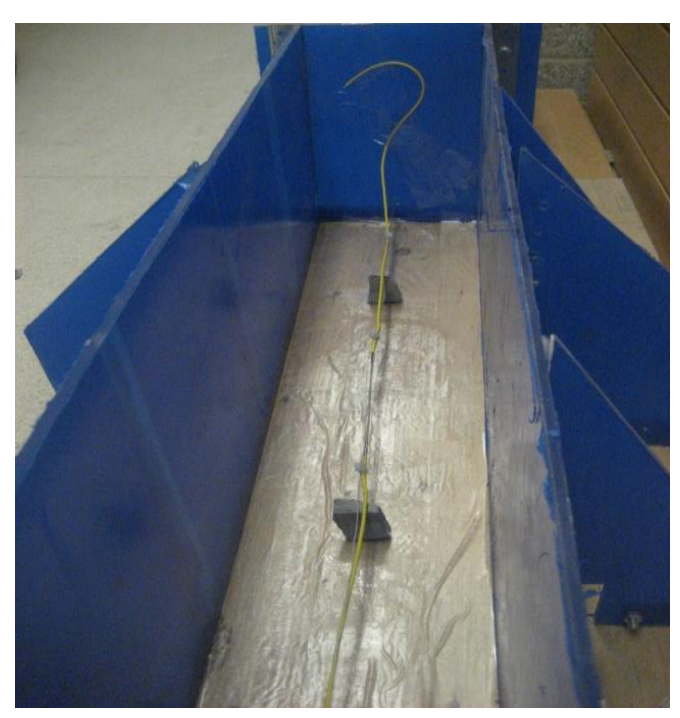

(a)

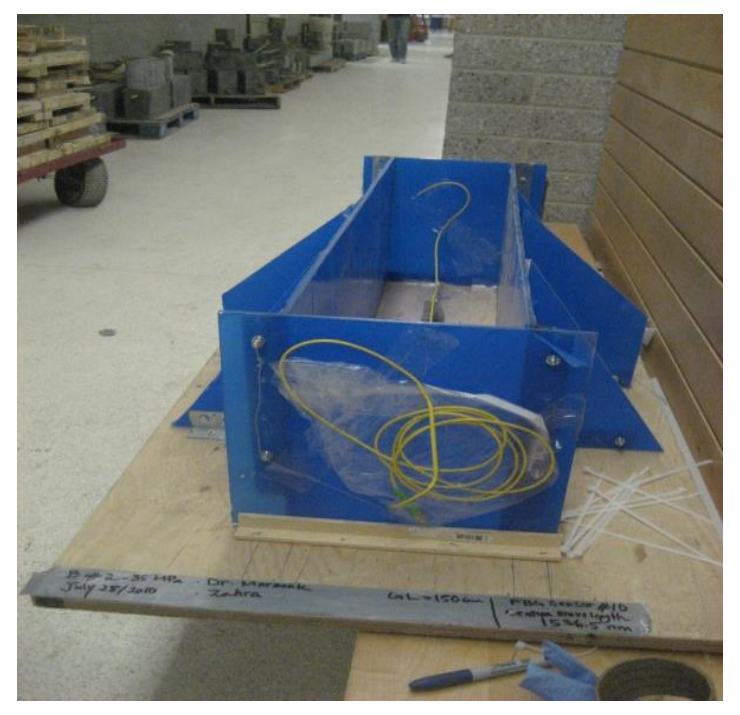

(b)

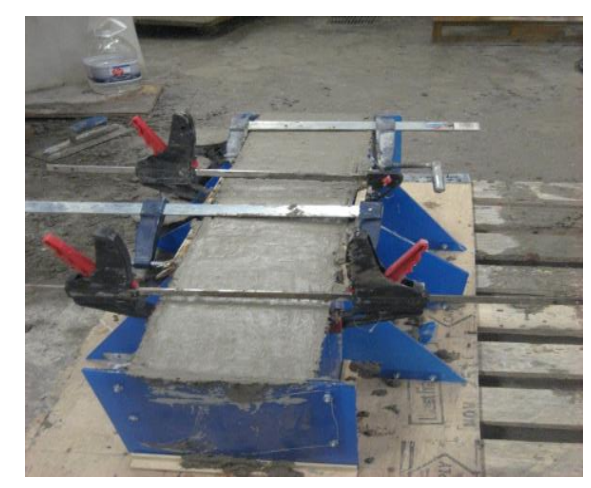

(c)

Figure 3-1 Beam with embedded FBG sensors, (a) FBG installation,(b) Frame preparation for Beam, (c) Beam after casting

\subsection{Experimental procedure for concrete beams}

Three beams with dimension of $200 \times 300 \times 1000 \mathrm{~mm}$ with the same compressive strengths of 30 MPa were tested under three different strain rates. The dynamic tests were performed using MTS 810 testing machine. To measure the strain along the fracture zone, a FBG sensor with $150 \mathrm{~mm}$ gauge length was installed for each beam. The beam specification shows in Figure 3-2.

Most researchers suggest strain or deflection control loading rate to capture facture energy of concrete. MTS machine used to apply the load in this experiment is capable to control load, 
strain and deflection loading rate. The first specimens were loaded at a displacement rate of $0.003,0.002$ and 0.0002 .

The machine was programmed displacement controlled loading rate at three different rates of loading $0.0002,0.002$ and $0.003 \mathrm{~mm} / \mathrm{sec}$. Their average force capacity was $78 \mathrm{kN}$. The FBG sensors with gauge length (GL) of $150 \mathrm{~mm}$ were embedded in bottom of beam with $40 \mathrm{~mm}$ clear space.

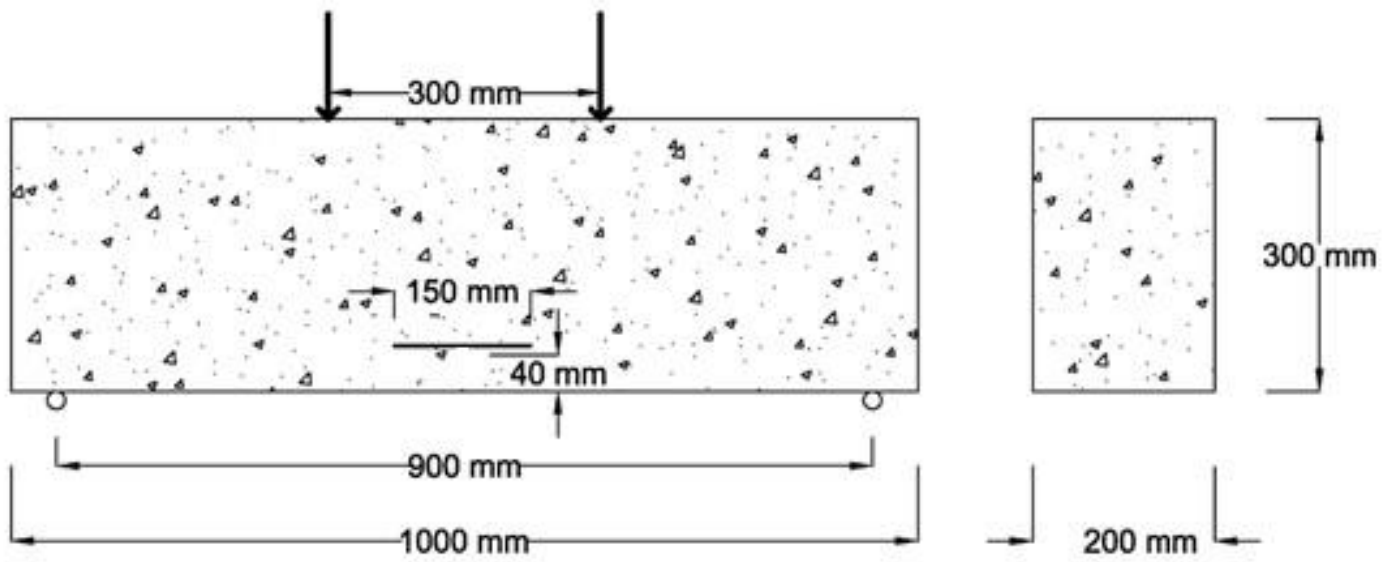

Figure 3-2 Beam details with embedded FBG sensor

\subsection{Testing procedure}

The FBG sensors with gauge length of $150 \mathrm{~mm}$ use to monitor strain variation in beams. Three separate trial preformed on single beam with two-point bending with dividing point $333 \mathrm{~mm}$ apart. Load displacements were recorded with MTS machine with the same time strain were recorded with FBG sensors. All acquisition systems were programmed to record reading at rate of 10 readings per second. The load applied until complete failure point and there was no longer possible to apply load. Figure 5-2 shows a typical beam testing setup. 


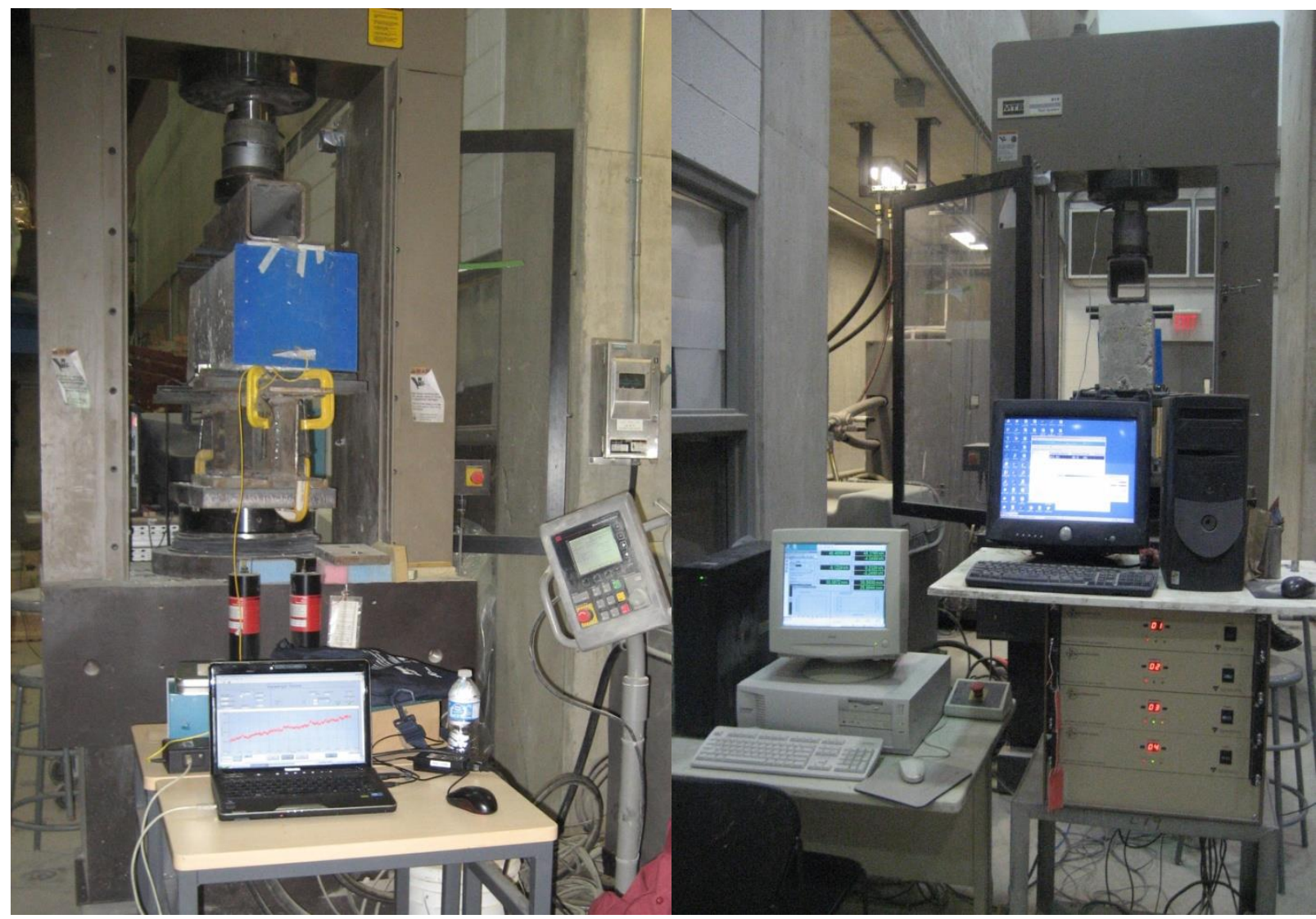

Figure 3-3 Typical beam under two point loading

\subsection{Creep and shrinkage tests [Phase 2]}

Concrete exhibits time-dependent strains because of creep and shrinkage. Shrinkage and creep are important due to the fact that significant long-term characteristics are being affected by these two factors. Shrinkage is time-dependent strain measured in unloaded concrete cylinders after 28 days curing, and it happens mainly due to loss of water during the drying process. Also, creep is the time-dependent increase in the strain of concrete cylinder under constant compressive or tensile stress. In large scale structures, drying shrinkage and creep become more significant and they have the largest effect on cracking, structural deformation and deflection and other damaging effects in concrete structures that lead to serviceability and durability failures as well.

The utilization of FBG sensors to measure creep and shrinkage of concrete is new. The method will be used to estimate creep and shrinkage of normal strength concrete (NC), high performance concrete (HPC), and ultra-high performance concrete (UHPC). There are not many research and 
investigation about measurement of creep and shrinkage with FBG sensors especially for UHPC. ASTM does not specify the details for this type of test.

\subsection{Concrete Mix Design for Creep Investigation}

Three different grades of concrete mix was prepared and cast into cylinders type according to ASTM standard; Normal strength with compressive strength $30 \mathrm{MPa}$, High with compressive strength of $70 \mathrm{MPa}$, and Ultra-High performance with compressive strength of $140 \mathrm{MPa}$. All specimens are moist cured for 28 days before it was subjected to creep and shrinkage measurement. Table 3-1 provides available information for mix portions.

\subsubsection{Normal strength concrete}

Normal strength concrete mix is composed of cement, sand, coarse aggregate (gravel with the maximum particle size of $19 \mathrm{~mm}$ ) and water with the water-cement ratio of 0.45 .

\subsubsection{High performance concrete}

Mix concrete with strength of $70 \mathrm{MPa}$ was prepared in Civil Concrete Lab. The ordinary Portland cement (type 10) CSA3-AS5 was used for this mix. The water-cement ratio of $0.27 \%$ with maximum aggregate size of $14 \mathrm{~mm}$ and with slump of $150 \mathrm{~mm}$ was measured for HPC mix.

\subsubsection{Ultra-High performance concrete}

New shear mixers have been used effectively in Ryerson Civil Concrete Lab to produce UHPC. Shear mixer scatter the water and admixtures onto cement without heating the mix by kinetic energy produced by the mixing process. The mixing procedure for UHPC has been done according to typical mix design. All the dry materials such as cement, slag, silica fume, and silica sand has been mixed in first portion to even distribution. Then water and water reducer admixture were gradually added to dry materials. Next, when the mix reached the required consistency the steel fibers were evenly added to the mix. The exact portions and mix procedure for UHPC cannot be disclosed due to confidential agreement with provider of mix design 
Table 3-1 Mix Properties of three graded concrete

\begin{tabular}{|c|c|c|c|}
\hline Mix Properties & $\begin{array}{l}\text { Normal-Strength } \\
\text { (NS) }\end{array}$ & $\begin{array}{l}\text { High-Performance* } \\
\text { (HPC) }\end{array}$ & $\begin{array}{l}\text { Ultra-High Performance } \\
\text { (UHPC) }\end{array}$ \\
\hline$f_{\mathrm{cm} 28} M P a$ & 30 & 70 & 140 \\
\hline Water Content & $0.40-0.45$ & $0.27-0.3$ & $0.17-0.20$ \\
\hline $\begin{array}{l}\text { Cement Content } \frac{\mathrm{kg}}{\mathrm{m}^{3}} \\
\text { (silica fume) }\end{array}$ & 350 & $\begin{array}{l}440 \\
5 \%\end{array}$ & $\begin{array}{l}883 \\
24 \%\end{array}$ \\
\hline Coarse aggregate $\frac{\mathrm{kg}}{\mathrm{m}^{3}}$ & 1200 & 1100 & - \\
\hline $\begin{array}{l}\text { Air entrainment } \\
\text { agent }\left(\mathrm{ml} / \mathrm{m}^{3}\right)\end{array}$ & 300 & 325 & - \\
\hline $\begin{array}{l}\text { Water reducing agent } \\
\left(\mathrm{ml} / \mathrm{m}^{3}\right)\end{array}$ & 1400 & 825 & $4 \%$ of cement content \\
\hline Superplasticizers $\left(\mathrm{ml} / \mathrm{m}^{3}\right)$ & 1500 & 7500 & $\mathrm{Na}$ \\
\hline Relative Humidity, $\%$ & 95 & 95 & 95 \\
\hline Type of Cement & ASTM (I) & ASTM (I) & ASTM (I) \\
\hline $\mathrm{t}_{0}$ (time of curing, days) & 28 & 28 & 28 \\
\hline $\mathrm{t}$ (time of loading, days) & 28 & 28 & 28 \\
\hline Type of curing & Moist & Moist & Moist \\
\hline
\end{tabular}

*Mix design from: (Marzouk, 1991)

\subsection{Concrete specimen preparation}

\subsubsection{Cylinder preparation for FBGs}

10 cylindrical moulds (100 mm diameter and $200 \mathrm{~mm}$ height) were prepared for the three different mix types with volume to surface ratio of $25 \mathrm{~mm}$ as shown in Figure 3-1. Out of the 10 cylinders per mix type, three cylinders were cast with embedded FBG sensors in middle center of 
cylinder vertically as shown in Figure 3-4. Cable of FBG sensors were brought out from bottom and end side from drilled hole in moulds. The sensors are put horizontally at the center of cylinders and kept parallel to longitudinal axis by stretching both ends at the same time during casting the concrete mix. The fiber cable was brought out from the surface sides of cylinders as shown in Figure 3-4. Another two cylinders out of 10 are used to install the electrical strain gauge (ESG) after moist curing for 28 days. The remaining 5 cylinders for each mix type are tested after 28 days of moist curing for average compressive strength.

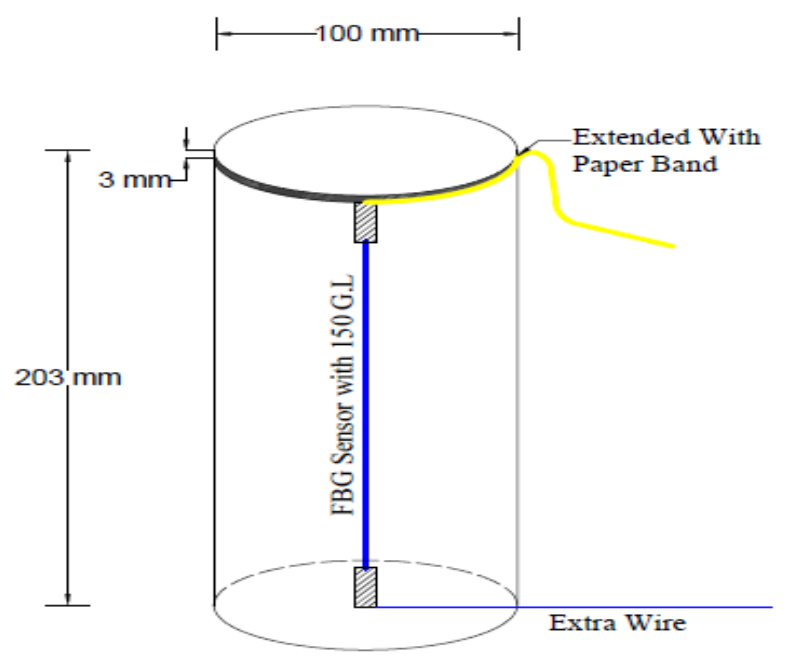

Figure 3-4 Cylinder with embedded FBG 


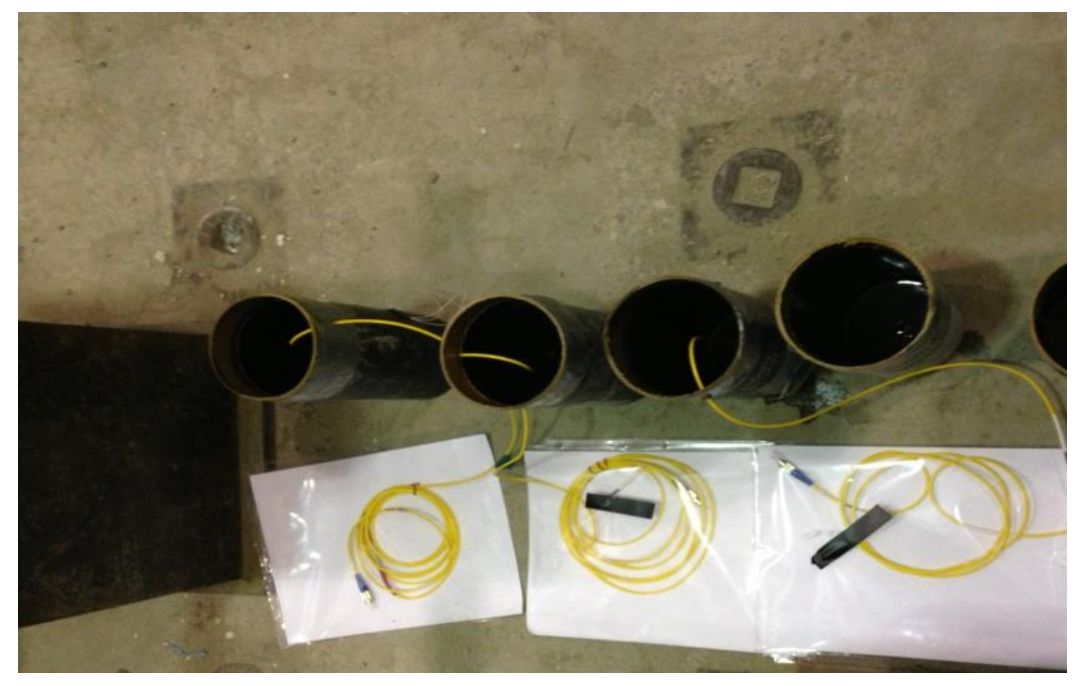

Figure 3-5 Preparation before casting

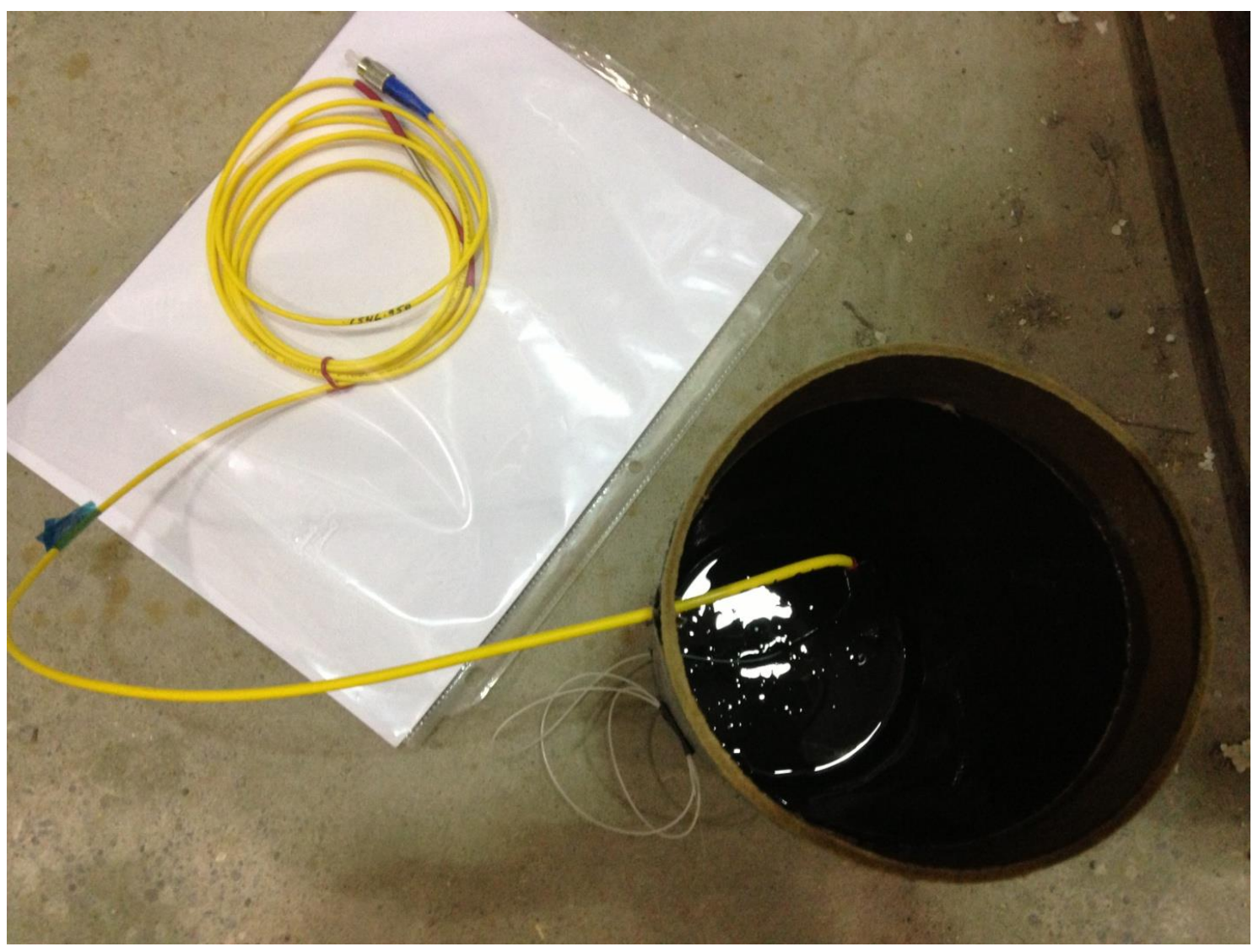

Figure 3-6 Cylinder with FBG in middle center 


\subsubsection{Casting}

Before pouring of the concrete into cylinders mould, all moulds were cleaned and slightly oiled to ease the demolding process. To prevent any physical damage during casting, all cylinder moulds were extended by paper board about $1 \mathrm{~cm}$ from top of moulds. FBG sensors were inserted and placed into their positions in mould as shown in Figure 3-7 before casting. When pouring the concrete mix, the two ended wires were kept stretched in order to keep the orientation of the sensors parallel to the longitudinal. Also, the fiber has to be brought out from the side of the cylinders as compressive load was to be applied on both ends for creep test. All cylinders were placed on vibrating table to allow the mix to eventually be redistributed and fill all small spot between sensors and concrete mix.

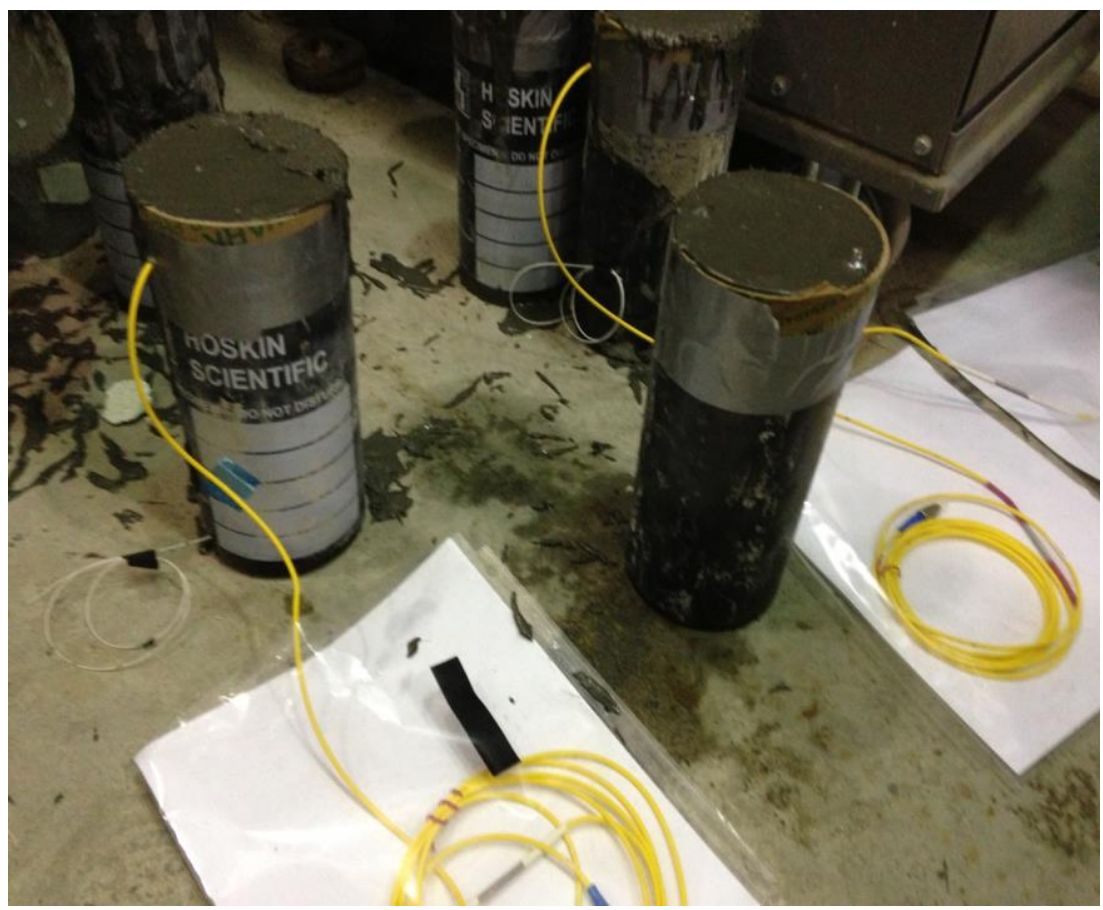

Figure 3-7 Cylinders after pouring concrete with embedded FBG sensor

\subsubsection{Curing}

All cylinders were placed in curing room at the same time of casting with identical conditions for 28 days. The humidity of cure room was $95 \%$ with steam cure condition. Output wire for FBG sensors were looped and placed in plastic bags to prevent any damage during curing. However, the sensors were well-built and protected from any wet condition damage. In order to maintain a moist environment for UHPC and HPC cylinders, plastic sheeting were placed over the moulds during curing as required for curing of these two type of concrete. 


\subsection{Measurement Devices}

\subsubsection{Load measurement}

For each set up the Material Testing System (MTS) machine was equipped for 28 days constantly. The device allowed simultaneous loading of four specimens at same time. The constant applied load depends on type of concrete in the cylinder. The MTS machine recorded load, displacement and time simultaneously. MTS has the ability to control required loading rate and time. A high speed data acquisition system was used to record massive data from MTS machine for 28 days.

\subsubsection{Electrical strain gauges}

Longitudinal deformations were recorded by strain gauges. Traditional electrical strain gauges measure the relative displacement of middle section of cylinders and are attached to the middle surface of cylinders. The traditional strain gauges (EGS), $12 \mathrm{~mm}$ long with a resistance of $120 \Omega$ and gauge factor of $2.07 \pm 0.5 \%$, were glued to surface of concrete cylinders. All ESGs were installed according to specifications presented in Figure 3-8. Initially the cylinders surface was ground to achieve a smooth and even surface without compromising the shape of cylinders. Then some alcohol is applied to smooth surface to clean the contaminated surface. Then, conditional was applied to the surface and finally the strain gauge was glued to the surface of concrete cylinder.

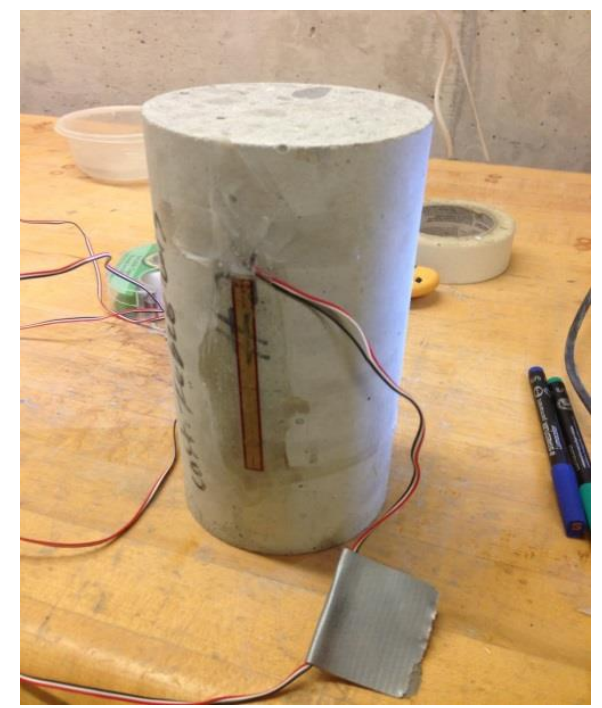

Figure 3-8 Cylinder with ESG 


\subsection{Testing Procedure}

\subsubsection{Creep testing}

Four samples were loaded at the same time for 28 days with MTS machine in Ryerson Civil Lab. Literature review suggests that creep is proportional to stress from 0 to $40 \%$ of concrete compressive stress. Therefore, normal, high and ultra-high performance concretes were loaded between $30 \%$ to $50 \%$ of their maximum compressive strength (The details are highlighted in results section). The MTS machine which was used to apply the load in this experiment is capable of controlling the load, strain and deflection loading rate. Also, for strain measurement, strain gauge and FBG sensors were used to record strain in cylinders. For each grade of concrete, 5 cylinders were used to install strain devices. Three of the cylinders had embedded FBG sensors and two other had strain gauges. Figure 3-5 shows the set up for creep test experiment.

The cylindrical specimen from each batch of concrete was cured for 28 days in the controlled environment of $23.0{ }^{\circ} \mathrm{C}$ and relative humidity of $95 \%$. The creep specimen were stacked in loading frames and loaded to $30 \%$ to $45 \%$ of their ultimate compressive strength. The applied load was kept constant through test for 28 days. For each specimen strain from FBGs was recorded every day in the first 7 days and on $14^{\text {th }}, 21^{\text {st }}, 28^{\text {th }}$ day of loading afterwards. Creep and shrinkage measurement were taken from FBG to measure changes in wavelength in sensors and convert it to creep strain over time.

In order to calculate creep strain, the loaded cylinders with FBGs measured for creep strain and subtracting initial elastic strain and companion shrinkage cylinder strain from the total strain. 


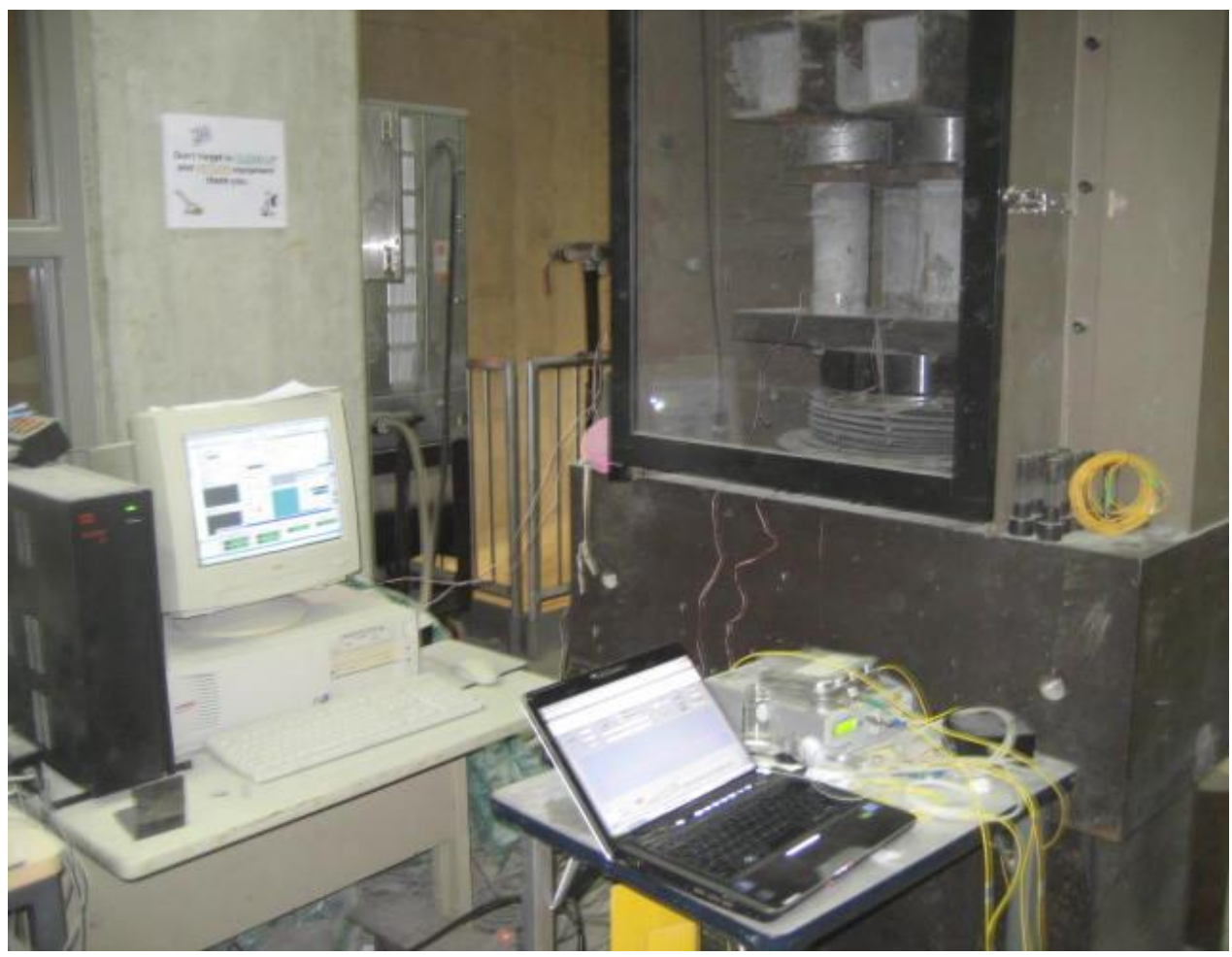

Figure 3-9 Experimental set up for creep test

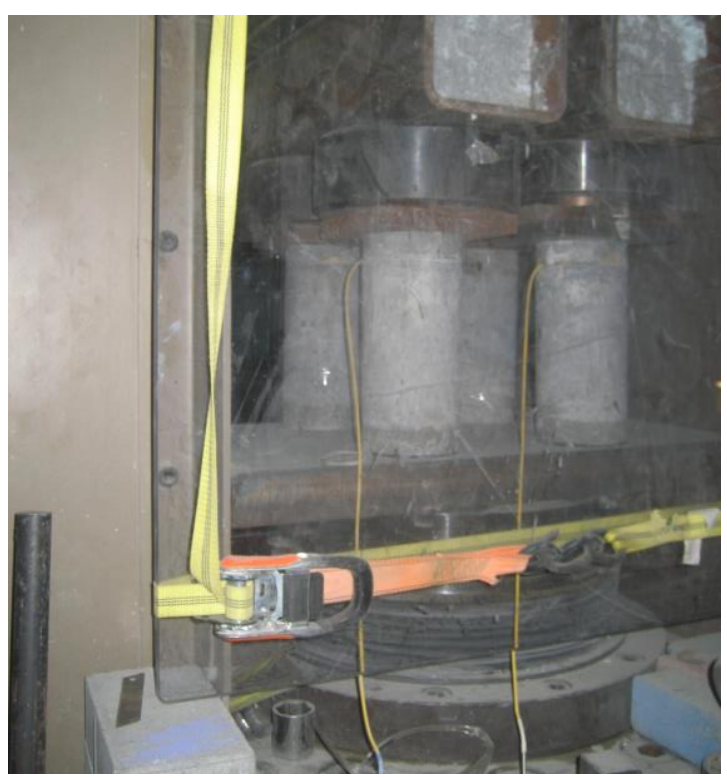

(a)

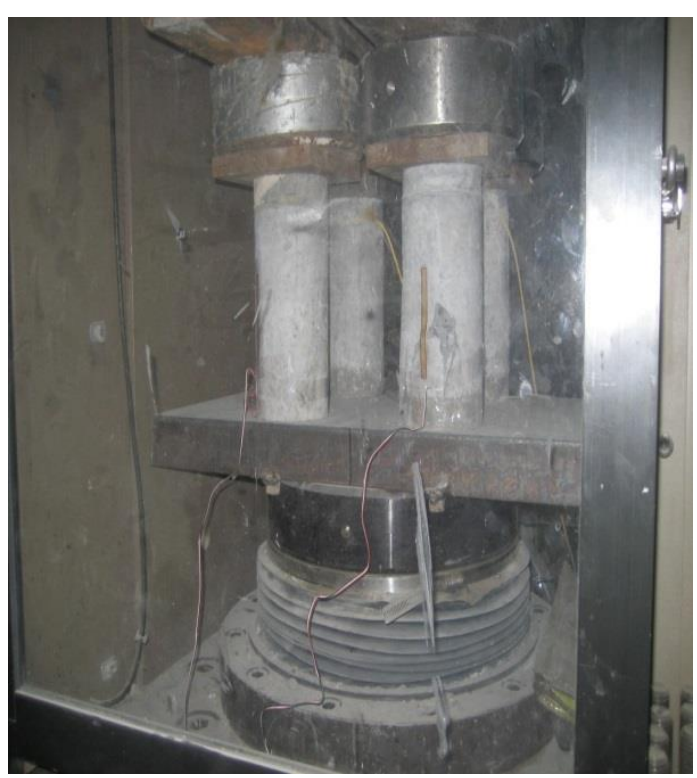

(b)

Figure 3-10 Cylinders under constant load with (a) FBG embedded (b) ESG on surface 


\subsubsection{Shrinkage test}

In order to measure shrinkage, one unloaded cylinder with FBG stays in the same environment as loading cylinders. The cylinder kept in the same environment as the creep cylinders and measured at the same time intervals, using a same data acquisition system Figure 3-11.

\subsubsection{Strength testing}

Compressive strength tests were performed for each mix. After casting each specimen, a minimum of three compressive strength test cylinders were cast. The cylinders were tested on the same day as their respected test specimen. To achieve a uniform, smooth and even surface for creep test and compressive test, all cylinders are ground with grinder machine in Ryerson Concrete Lab Figure 3-12

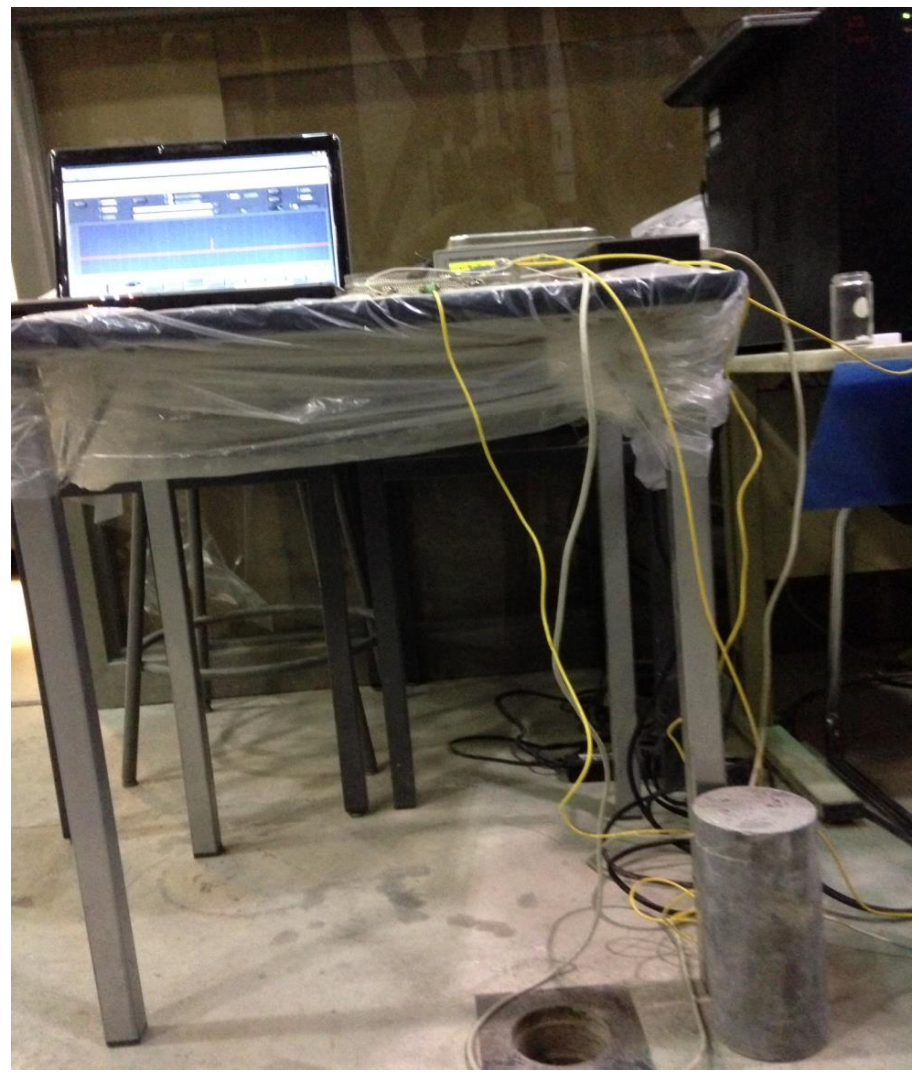

Figure 3-11 Shrinkage Test- Cylinder with embedded FBG 


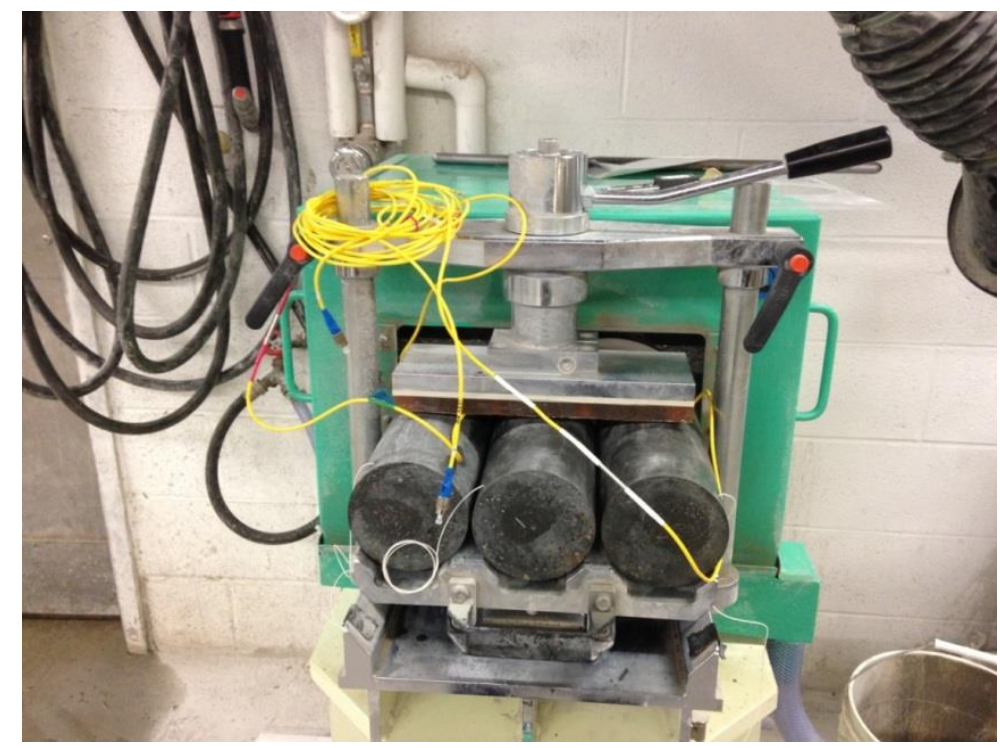

Figure 3-12 Grinder machine while grinding cylinders

\subsubsection{Modulus of elasticity test}

The modulus of elasticity test was performed right after creep test, following the procedure of ASTM standard as showed in Figure 3-13. The test was performed with one cylinder with embedded FBG to measure strain at the same time of loading.

FBG sensor in the tested specimen was working properly after load reached to ultimate. The signals from sensor were notable even after complete failure (Figure 3-14).

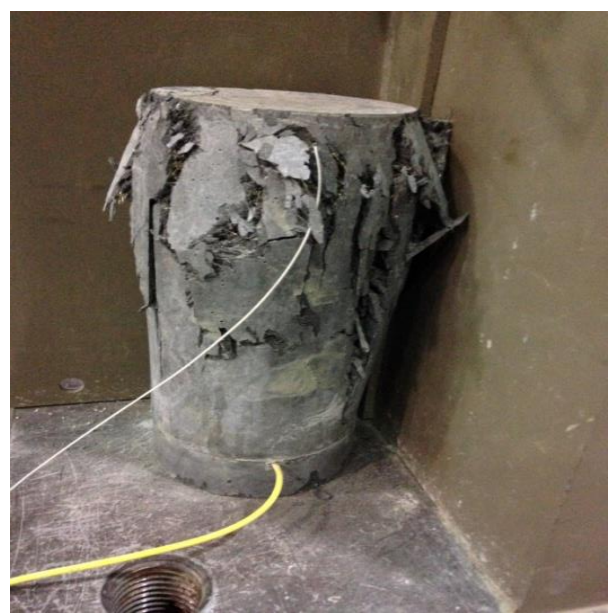

a)

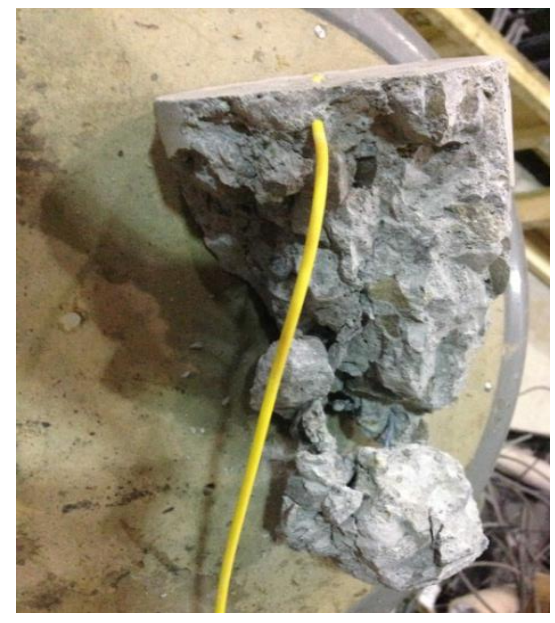

b)

Figure 3-13 Cylinders after modulus of elasticity test a) UHPC b) Normal concrete 


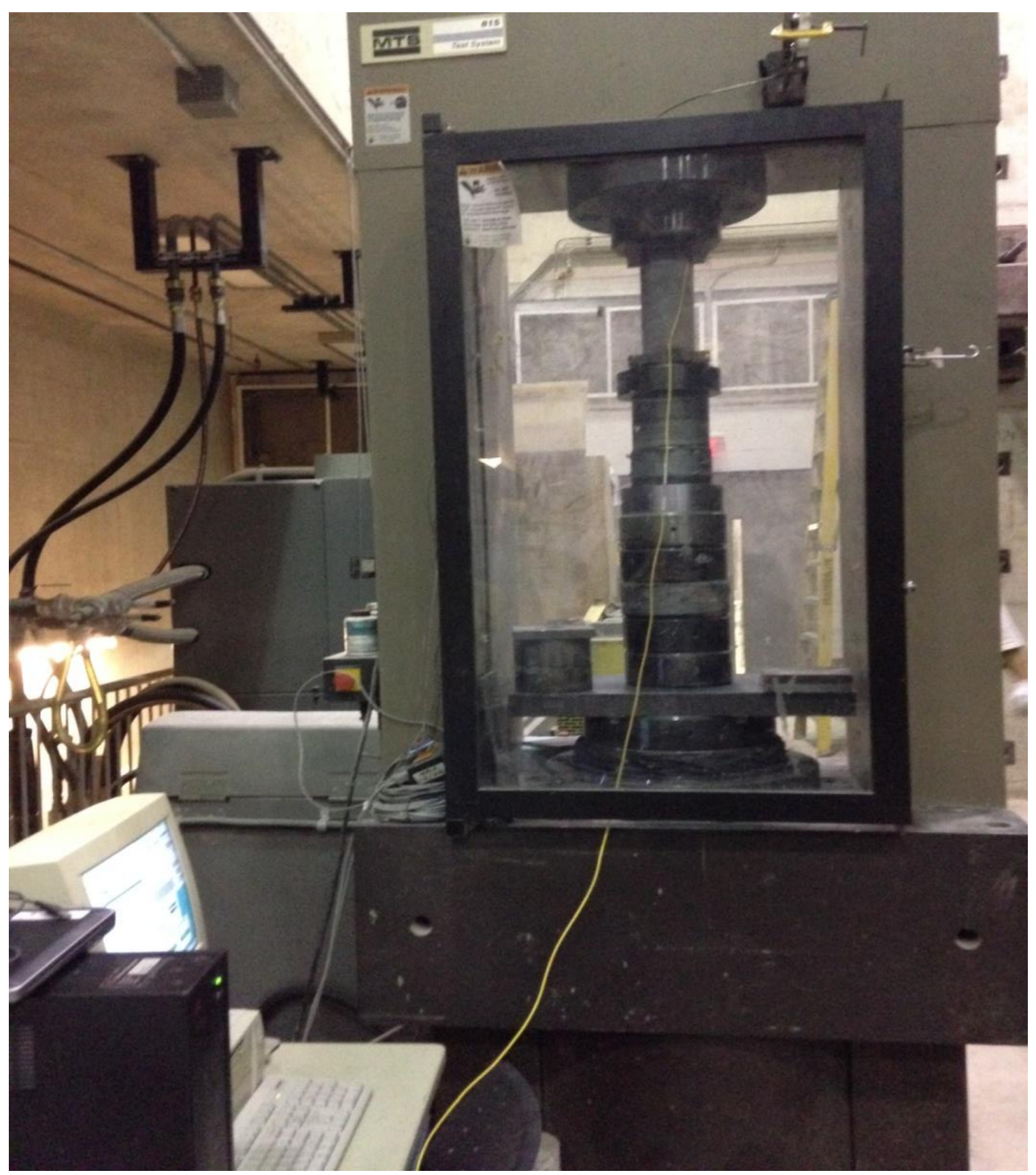

Figure 3-14 Modulus of elasticity test with embedded FBG sensor 


\section{Chapter4}

\section{Assembling and fabrication of FBG sensors for civil applications}

Fiber Bragg Grating (FBG) sensors is a type of optic sensor technology that is recently being used in SHM systems is structures. Fiber optic sensors have been researched for different types of applications for sensing mechanical properties of different materials (Friebele E, 1998) (Tennyson, et al., 2001). It is recommended for concrete structures that the gauge length of FBG sensors has to be two to three times longer than the size of coarse aggregate in mix properties of concrete (Ansari \& Sture, 1992). The suitable wavelength in most FBG sensors in civil application has the range of $1520-1550 \mathrm{~nm}$. The sensor operates by detecting a shift in specified wavelength of the reflected maximum which strain applied in than section.

\subsection{FBG sensors assembling Procedure:}

For experimental application of FBG in Civil structures, all sensors were designed, manufactured, and packaged by myself in Electrical department of Ryerson University under supervision of technical staffs.

List of materials used for manufacturing of FBG: The following materials are required for assembling FBG sensors with desired packaging and specifications:

- Polymer tubing - polymer circular tubing sleeve with $254 \mu \mathrm{m}(0.010$ ") $) \mathrm{ID} \times 1.5875 \mathrm{~mm}$ (0.0625') OD

- Stainless steel tube type A - 304 Hypodermic circular 14.5 Gauge tubing with 1.6002 mm (0.063") $\mathrm{ID} \times 1.9812 \mathrm{~mm}(.078 ") \mathrm{OD} \times .1905 \mathrm{~mm}(.0075 ")$ Wall

- Stainless steel tube type B - 316 Hypodermic thin wall tubing 10 Gauge $2.8956 \mathrm{~mm}$ (.114") ID × $3.4036 \mathrm{~mm}(0.134$ ") $\mathrm{OD} \times .254 \mathrm{~mm}(.010 ")$ Wall

- Epoxy - 353ND thermosetting polymer with Part A, epoxy resin and Part B, polyamine hardener 
- FBG - fiber Bragg grating - all grating were prepared with electrical technician in advance to preparation of packaging.

\subsection{List of equipment for FBGs preparation}

The following equipments are required for assembling sensors.

- OSA - optical spectrum analyzer

- Fusing splicing machine

- Thermal heater

\subsection{Preparation steps}

1. The polymer tube (blue tubes) is adjusted in length with a sharp knife, two bore holes with $0.4572 \mathrm{~mm}$ steel drill bit are drilled in polymer tube on both sides as shown in Figure 4-1. The polymer tube is cleared inside the cavity so as to let $250 \mu \mathrm{m}$ fiber penetrate through at a distance $0.5 \mathrm{~cm}$ from the end of the tube (if the required strain guage is $15 \mathrm{~cm}$ then the tube is cut to be $16 \mathrm{~cm}$ ). The hole location is marked before drilling. In our case, a precise drill of 0.018 is used for drillings.

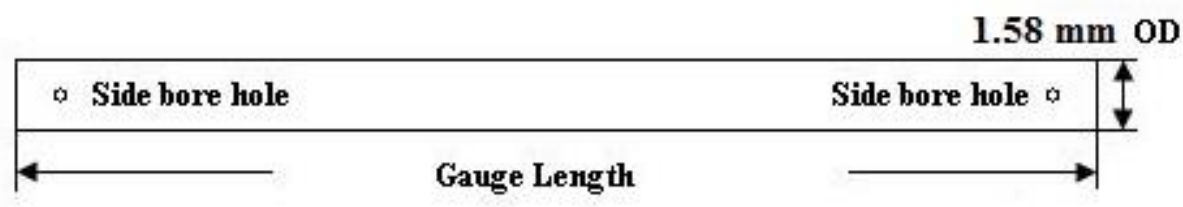

Figure 4-1 Polymer tube preparation

2. The satainless steel tube is cut into $30 \mathrm{~mm}$ pieces (thin tubes). Two tubes are required for each sensor. A thick tube (B) is cut into $70 \mathrm{~mm}$ pieces (thick tubes). One tube peice is needed for each sensor. Both ends are ground smoothly and burrs are cleaned. In our case, cuts are done in the mechanical lab.

3. A bore hole is drilled at one side of stainless steel tube type (A) for later calibration with a $0.99 \mathrm{~mm}$ steel drill bit. The hole locations are marked before drilling. Tube movement should be avoided during drilling by fixing it on the table using tapes. In our case, drilling of the tubes are done using two drillers. 
4. Part $\mathrm{A}$ and part $\mathrm{B}$ epoxies are mixed by the ratio of 9:1 and stored it in fridge. In our case, 11 gr of mixture glue is produced using 9.9 gr part A and 1.1 gr part B. Also, a big container is needed to mix and five more smaller ones are needed to store them in freezer because it spoils within 2 hours if kept out of the freezer. This procedure is done in a chemical lab to ensure good quality.

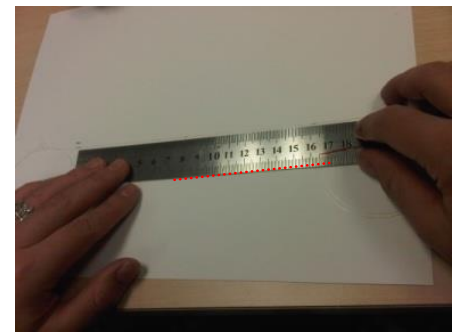

Figure 4-2 Gauge length marked before packaging

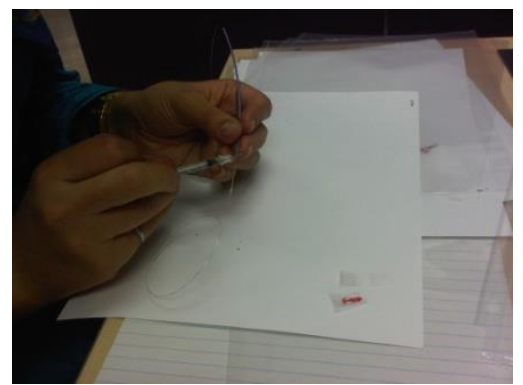

Figure 4-3 Epoxy injection

5. The thermal heater plate is set to $40^{\circ} \mathrm{C}$ and the thermocoupler monitor is arranged properly and then fixed on the heater. The heater plate is prepared as the epoxy filling plate, the microscope focus is adjusted for epoxy filling quality observation (glue color will turn into yellow color).

6. The FBG pigtail is penetrated into the polymer tube; the FBG should be located at the polymer tube center; the fiber coating should be stripped out at both end sides for $40 \mathrm{~mm}$, aiming at two polymer tube side bore holes, as shown in Figure 4-4.

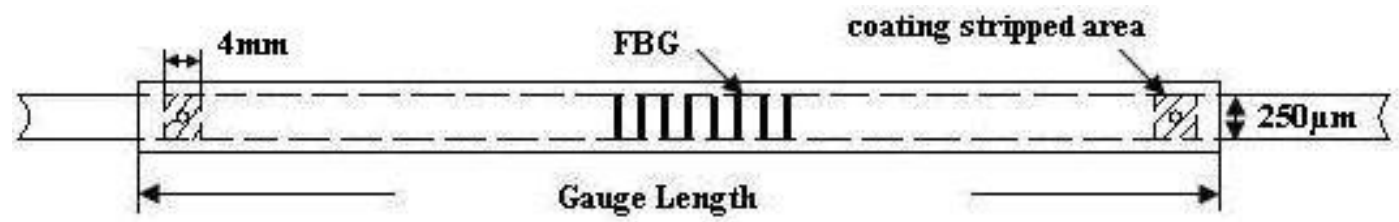

Figure 4-4 FBG and epoxy bonding location at the polymer tube 
7. A syringe is filled with epoxy mixture drops; epoxy drops are pushed into polymer tube side bore hole, the epoxy should flow completely into all bonding area (observe it by microscope). For the second epoxy filling spot, certain strain must be applied beforehand, which can be monitored by OSA wavelength shift; the heating temperature should be increased to $80^{\circ} \mathrm{C}$, and epoxied should be cured it for 2 hours (keeping this temperature stable).

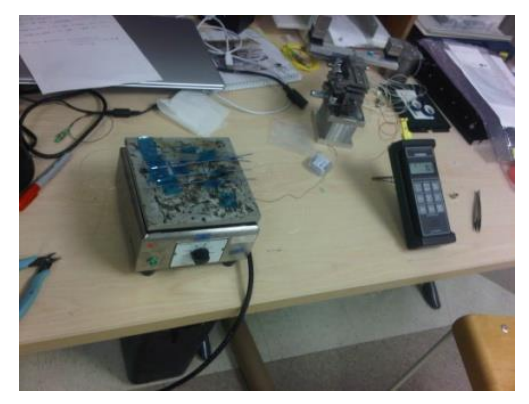

Figure 4-5 Curing epoxy for $2 \mathrm{hr}$.

8. Stainless steel tubing (A) should be bonded with polymer tube by epoxy, and be cured for 2 hours, as shown in Figure 4-6. Shrinkage rubber tube should be positioned properly.

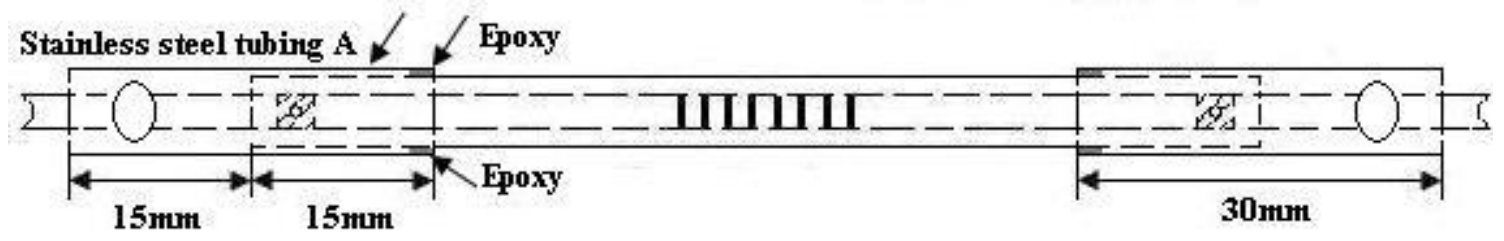

Figure 4-6 Bond stainless steel tubing with polymer tube $(\mathrm{Pu}, 2010)$

9. The fiber pigtail is covered with $900 \mu \mathrm{m}$ white jacket, and bonded with stainless steel tubing end by the epoxy and cured for 2 hours.

10. The fiber pigtail with bullet proof vest teflon material and outside $3 \mathrm{~mm}$ patchcord yellow jacket is installed.

11. The $40 \mathrm{~mm}$ yellow jacket is removed on the side of polymer tube, that space is taken with splicing protection sleeve. Stainless steel tubing B should be made through $3 \mathrm{~mm}$ jacket buffer; a $45 \mathrm{~mm}$ fiber splicing space should be vacaned for the fusing splicing machine 
operation. The fiber ends is cleaved nicely. It should be spliced and control loss should be set to less than $(.04 \mathrm{~dB}) .40 \mathrm{~mm}$ yellow jacket should be removed back which will cover 40 $\mathrm{mm}$ splicing protection sleeve. The stainless steel tubing $\mathrm{B}$ is covered to all protection areas, and should be bonded with $3 \mathrm{~mm}$ yellow jacket ends by epoxy and be cured for 2 hours. The yellow $3 \mathrm{~mm}$ jacket buffer is tightened with stainless steel tubing A, epoxy is to be applied for bonding and be cured for 2 hours as well. Shrinkage rubber tube should be applied to protect all connection sections. The final product is shown in Figure 4-8.

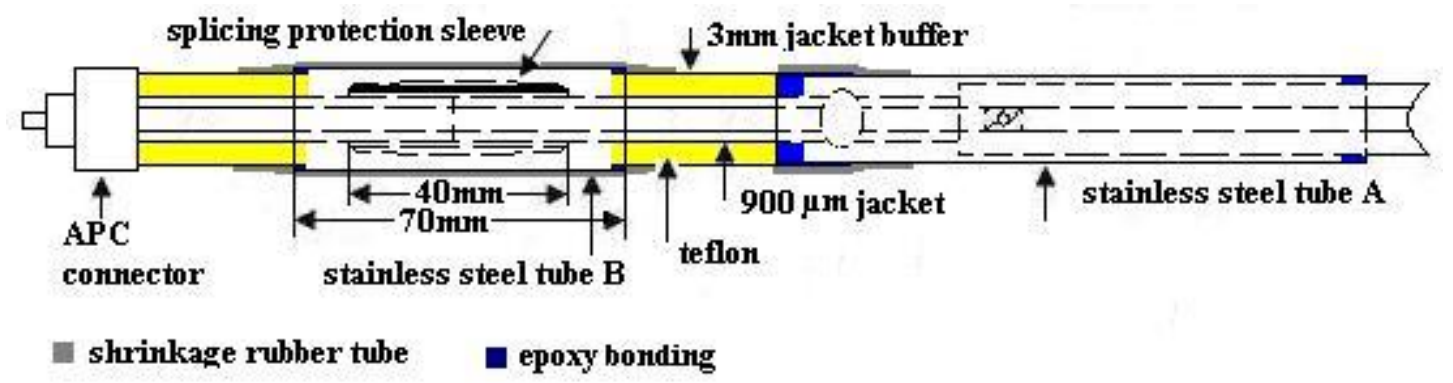

Figure 4-7 Fiber splicing spot steel tubing protection (Pu, 2010)

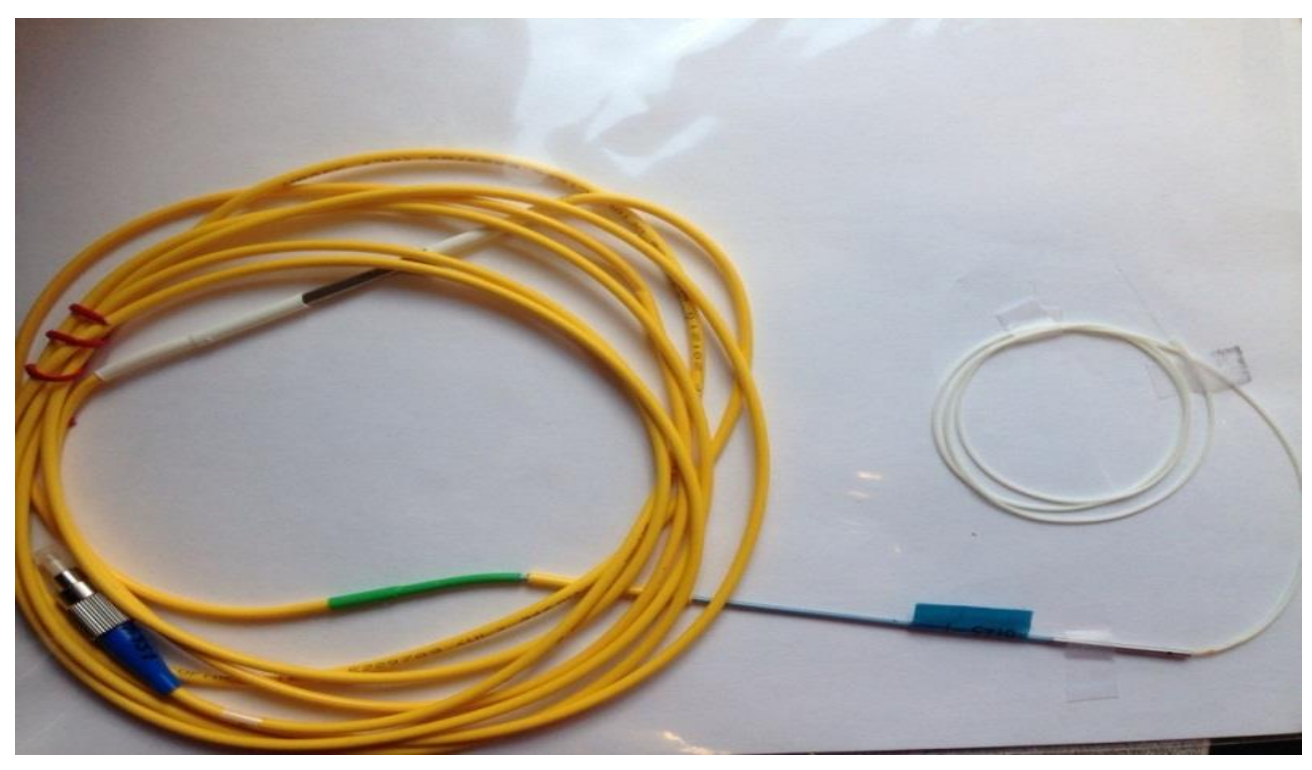

Figure 4-8 View of FBG strain sensors

\subsection{The Peek FBG calibration}

In our case, sensors were calibrated after first stage of packaging to make sure about sensitivity of sensors and wavelength movement. Three different small loads of (100 , 200, 300 grams) were applied to each senor and wavelengths had been measured each time. The linearity of results shows that the packaging did not have big contribution to sensitivity and wavelength movement. 


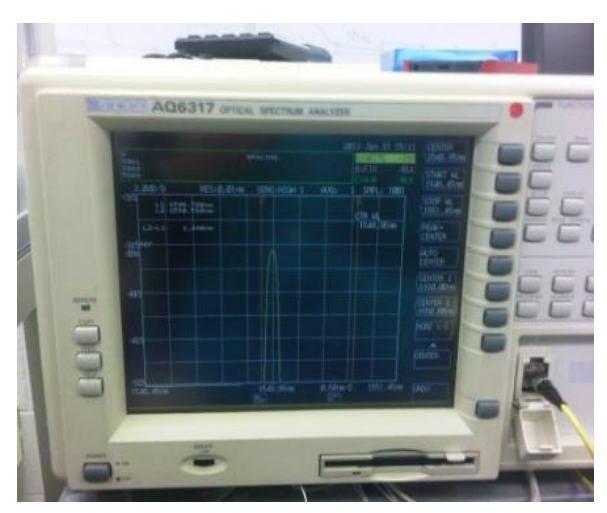

Figure 4-9 View of a device for wavelength measurement with different load
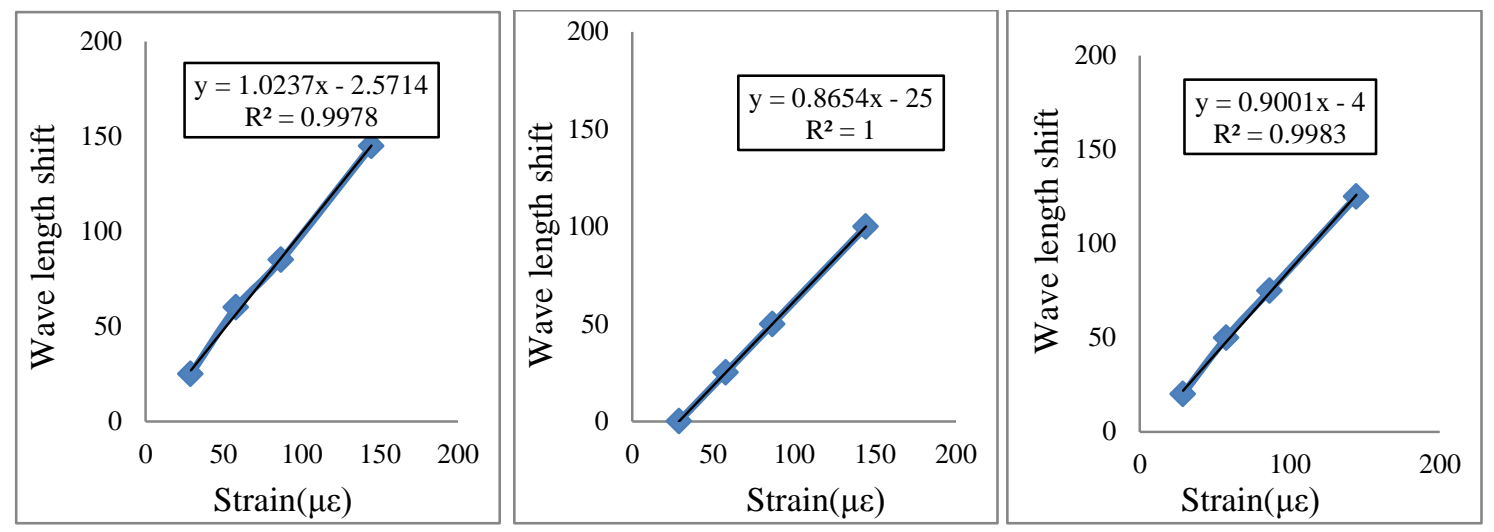

Figure 4-10 Peak FBG calibration result for three different sensors

\subsection{Monitoring system}

The data acquisition system included an optic electronic demodulation unit manufactured by Micron-Optics Incorporation and a PC laptop and a digital interface PCMCIA card. The PC and demodulation unit has direct communication with digital interface card. Digital interface card make communicates between the PC and demodulation unit. The wavelength of the light is reflected from the brag grating sensors interrogated with the FBG-SLI demodulation unit and sent this data to software application running on the PC. The FBG-SLI is fundamentally a fiberFP tunable filter and can normally recognize pm wavelength resolution. I-MON E-USB 2.0 is a custom software application which runs under the Lab View (National Instrument) programming environment. The PC laptop is specifically dedicated to control the demodulation system as well as obtain and save data from the sensors. The Figure 4-11 shows a scheme of FBG monitoring system. 


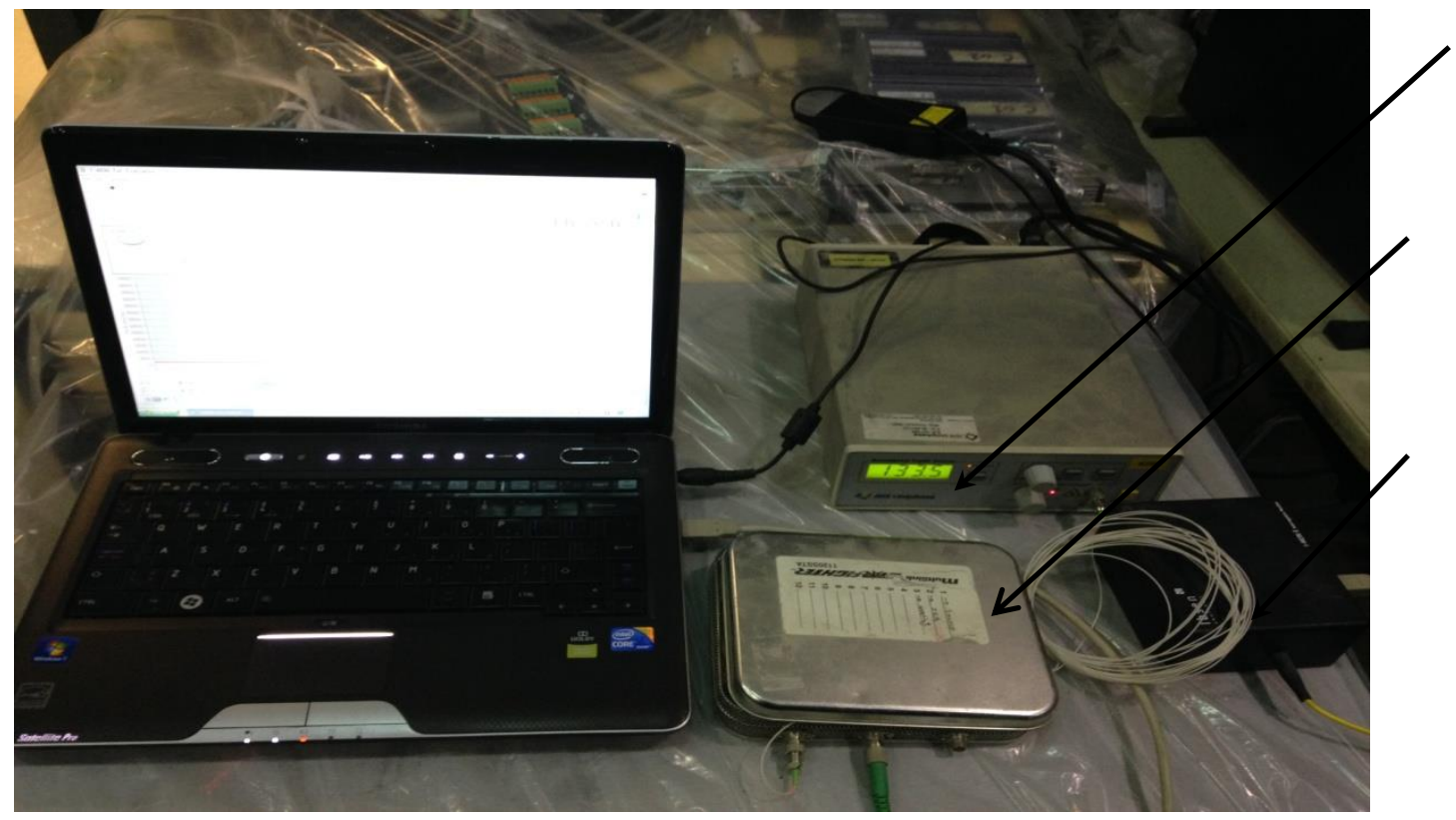

Source of Light

Optic electronic demodulation unit

Digital Interface PCMCA card

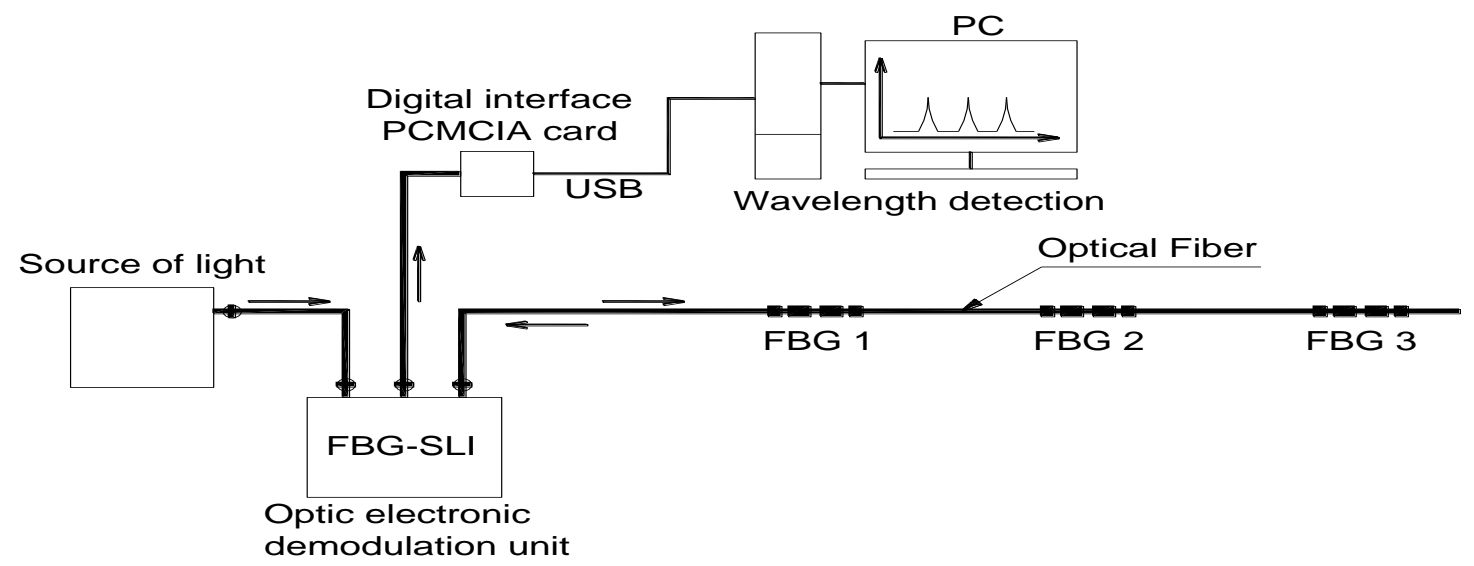

Figure 4-11 Fiber Bragg grating wavelength sensing system (Rizk, et al., 2012)

\subsection{Data Acquisition Software}

The I-MON E-USB 2.0 Interrogation Monitor offers real-time spectrum monitoring of Fiber Bragg Grating (FBG) sensors. High spectrometer resolution combined with broad wavelength range provides a high resolution interrogation monitor allowing measurement of a large number of FBG sensors. High sensitivity allows high resolution even at very low light levels. With its USB interface and data acquisition software it provides easy setup with a laptop PC. PC or laptop minimum requirement for the software is specified in following table: 
Table 4-1 PC Requirements for I-MON-USB2

\begin{tabular}{|l|l|l|l|}
\hline Parameter & $\begin{array}{l}\text { Minimum } \\
\text { Requirement }\end{array}$ & Recommended & Unit \\
\hline CPU & Pentium III, 1GHz & Pentium IV, 2.8 GHz & \\
\hline Screen-resolution & $1280 x 800$ & & Pixels \\
\hline Memory & 64 & 512 & Mbytes \\
\hline Available slots & USB 2.0 & & \\
\hline Operating System & Windows 2000/XP & Windows 2000/XP & \\
\hline
\end{tabular}

\subsection{FBG Lab Calibration with a Strain Gauge}

\subsubsection{Fiber Bragg Grating (FBG) sensors Results}

The concrete and reinforcement bars are all rigidly anchored together. A small value of slip was captured, as the applied load is lower than the expected cracking load. Hence, any change in the length of the concrete is accompanied by an approximately identical change in the length of the reinforcement value $\left(\varepsilon_{t} \approx \varepsilon_{s}\right)$. The value of concrete and steel strain is calculated based on the following equation:

$\left(\lambda_{2}-\lambda_{1}\right) / 1.2=\mu \varepsilon$

Equation 4-1

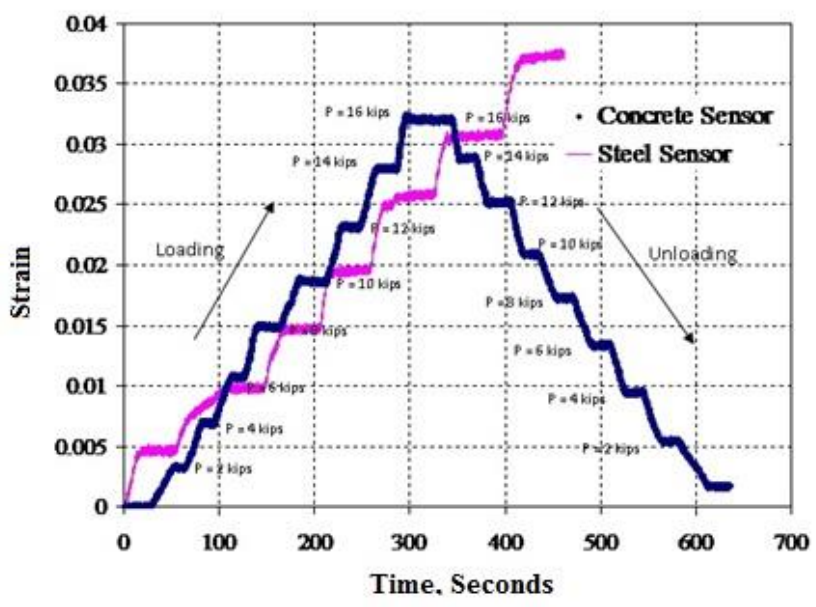

Figure 4-12 Time-strain relationship of the concrete and steel FBG sensor 


\subsubsection{Conventional Electrical Strain Gauges (ESG) Results}

Figure 4-2 shows the experimental values of the average steel strain measured using conventional electrical strain gauges (ESG) affixed to the steel reinforcing bars.

Based on comparison between Figures 4-2 and 4-3, it is recommended to multiply equation 4-1 by 1000 for calculating the value of strain to express the value of in microstrain. Thus, the value of strain using Fiber Bragg Grating (FBG) sensors in microstrain can be calculated based on the following equation:

$$
\operatorname{Strain}(\mu \varepsilon)=\frac{\lambda 2-\lambda 1}{1.2} \times 1000
$$

Equation 4-2

\subsubsection{Comparison between Fiber Bragg Grating (FBG) and Conventional Electrical Strain Gauges (ESG) Results}

Figure 4-3 presents a comparison between the average steel strain measured using conventional electrical strain gauges (ESG), and Fiber Bragg Grating (FBG) based on equation 4-2. Meanwhile, table 4-2 presents the experimental values of the strain for the steel and concrete measured by FBG and ESG, for various loading levels.

This comparative study presents a favorable agreement for the average steel strain measured using the two different approaches.

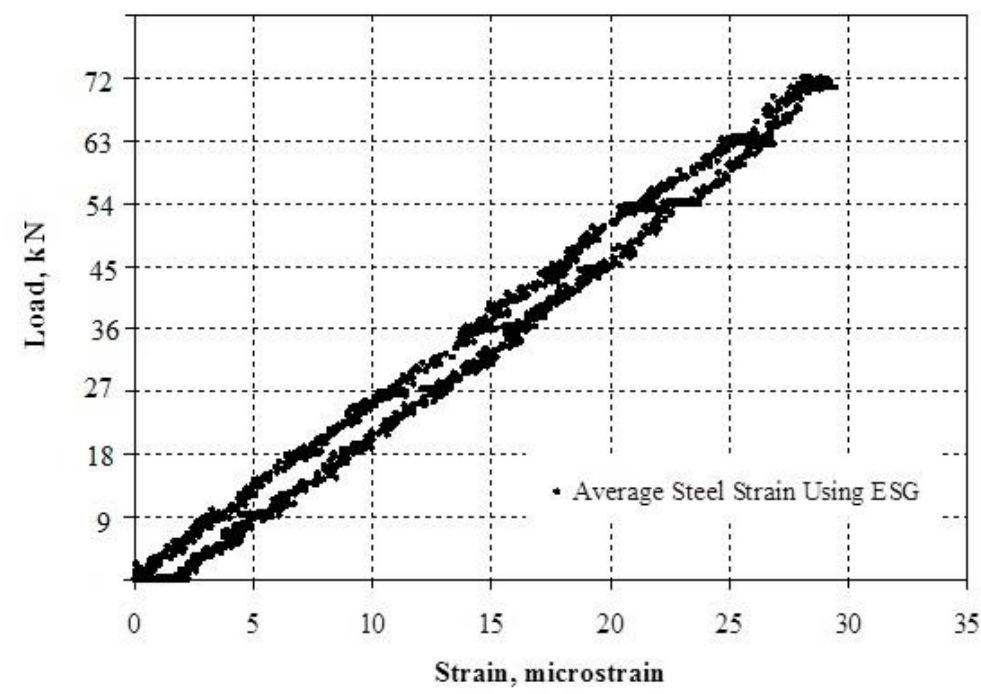

Figure 4-13 Load- average strain relationship of the reinforcement using ESG 
Table 4-2 Concrete and steel strain measured by FBG and ESG

\begin{tabular}{|c|c|c|c|c|}
\hline \multirow{2}{*}{$\begin{array}{c}\text { Load Value } \\
\qquad(k N)\end{array}$} & \multicolumn{2}{|c|}{ Fiber Bragg Grating (FBG) } & \multirow{2}{*}{$\begin{array}{l}\text { Conventional Electrical } \\
\text { Strain Gauges (ESG) } \\
\begin{array}{c}\text { Steel Strain } \\
\text { (microstrain) }\end{array}\end{array}$} & \multirow{2}{*}{$\begin{array}{c}\text { Steel Strain } \\
\text { FBG/ESG }\end{array}$} \\
\hline & $\begin{array}{c}\text { Concrete Strain } \varepsilon c \\
\text { (microstrain) }\end{array}$ & $\begin{array}{l}\text { Steel Strain \&s } \\
\text { (microstrain) }\end{array}$ & & \\
\hline 0 & 0 & 0 & 0 & - \\
\hline 9 & 3.2 & 3.2 & 3.25 & 0.985 \\
\hline 18 & 6.85 & 6.87 & 6.65 & 1.033 \\
\hline 27 & 10.85 & 10.73 & 10.7 & 1.003 \\
\hline 36 & 14.88 & 14.9 & 14.5 & 1.028 \\
\hline 45 & 18.369 & 18.78 & 17.9 & 1.049 \\
\hline 54 & 23.16 & 23.1 & 21.2 & 1.089 \\
\hline 63 & 27.98 & 27.95 & 25.2 & 1.109 \\
\hline 72 & 32.03 & 32.1 & 28.4 & 1.130 \\
\hline \multicolumn{4}{|c|}{ Average (FBG/ESG) } & 1.047 \\
\hline \multicolumn{4}{|c|}{ Standard Deviation (FBG/ESG) } & 0.052 \\
\hline \multicolumn{4}{|c|}{ Coefficient of Variance (FBG/ESG) } & 4.92 \\
\hline
\end{tabular}




\section{Chapter 5}

\section{Concrete Cylinders}

The first phase of this investigation is focused on using FBG sensors to measure concrete strain in cylinder and unreinforced beams to determine the modulus of elasticity, the modulus of rapture and the fracture energy.

\subsubsection{Compressive Strength}

The average compressive strength characteristic of UHPC was investigated with embedded FBG sensors .The test provided results related to strength, modulus of elasticity and compressive strain capacity of UHPC cylinders. Figure 5-1 shows average results from 3 cylinders were tested.

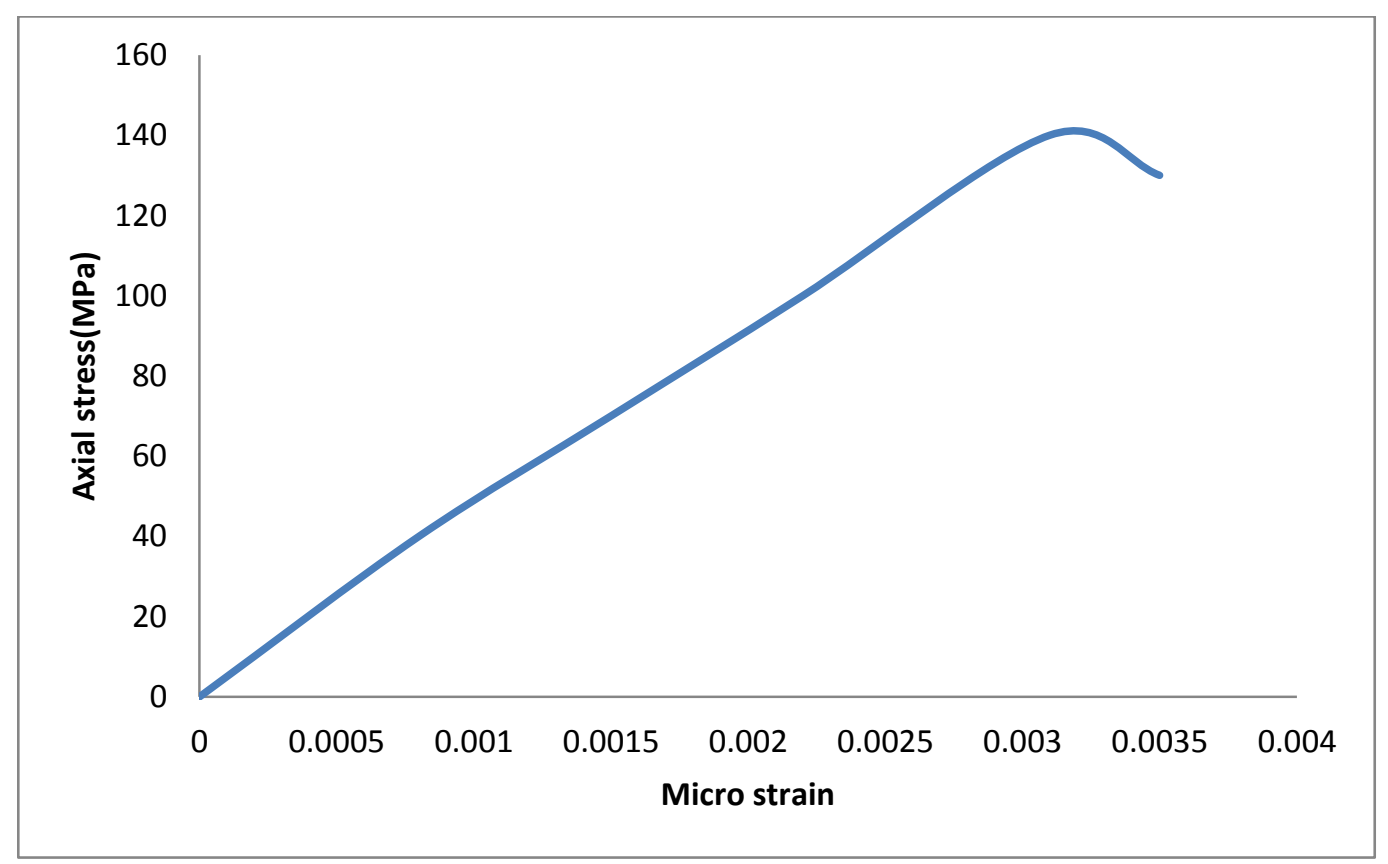

Figure 5-1 Stress-Strain graph for UHPC cylinders 


\subsubsection{Modulus of Elasticity}

In this experiment, the average value of the modulus of elasticity is calculated based on strain recorded with FBG sensors. The average of modulus of elasticity for UHPC cylinders was 49.9 GPa with strain at peak of 0.00315 .

\section{Table 5-1 Result for UHPC cylinders}

\begin{tabular}{|l|l|l|}
\hline Compressive strength $(\mathrm{MPa})$ & Modulus of elasticity $(\mathrm{GPa})$ & Strain at Peak (microstrain) \\
\hline 145 & 49.9 & 0.00315 \\
\hline
\end{tabular}

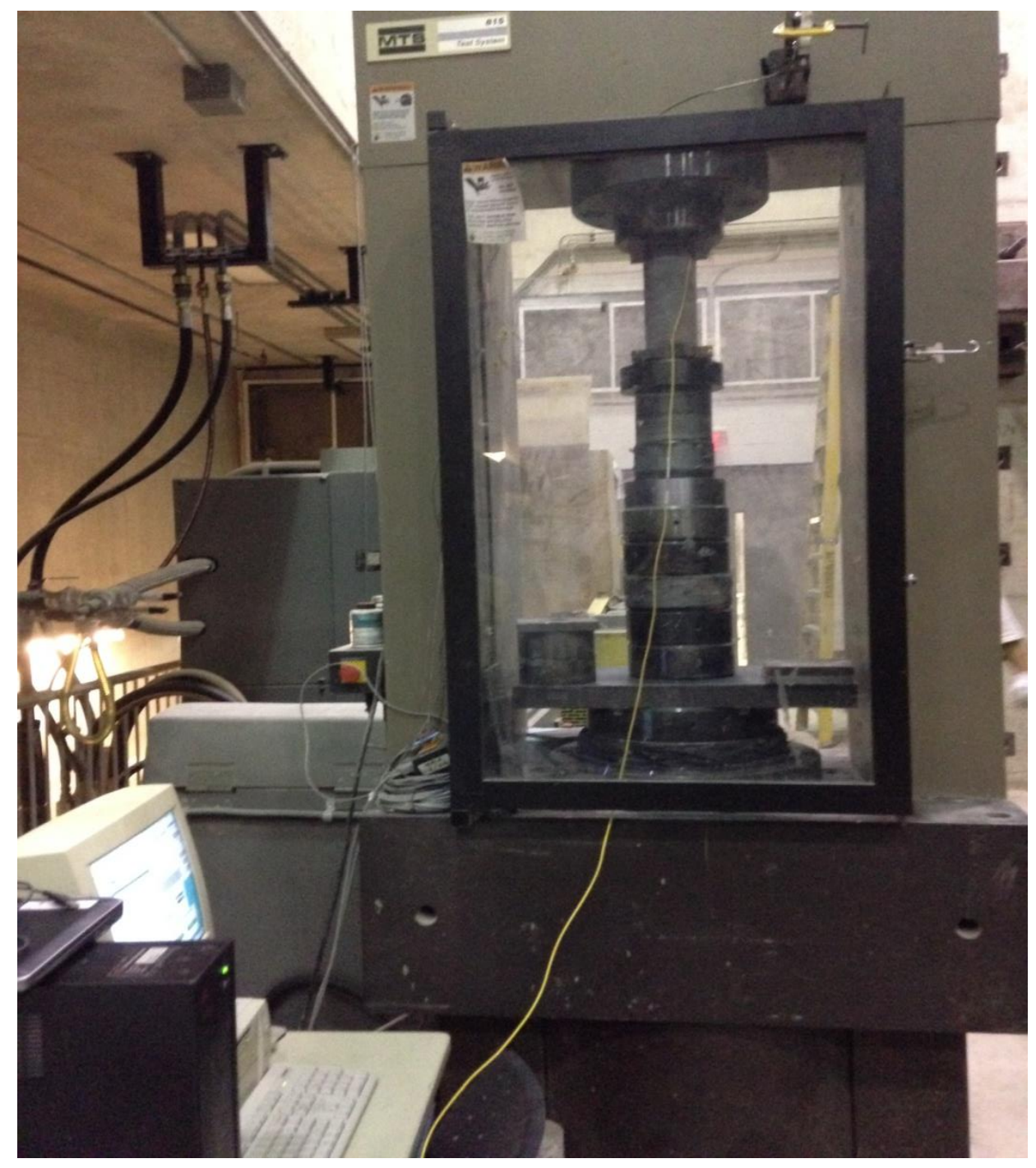

Figure 5-2 Modulus of Elasticity test with embedded FBG sensor 


\subsection{Concrete beam}

\subsubsection{Effect of the loading rate on normal strength concrete}

Over past few decades, many researches have been done on the dynamic fracture of normal strength concrete and there have been many different ideas about the effect of the loading rate (strain rate) on fracture energy of concrete. Most researchers accepted that fracture energy is rate independent at low loading rate due to straight effect of the loading velocity at low rates compared with fractures energy variations. (Ruiz, et al., 2009). But , Oh( (Oh, 1990) reported that in three-point bend specimens to measure fractures energy at different low loading rate (from $8.3 \times 10^{3} \mathrm{~mm} / \mathrm{s}$ to $0.8 \mathrm{~mm} / \mathrm{s}$ ), can provide accurate measurement for the fracture energy and nominal failure stress increase with the loading rate. In general, this increase is assigning to the presence of water in micro pore structure of the material. (Ruiz, et al., 2009)

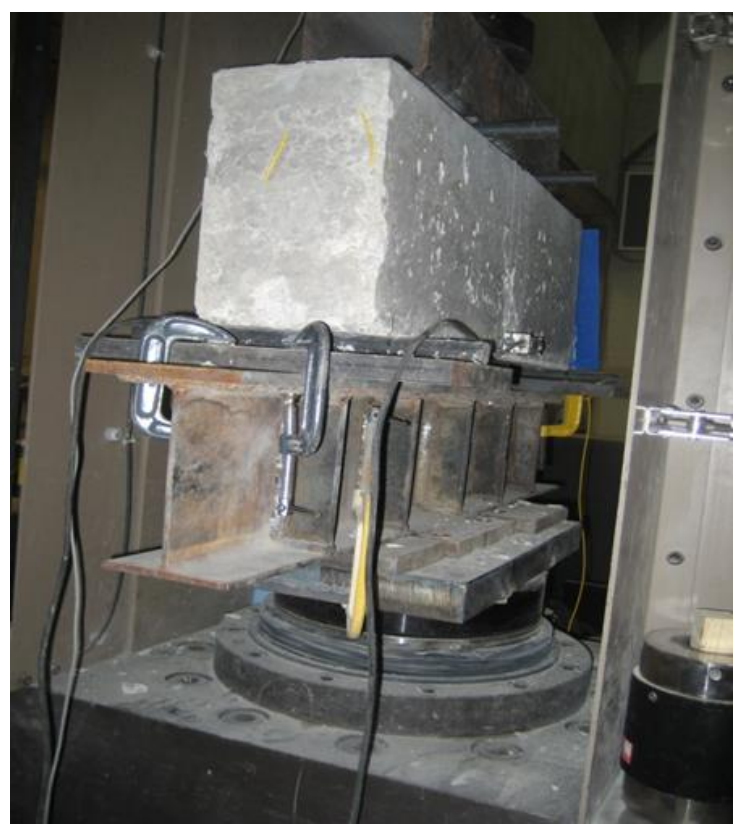

Figure 5-3 Typical beam under two point loading 


\subsubsection{Deformation behaviour}

Many researchers investigated the effect of strain rate on critical strain. The different scholars' experimental results are contradictory, some indicate an increase in critical strain at peak stress and some a decrease as strain rate increase (Yan \& Lin, 2006). It has been recommended that a small increase of critical strain with increasing strain rate (Bazant \& OH, 1982). Figure 5-4 shows the stress-strain curves obtained from FBG sensors with different strain rate. The figure shows that the beam with higher strain rate, the peak of the stress becomes sharper.

\subsubsection{Facture energy}

Fracture energy $\left(\mathrm{G}_{\mathrm{F}}\right)$ is measured as area under the stress-strain curve and in reality fracture energy is the energy required to form a unit area of crack in surface of concrete specimen. Many researchers obtained that the fracture energy of concrete would presented as a material property. To measured fracture energy from stress-strain curve, the descending portion of the stress-strain curve will consider.

In all three tested beams, surface cracks observed at approximately $80 \%$ to $90 \%$ of the ultimate load. Afterward, the strain increase to $95 \%$ and after, internal cracks, immediately propagate the surface.

\subsubsection{Modulus of rapture}

Modulus of rapture $\left(f_{r}\right)$ used as an indicator of concrete tensile strength. The modulus of rapture is theoretical maximum tensile strength reach in the extreme fiber of a flexural member (Brzev \& Pao, 2006). While the tensile stress in concrete reach the modulus rapture, cracks develop in structure. After crack development, the concrete is unable to resist any tension beyond that point. FBG sensors were used to record strain at modulus of rapture for three beams under different loading rate.

\begin{tabular}{|l|l|l|l|l|}
\hline BEAM & Loading rate & $\varepsilon$ & $\mathrm{f}_{\mathrm{r}}(\mathrm{MPa})$ & $\mathrm{E}_{\mathrm{t}}(\mathrm{GPa})$ \\
\hline 1 & $0.0030 / \mathrm{sec}$ & 100 & 2.25 & 30 \\
\hline 2 & $0.0020 / \mathrm{sec}$ & 120 & 1.70 & 25 \\
\hline 3 & $0.0002 / \mathrm{sec}$ & 120 & 1.50 & 22 \\
\hline
\end{tabular}




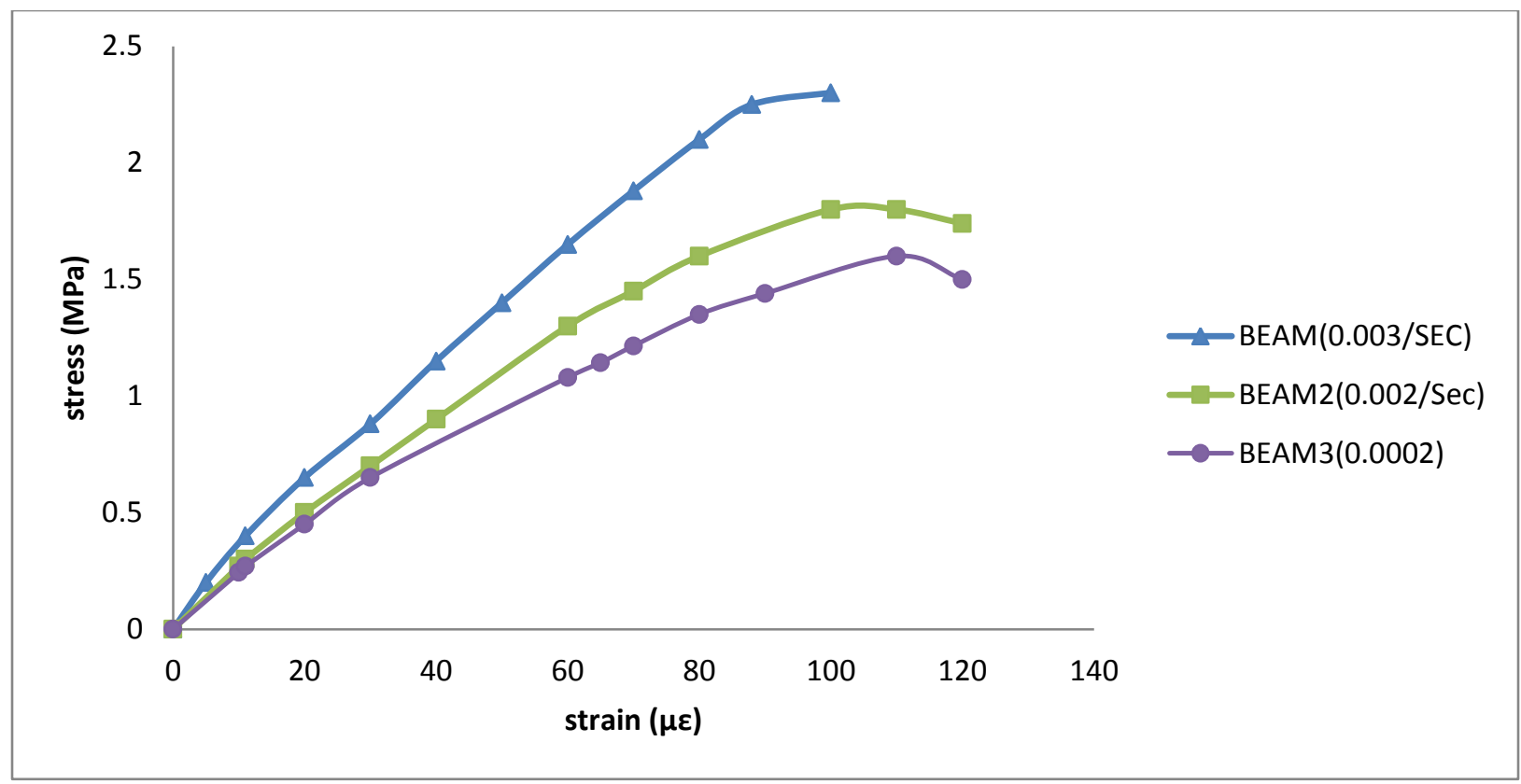

Figure 5-4 Stress-strain curve for beams 


\section{CHAPTER 6}

\section{Creep Results and Discussions}

\subsection{Introduction}

Three types of concrete are used in this investigation namely, normal concrete (NC), High performance concrete (HPC) and ultra-high performance concrete (UHPC), experimental strain, shrinkage and creep measurements. Measurements were taken on a daily basis for a week after loading, then weekly thereafter for creep and shrinkage. For each type of concrete, the curve represents an average of two cylinders with Fiber Bragg Grating (FBG) sensors and two cylinders with Electrical strain gauge.

\subsubsection{Compressive strength}

The specific compressive strength ( $\left.f_{c}^{\prime}\right)$ of each type of concrete (NC, HPC, UHPC) were tested right before creep test. The 28-day average compressive strength for NC, HPC and UHPC were 30, 65 and $140 \mathrm{MPa}$, respectively.

\subsubsection{Applied creep load}

The compressive strength of concrete was tested after 28 days of curing and measured at the same day of loading. The value of compressive strength for each set up was recorded respectively as, $30 \mathrm{MPa}$ for Normal strength concrete, $65 \mathrm{MPa}$ for High performance and 140 MPa for Ultra-high performance concrete. For the first setup (Normal performance), 24\% of compressive strength (6.8 MPa), for the second setup (High performance), 30\% of compressive strength (17.0 MPa) and 32\% of compressive strength (44.9 MPa) for ultra-high performance specimen were applied. The load rating for all tests were kept same as $0.5(\mathrm{kN} / \mathrm{sec})$. NC cylinder has maximum displacement of $3.9 \mathrm{~mm}$ after 28 days and for UHPC and HPC the displacement were less than $2 \mathrm{~mm}$. The maximum displacement after 28 days for UHPC, HPC and NC concrete types were $0.061,0.10$ and $0.12 \mathrm{~mm}$ respectively as shown in Figure 6-1. Total average length of cylinders before loading were recorded $202 \mathrm{~mm}$ and strain was calculated from displacement of 28 days based on the recorded average length to compare the result with strain recorded from FBG sensors. 


\subsection{Total strain (Electrical strain gauge)}

The strains after applying load were recorded from ESG with gauge length of $80 \mathrm{~mm}$ for 28 days for all cylinders. While load was being applied, one (NC) cylinder supplied with ESG sensor and a second (UHPC) cylinder sensor were damaged due to small cracks in surface of cylinders and consequently all data were lost. However, all FBG sensors were working properly until the end of experiments. Strain reading after applying load does not remain constant, due to the fact that the signal from ESG fluctuates, ESG were not enough sensitive to record small changes in strains.

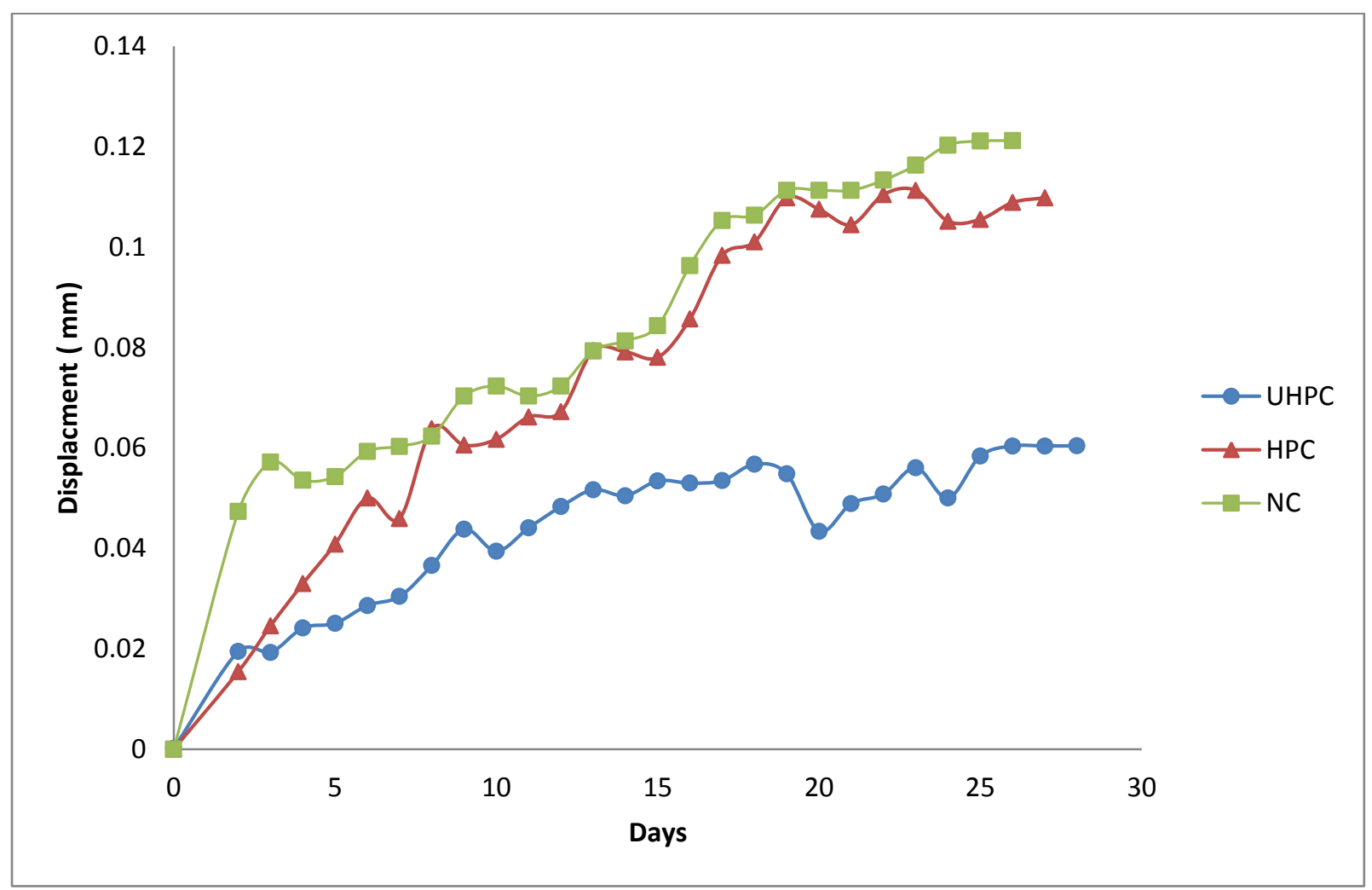

Figure 6-1 Displacement after Load kept constant for 28 days 


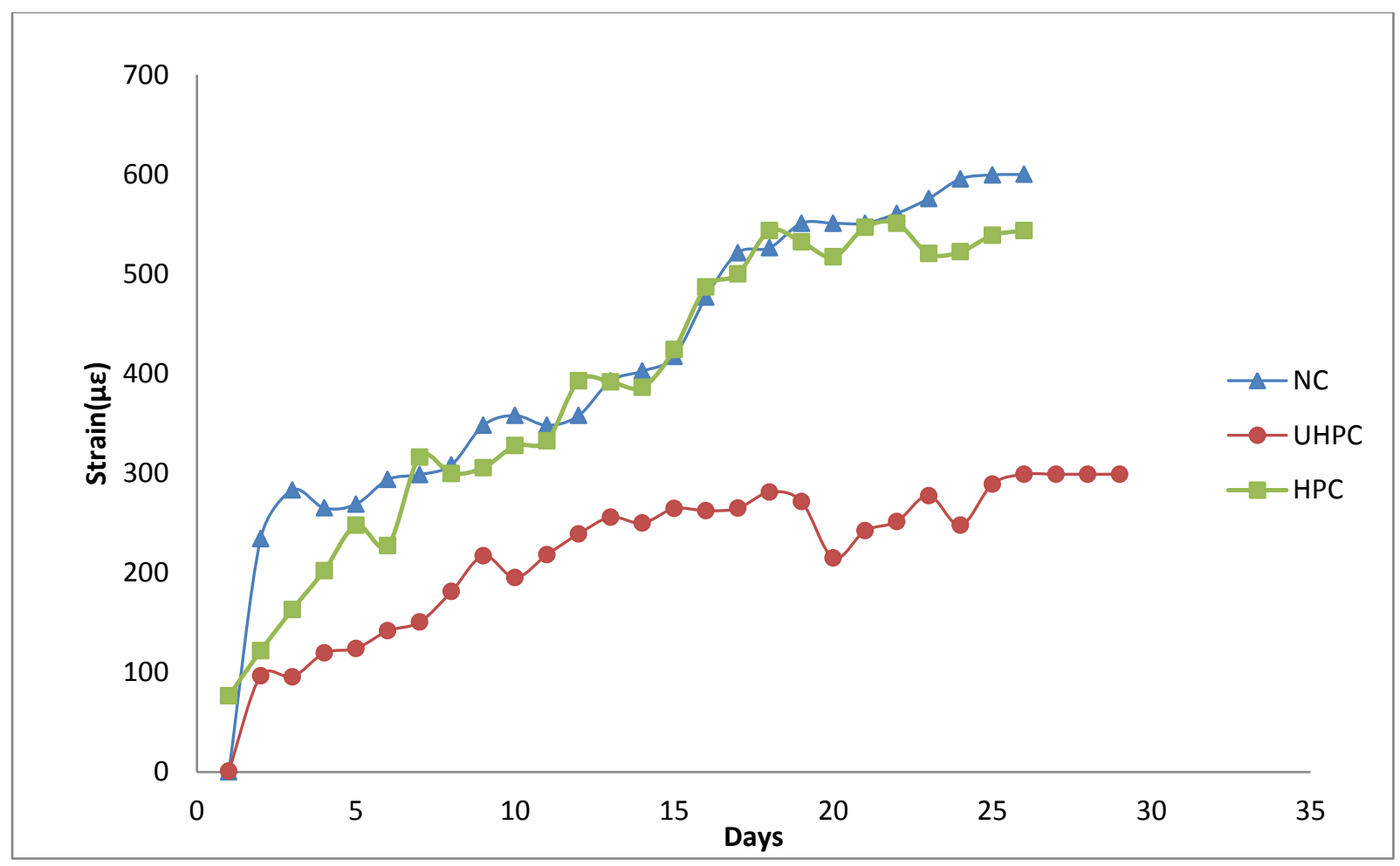

Figure 6-2 Strain calculated from cylinder displacement of 28 days

\subsection{FBG sensors}

FBG sensors recorded wavelength movement over 28 days period for cylinders in this experiment. Figures 6-3, 6-4 and 6-5 show overall movement of wavelength (nm) of FBG sensors over 28 days. Calculations and data analysis of FBGs sensors were done based on these measured movements.

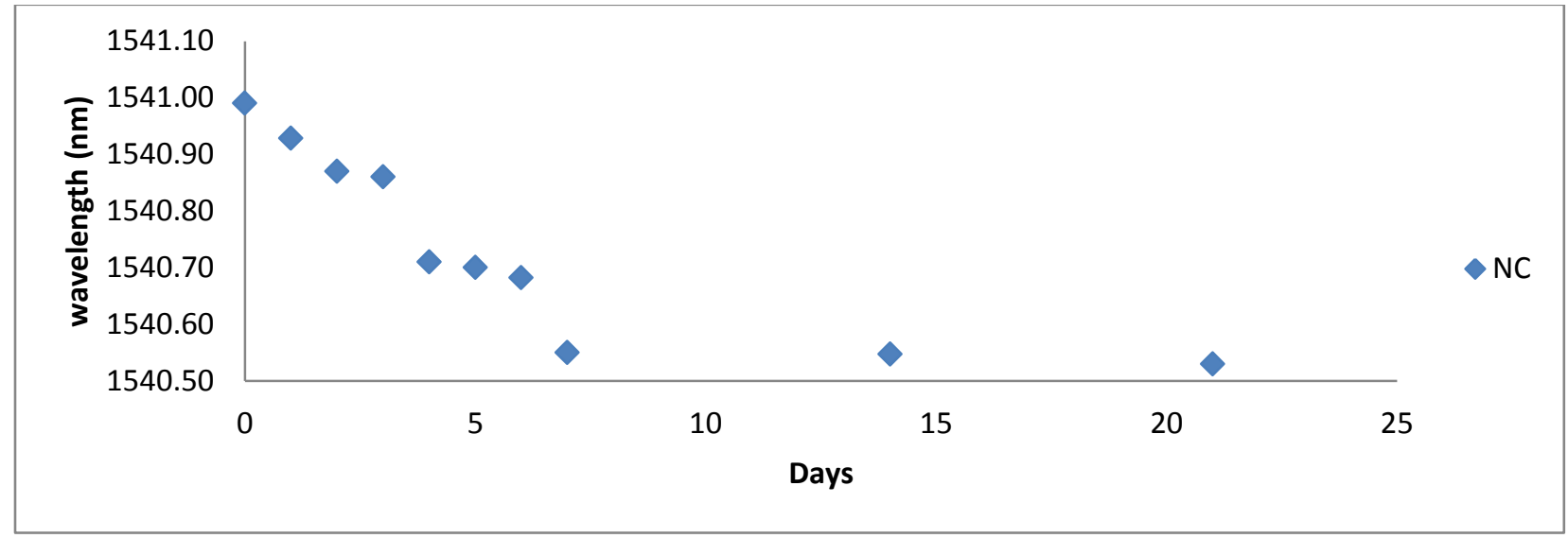

Figure 6-3 Wavelength Movement of NC 


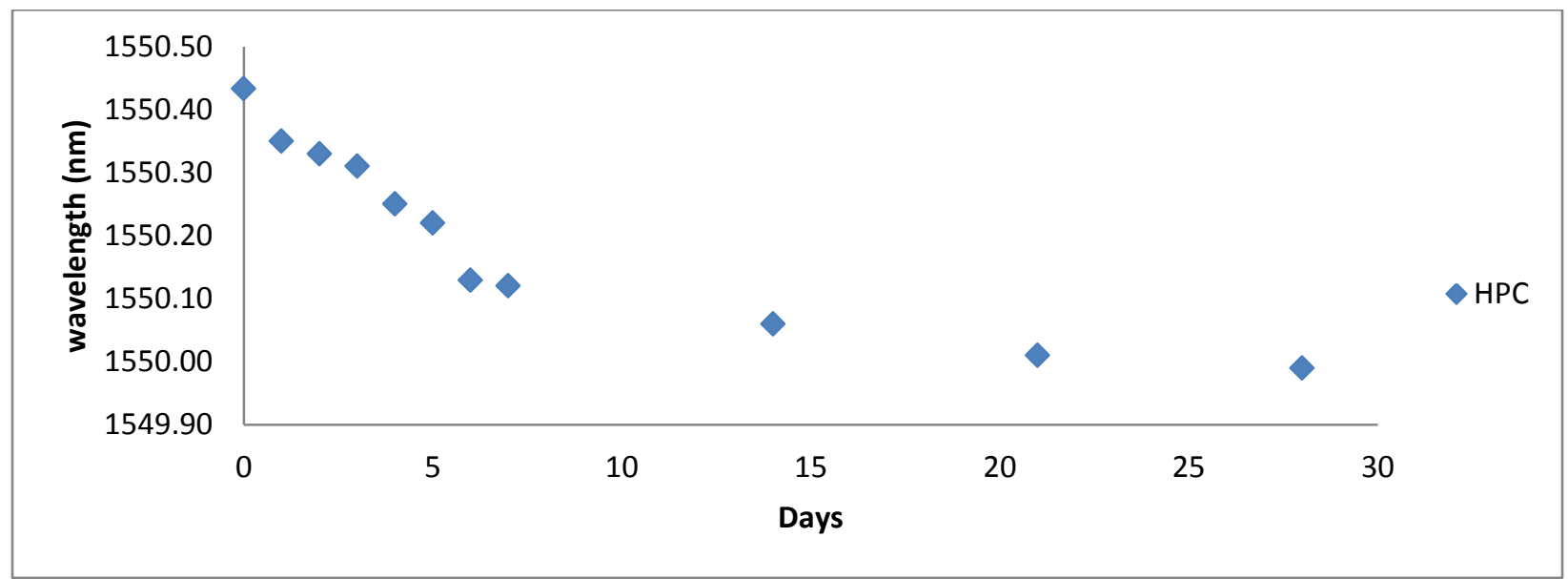

Figure 6-4 Wavelength Movement of HPC

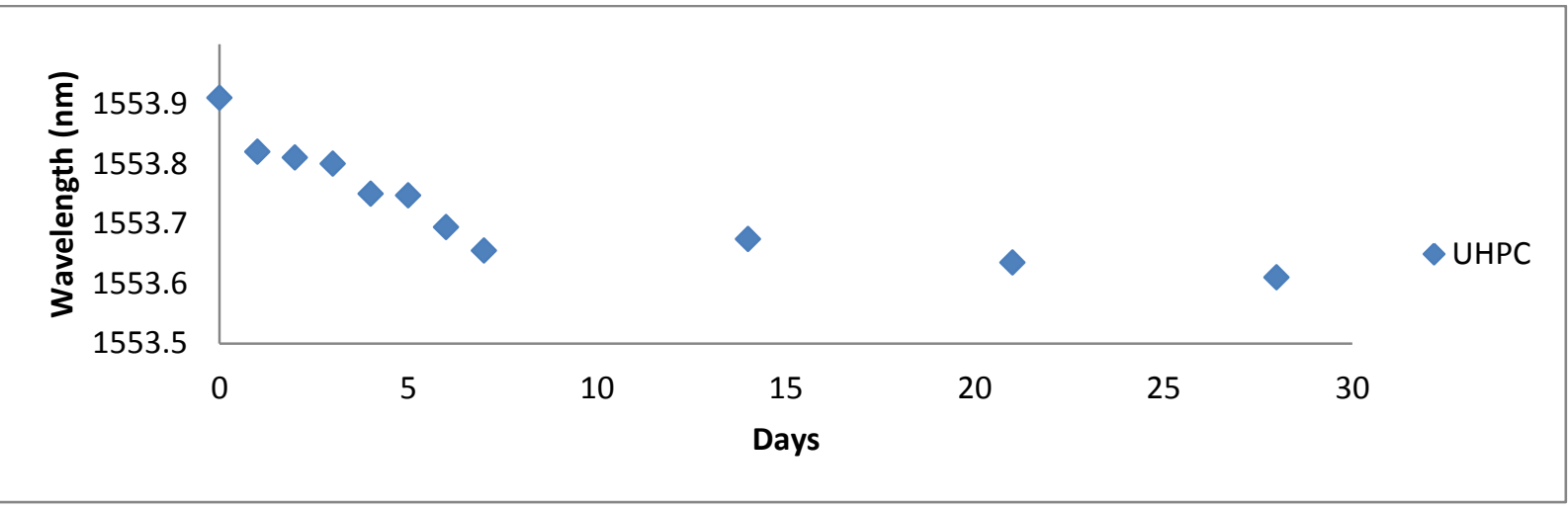

Figure 6-5 Wavelength Movement of UHPC

\subsubsection{Total strain (FBG sensors)}

Total strain of concrete cylinders is measured under a constant and sustained compressive load. Total strain is determined from the following equation:

$$
\varepsilon_{T}=\varepsilon_{\text {ins }}+\varepsilon_{\text {crp }}+\varepsilon_{\text {shr }}
$$

Equation 6-1

The first reading was taken before loading, at the age of 28 days from demolding specimens and the second reading was done immediately after loading.

Two cylinders under load constant from each set up have strain electrical strain gauge ( $80 \mathrm{~mm})$. The average strain from EGS for NC, HPC, UHPC were recorded 560, 697, $1010 \mu \varepsilon$, respectively. 
It has to be mentioned that during the test, the ESG were placed on surface of concrete and consequently were damaged due to small crack on concrete surface. However, all FBG sensors were working properly even after samples failed in stress-strain test.

\subsubsection{Elastic strain}

The instantaneous elastic strain is measured right after loading. The average instantaneous elastic strain for a compressive strain of $7 \mathrm{MPa}$ for NC was $89 \mu \varepsilon, 18 \mathrm{MPa}$ for HPC and $492 \mu \varepsilon$ for UHPC with $44.8 \mathrm{MPa}$ was $931 \mu \varepsilon$, respectively.

\subsubsection{Thermal strain}

The thermal strain was safely ignored because temperature for all specimens was kept constant during all experiments.

\subsection{Total displacement up to required load applied}

The load-displacement was recorded from MTS machine. The displacement-load of all three types of concrete until load reaches its final constant value. The maximum displacement of NC with $7 \mathrm{MPa}$ was $3.8 \mathrm{~mm}$, for HPC with $17 \mathrm{MPa}$ was about $1.98 \mathrm{~mm}$ and for UHPC with applied load of 44.8 was $2.7 \mathrm{~mm}$.

\subsection{Total shrinkage strains}

The creep and shrinkage strain were measured from loaded cylinders consists of both the creep and shrinkage strain from each individual set up. Figure 6-6 shows the total shrinkage of each individual set up of specimen. The total shrinkage strains were determined from total strain taken directly from cylinders from the first day of casting until the day cylinders were removed from curing room. The maximum strain after 28 days for NC, HPC and UHPC were recorded as 435.7, 426.66 and $291.65 \mu \varepsilon$, respectively 


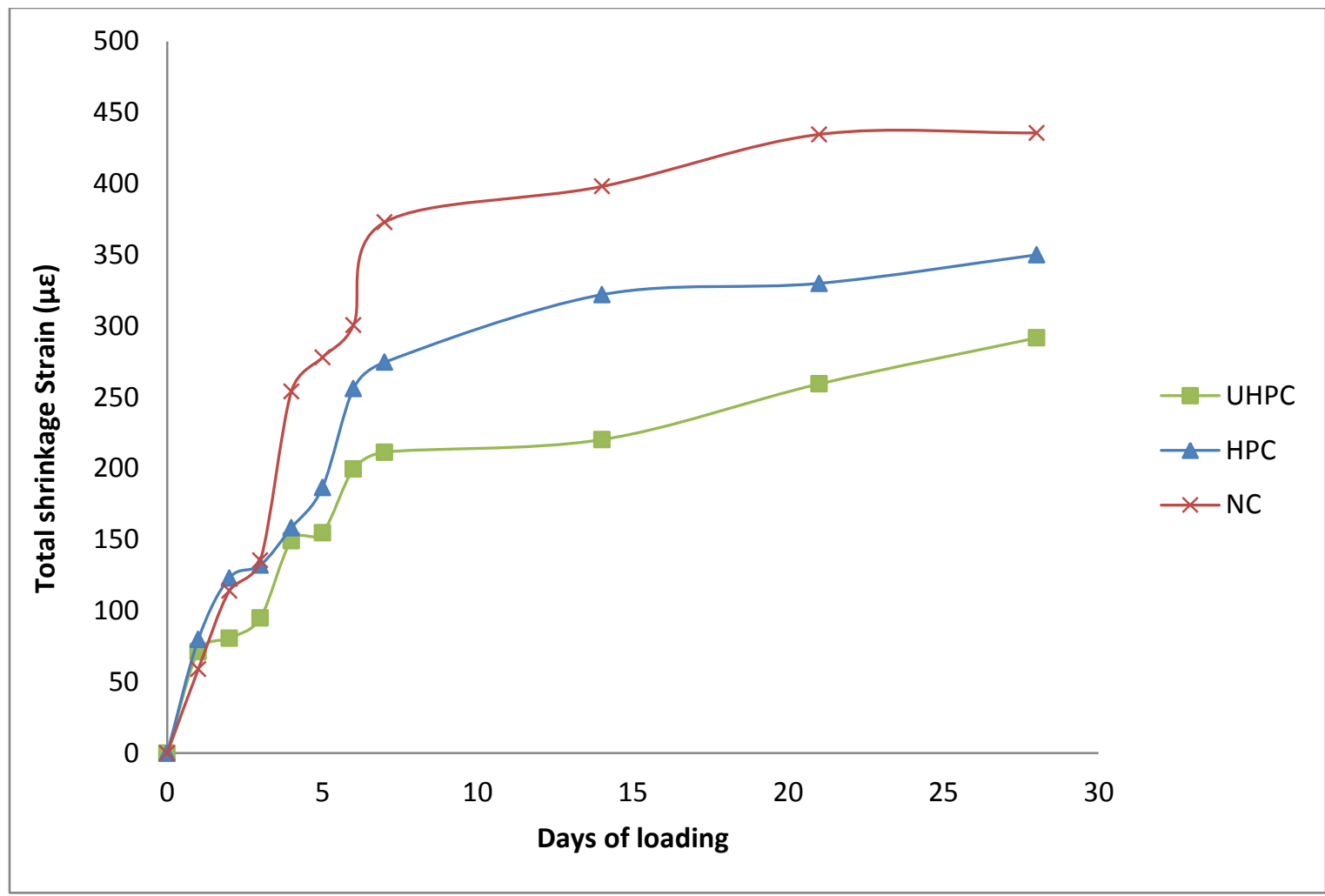

Figure 6-6 Total shrinkage strain from FBG sensors

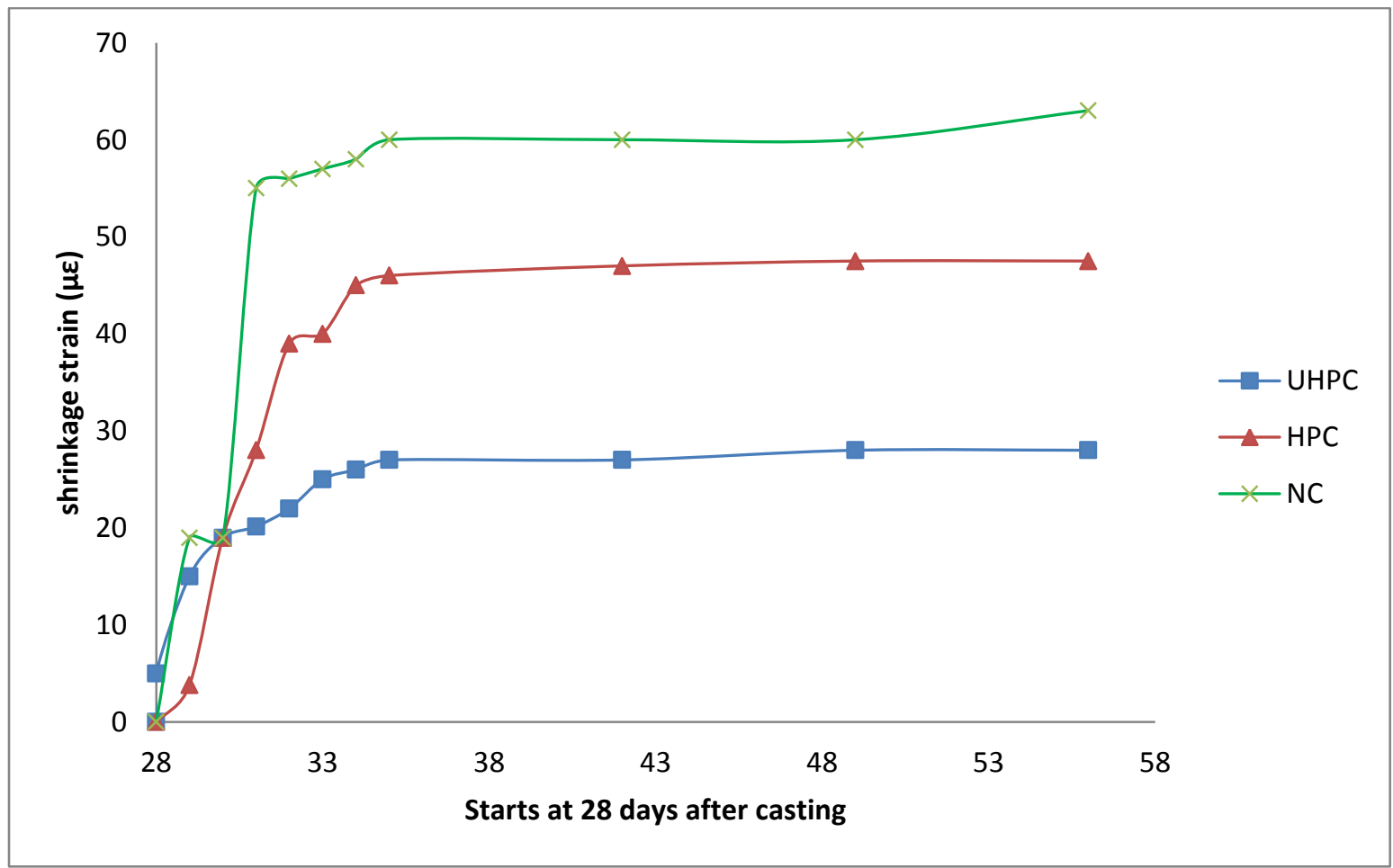

Figure 6-7 Drying shrinkage starting at 28 days after casting from FBG sensors 


\subsubsection{The drying shrinkage strain}

Figure 6-7 shows the drying shrinkage strain after 28 days measured right after moving specimens from curing room while the other specimens were loaded. The total shrinkage strain

after 28 days for NC, HPC, and UHPC were 60, 47.5 and $43 \mu \varepsilon$, respectively. The most shrinkage was recorded in the first 5 days in all three types of concrete after moving from curing room. The shrinkage strain for UHPC after 5 days staid constant and no more shrinkage happened.

\subsection{Creep Strain}

The strains from two cylinders under constant load with embedded FBG sensors were recorded. The elastic strain and drying shrinkage strain was subtracted from the total strain measured under constant load to measure creep measurement. Figure 6-8 shows the result for creep measurement in 28 days period for NC, HP and UHPC. The creep was measured as 300, 280 and $228 \mu \varepsilon$ for three types of concrete, respectively.

\subsection{Creep function}

Total stress-dependent strain per unit stress, also called creep compliance or creep function. Graph 6-9 shows creep function of NC, HPC, and UHPC. Also, all prediction models calculated bas on creep function to use for comparison the result.

\subsection{Specific creep}

Figure 6-10 shows specific creep for all three type of concrete. The specific creep for NC after

28 days under constant load of $6.8 \mathrm{MPa}$ was $55(\mu \varepsilon / \mathrm{MPa})$, for HPC under constant load of 17 $\mathrm{MPa}$ was $22(\mu \varepsilon / \mathrm{MPa})$, and for UHPC under constant load of $45 \mathrm{MPa}$ was $5.08(\mu \varepsilon / \mathrm{MPa})$. 


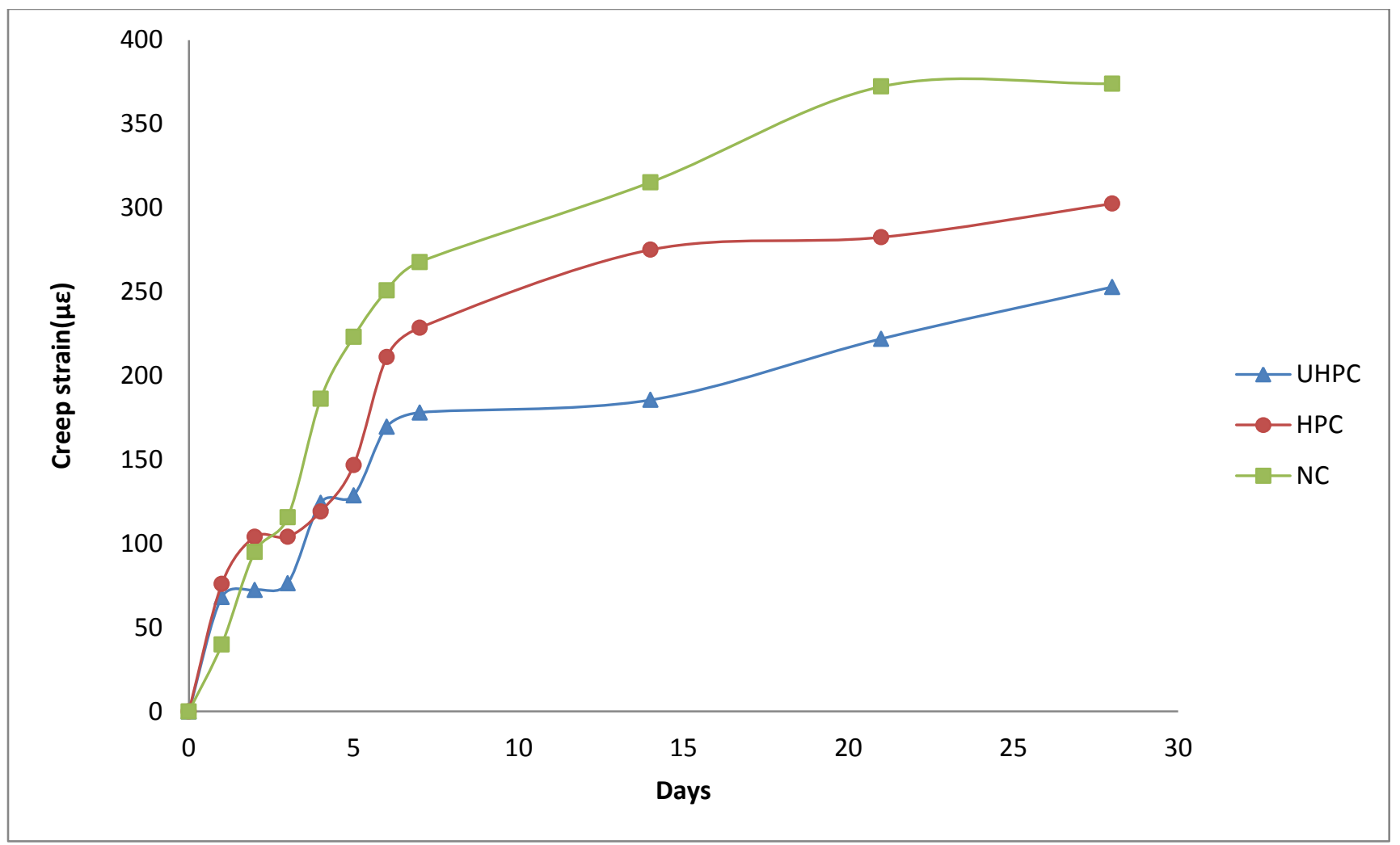

Figure 6-8 Creep strain from FBG sensors

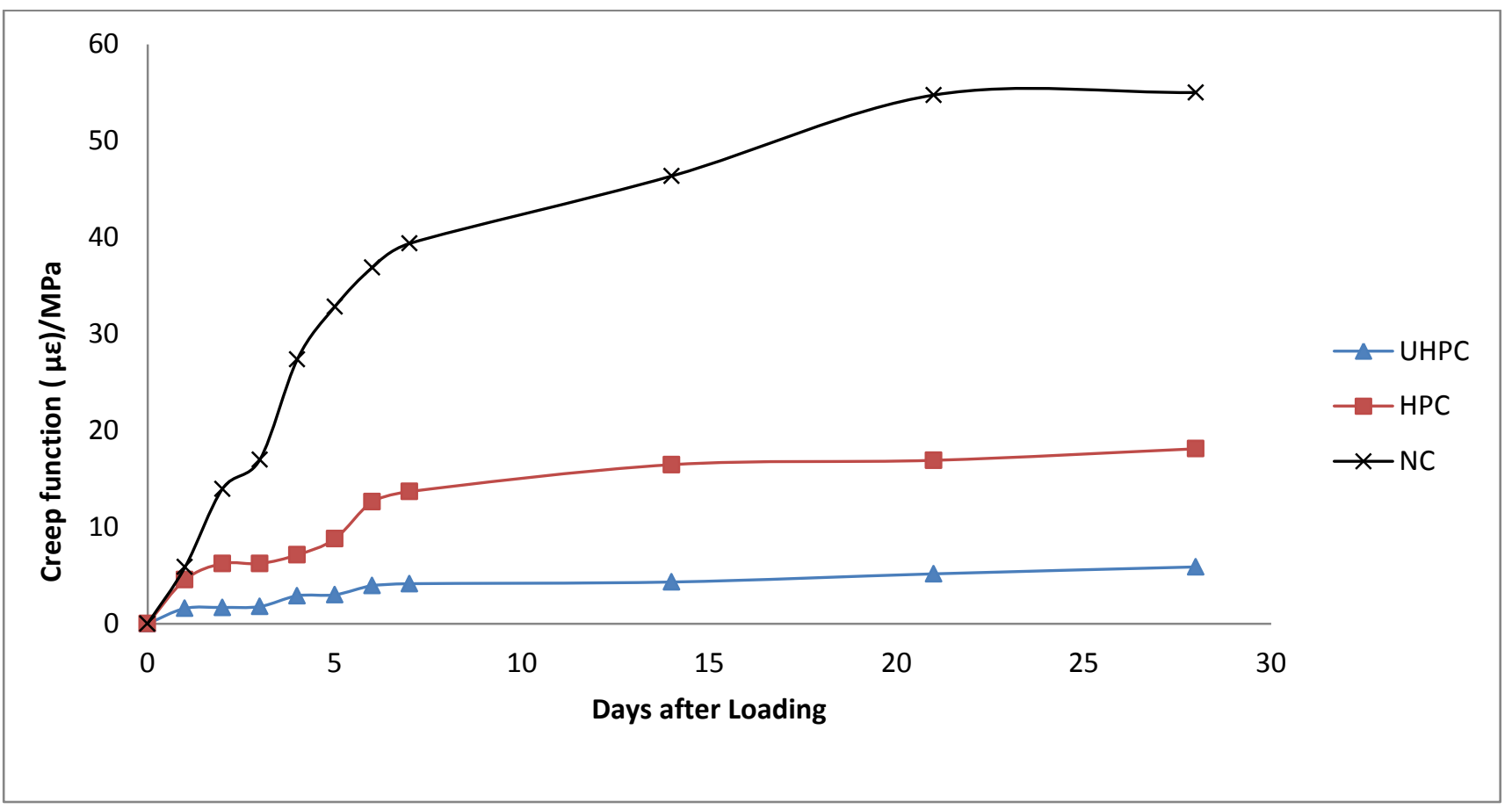

Figure 6-9 Creep function $(\mu \varepsilon / \mathrm{MPa})$ 


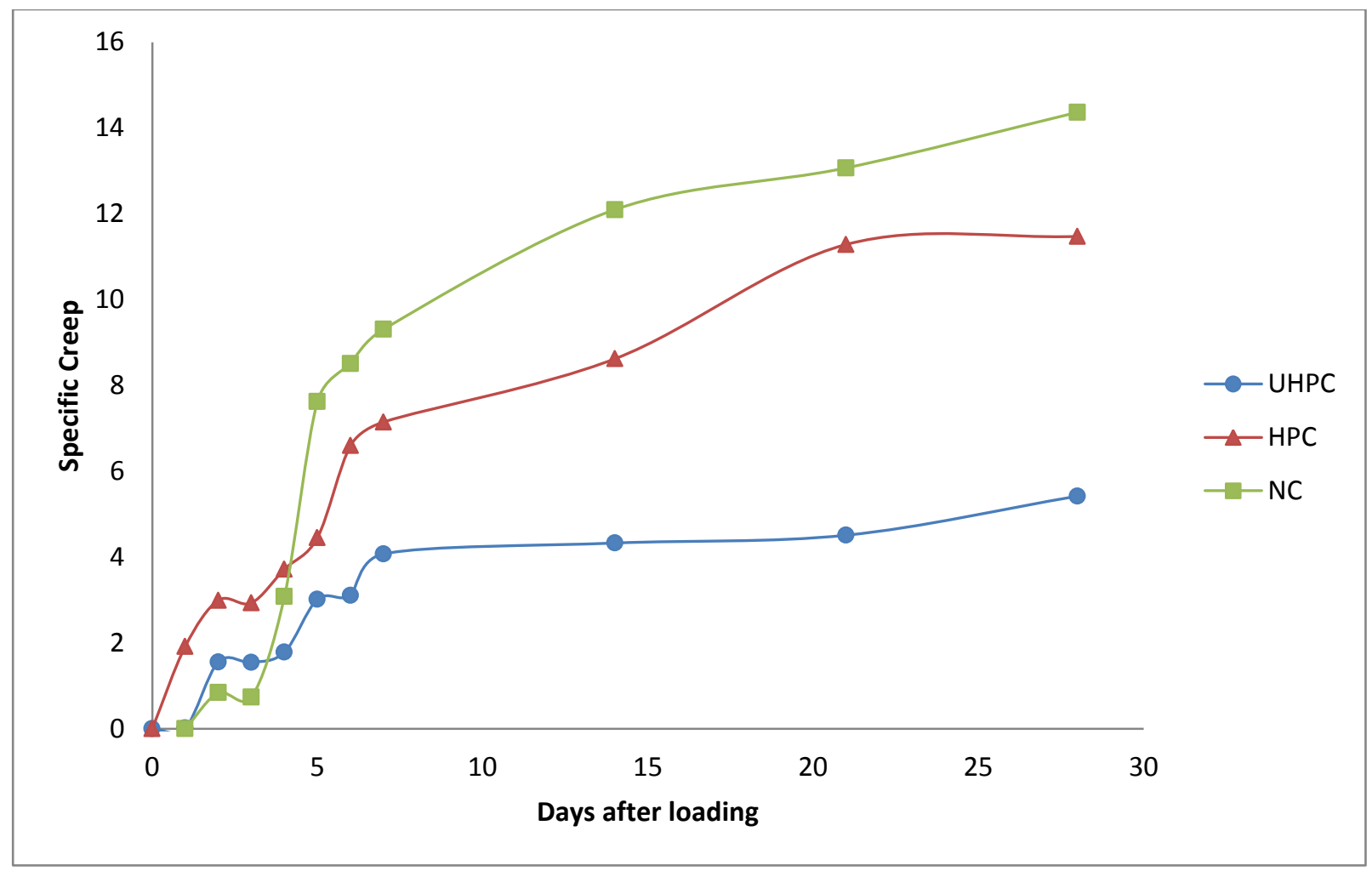

Figure 6-10 Specific creep

\subsection{Analysis and Discussion}

\subsubsection{Creep and shrinkage behaviour}

Measurement and modeling of creep and shrinkage of concrete in not an easy and straightforward measurement procedure due to the time dependency nature of creep and shrinkage and lack of accuracy in traditional measurement equipment. FBG sensors were embedded in the specimens to monitor shrinkage and creep in different types of concrete. FBG sensors overcome the disadvantages of traditional creep gauge such as Whittemore gauge or ESG. FBG can monitor strain deformation from before concrete starts hardening till it fails under ultimate load precisely and continuously. It has been concluded from the results of this research that certain factors have effects over creep and shrinkage as summarized in the following.

\subsubsection{Water cement ratio}

Water-cement ratio is the most dominant parameter, with respect to mixture portion, which affects the creep behaviour of concrete. In order to reach high and ultra-high compressive 
strength, lower W/C ratio is used compared with normal strength concrete. The specific creep of concrete increases with higher w/c ratio of mix design as reported (Neville, 2002). The mix of concrete with lower w/c ratio causes the volume of hydrates to reduce along with the free water content, and therefore creep will reduce. Concrete with higher w/c ratio has higher capillary porosity of cement paste, and it would absorb more water which result in larger final creep. (Smadi, et al., 1996). The lower w/c ratios in HPC and UHP appear in the form of less creep in experiments. Results show that creep significantly increases with more w/c ratio concrete in NC.

\subsubsection{Silica fume}

Silica fume is the effective supplementary binding material which is used in mix designs of HPC and UHPC with compressive strength of over $60 \mathrm{MPa}$. The size of SF particles is about $0.2 \mu \mathrm{m}$. The physical and chemical characteristic of SC makes it very active in reacting with hydration of cement. Many researches proved that SF (Silica fume) help hydrations of cement and react with $\mathrm{CH}$ crystal hydrates so as to increase the amount of C-S-H gel hydrates and density of hardened cement paste (Jianyong \& Yan, 2001).C-S-H gel hydrates in cement paste offers higher resistance to deformation caused by applied force. These ultrafine particles can fill small pores and voids to prevent harmful damages to structures and decrease creep. Wiegrink reported that the mix with more silica fume tend to creep less (Wiegrink, et al., 1996). Addition of SF to concrete mix will reduce the creep and drying shrinkage of concrete.

\subsubsection{Stress Level}

Creep is responsive to magnitude of sustained stress which is constantly applied. For instance; creep would be more if a specimen is loaded up to 80 percent of its compressive strength compared with the same specimen loaded up to 40 percent of its compressive strength (Smadi, et al., 1996). Most researchers suggest that sustained stress level should be between 40 to 80 percent of ultimate value for creep test on NC, HPC and UHPC. The creep strain is proportional to stress level until a certain limit. The limit was suggested to be 65 percent of ultimate compressive load for HPC and UHPC (Smadi, et al., 1996). In this experiment the stress level was kept the same for all three types of concrete to assess the results in the same condition. Therefore, the creep strain for HPC and UHPC were measured less than expected value due to lower stress level which was applied for the test. 
As mentioned in the above, in this experiment the applied stress were kept almost the same except for a small difference for NC. NC specimens were set up first, and then the required necessary adjustments were done to improve the measurement performance for the other two setups.

\subsubsection{Specific creep}

Specific creep is calculated by dividing creep strain by applied stress which is useful in comparing the creep behaviour of concrete under different compressive strengths. The typical creep coefficient recorded by different researchers normally range from 35 to 145 microstrain per MPa.

\subsubsection{Creep coefficient}

Creep coefficient is defined as the ratio of ultimate creep strain to initial elastic strain. A typical value of creep coefficient is normally in the range of 1.5 to 3 . Table 6-1 shows the results of experiments. $\mathrm{E}_{\mathrm{c}}$ was calculated based on equation 2-1 to equation 2-3 in chapter 2.

\section{Table 6-1 Result summary}

\begin{tabular}{|l|l|l|l|l|l|}
\hline $\begin{array}{c}\text { Type of } \\
\text { concrete }\end{array}$ & Strength(MPa) & Stress/Strength & $\begin{array}{c}\text { Final Creep } \\
\text { Strain }(\mu \varepsilon) \\
\text { after } 28 \\
\text { days }\end{array}$ & $\mathrm{E}_{\mathrm{c}}(\mathrm{GPa})$ & $\delta_{\mathrm{cu}}(\mu \varepsilon / \mathrm{MPa})$ \\
\hline NC & 30 & $24 \%$ & 372 & 25.9 & 55 \\
\hline HPC & 60 & $30 \%$ & 379 & 31.91 & 22 \\
\hline UHPC & 140 & $32 \%$ & 238 & 43.187 & 5 \\
\hline
\end{tabular}

\subsubsection{Shrinkage behaviours}

Shrinkage of concrete occurs in the absence of an applied load. It has three different stages which are known as drying shrinkage, autogenous shrinkage and carbonation shrinkage. Usually, a concrete mix keeps some extra water for initial hydration. Some of this extra water is stored in pores or void spaces of concrete. Extra water inside the pores and void spaces diffuses into surrounding environment after casting and this causes a net volume loss (Smadi, et al., 1996). 
Base on experimental results and literature reviews NC has higher drying shrinkage than HPC and UHPC but autogenous shrinkage was more in UHPC than the other two.

\subsubsection{Long -term creep prediction base on experimental result 28 days}

To determine the creep strain prediction in $(\mu \varepsilon / \mathrm{MPa})$ based on the short-term experimental data ASTM provided equations 2-46 and 2-47. The main idea here is to use the slope of the real data in the short term to predict creep in the long term. As it can be seen from the diagrams of this section, regression equation from real data is used to obtain the slope which is then used as the main parameter for long term creep prediction.

Some emprical methods with varying degree of complexicity for estimation of creep and shrinkage can be used, when short-term tests are not available for measuremnt of long term creep and shrinkage

Figures 6-16 to 6-23 present the prediction models based on experimental data for 28 day for three types of concrete. 


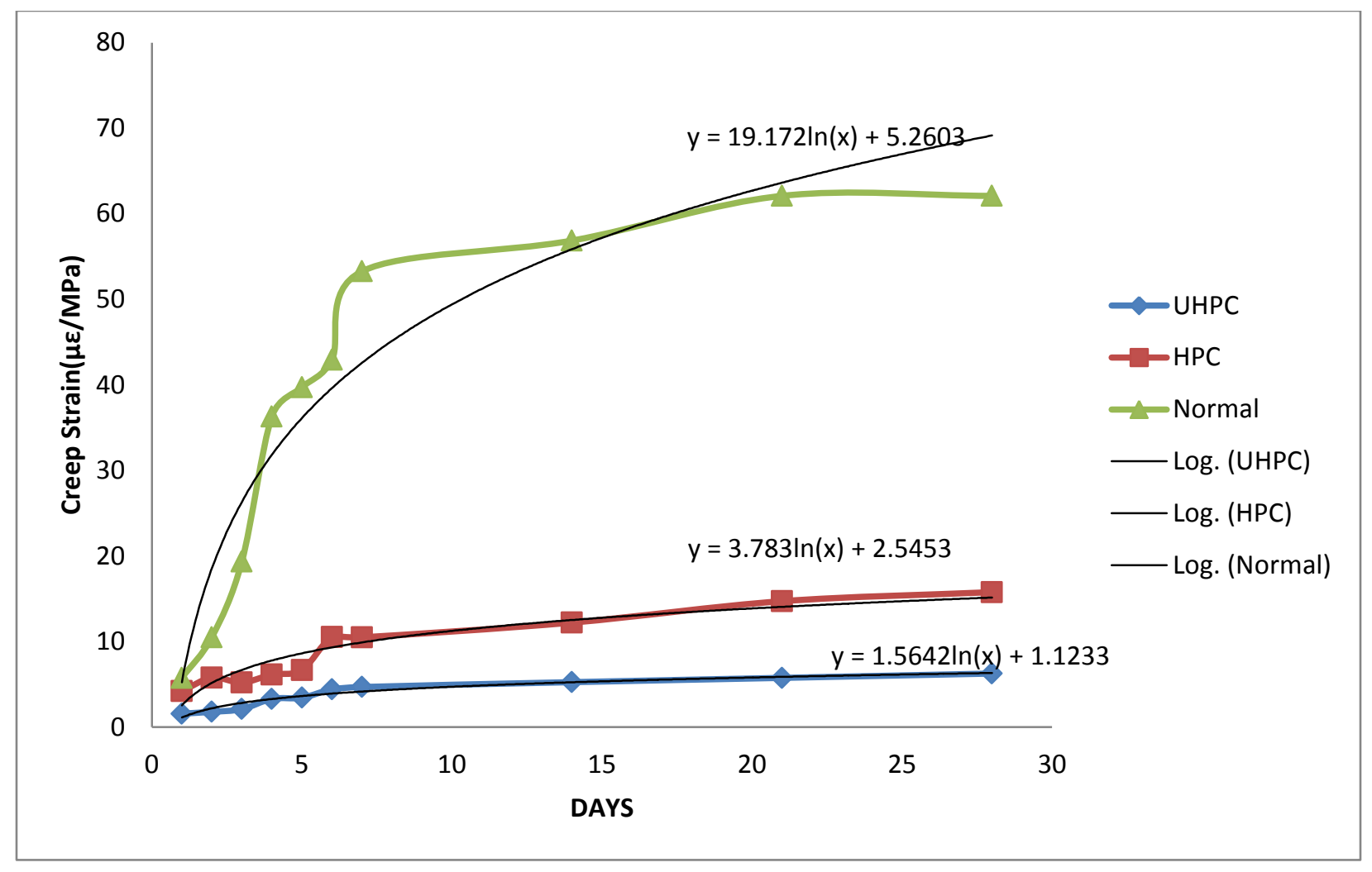

Figure 6-11 Creep strain regression lines base on 28 days results 


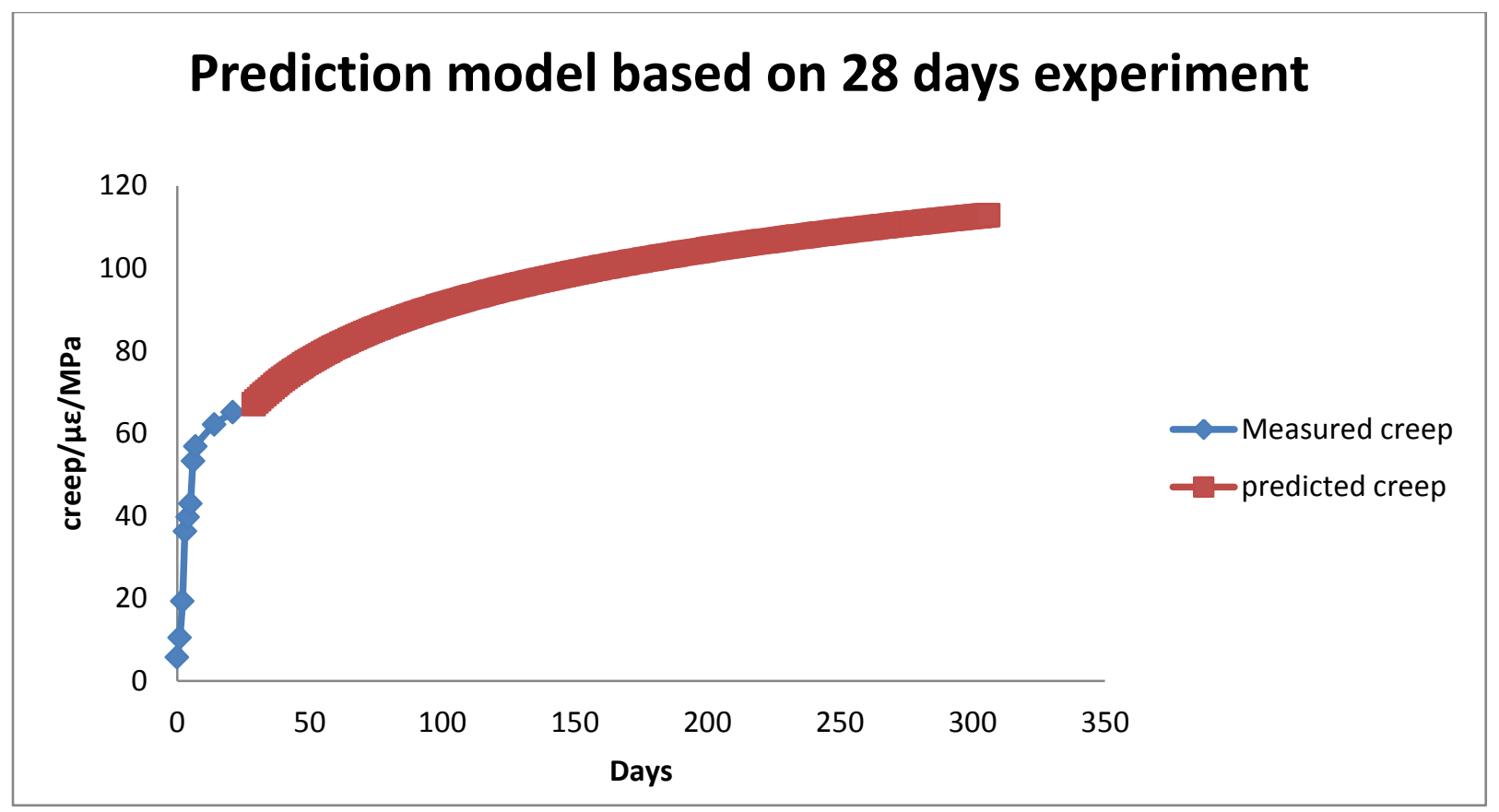

Figure 6-12 Prediction model result based on 28 days experiment results for normal NC

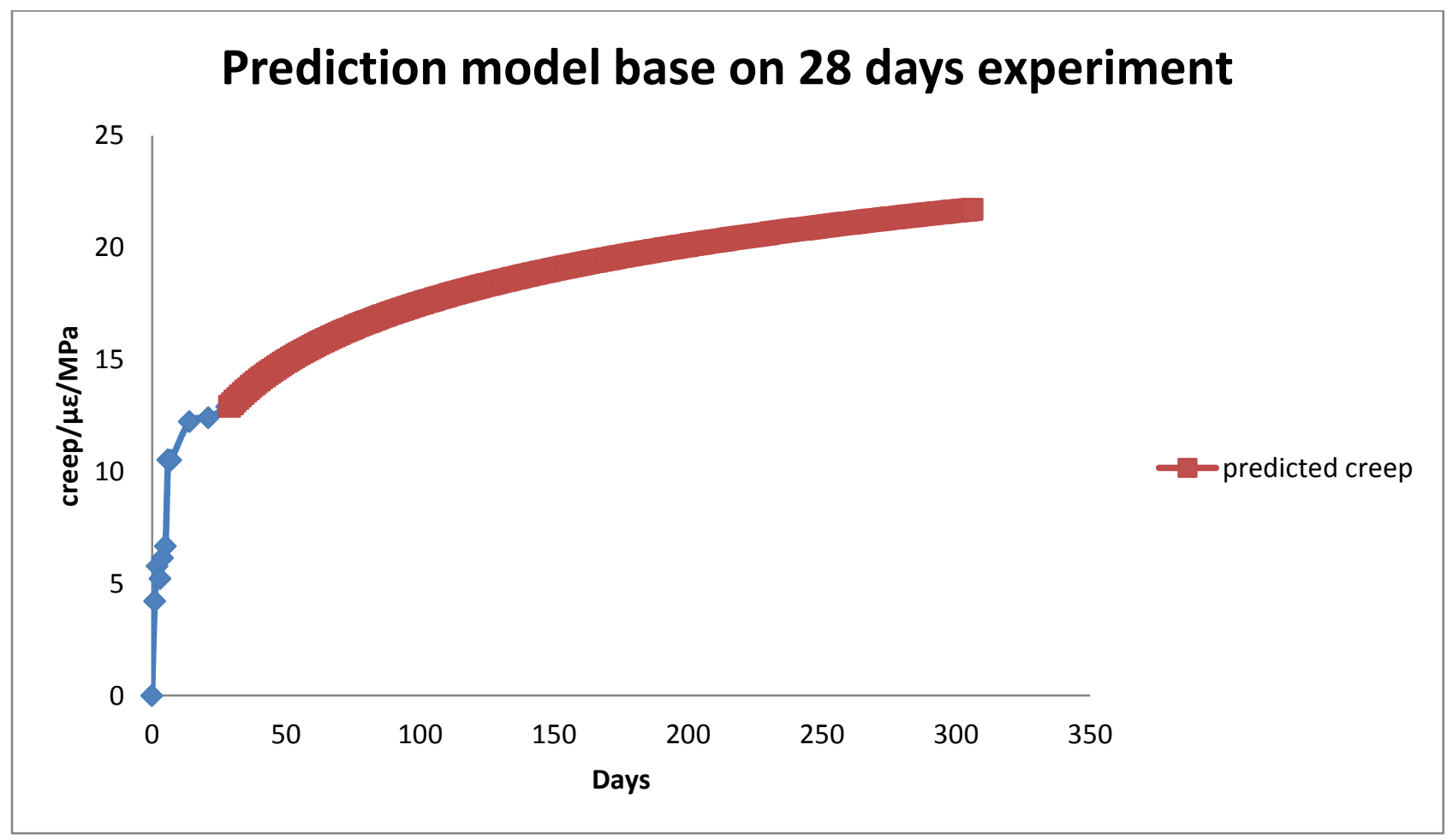

Figure 6-13 Prediction model result based on 28 days experiment results for HPC 


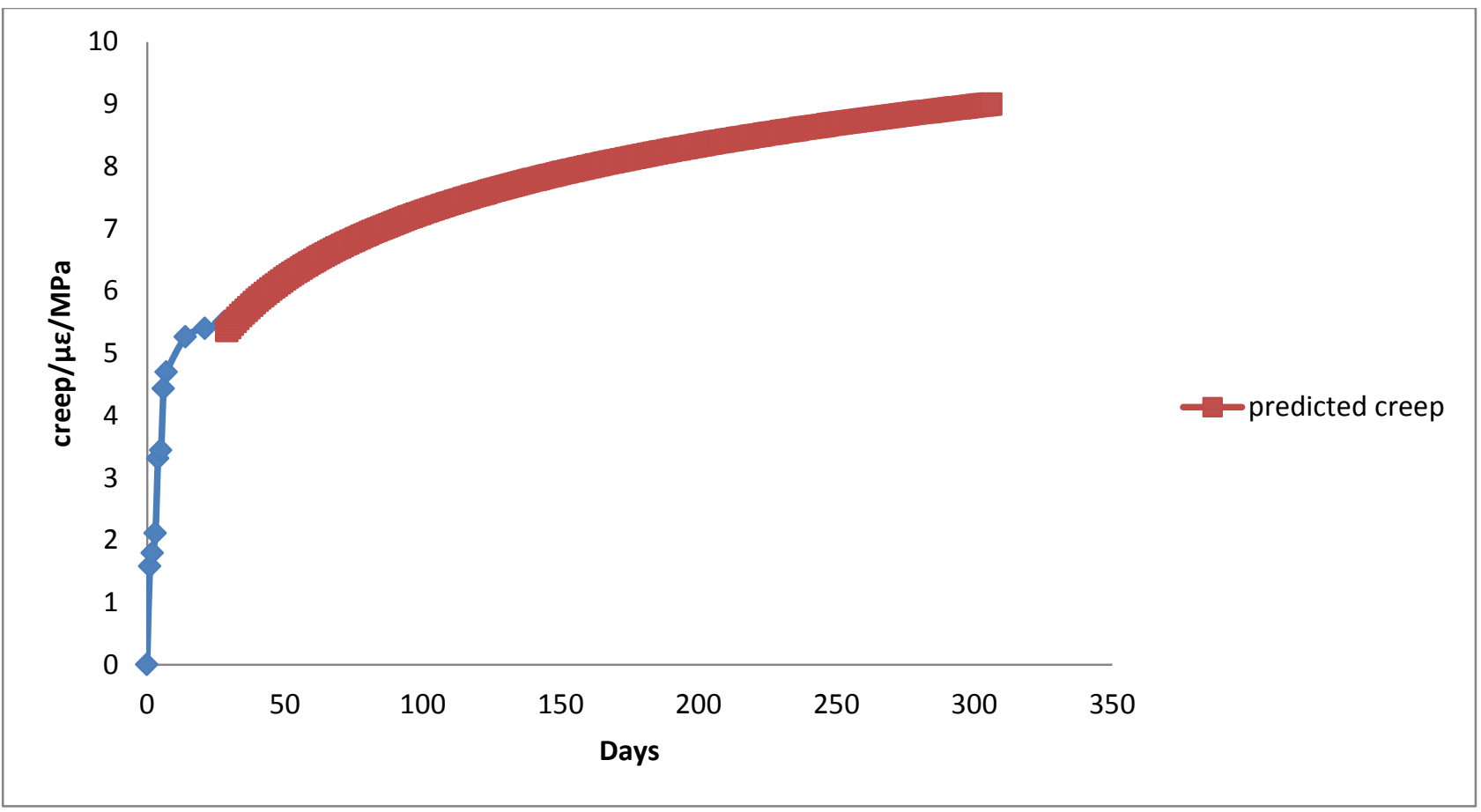

Figure 6-14 Prediction model results based on 28 days experiment results for UHPC

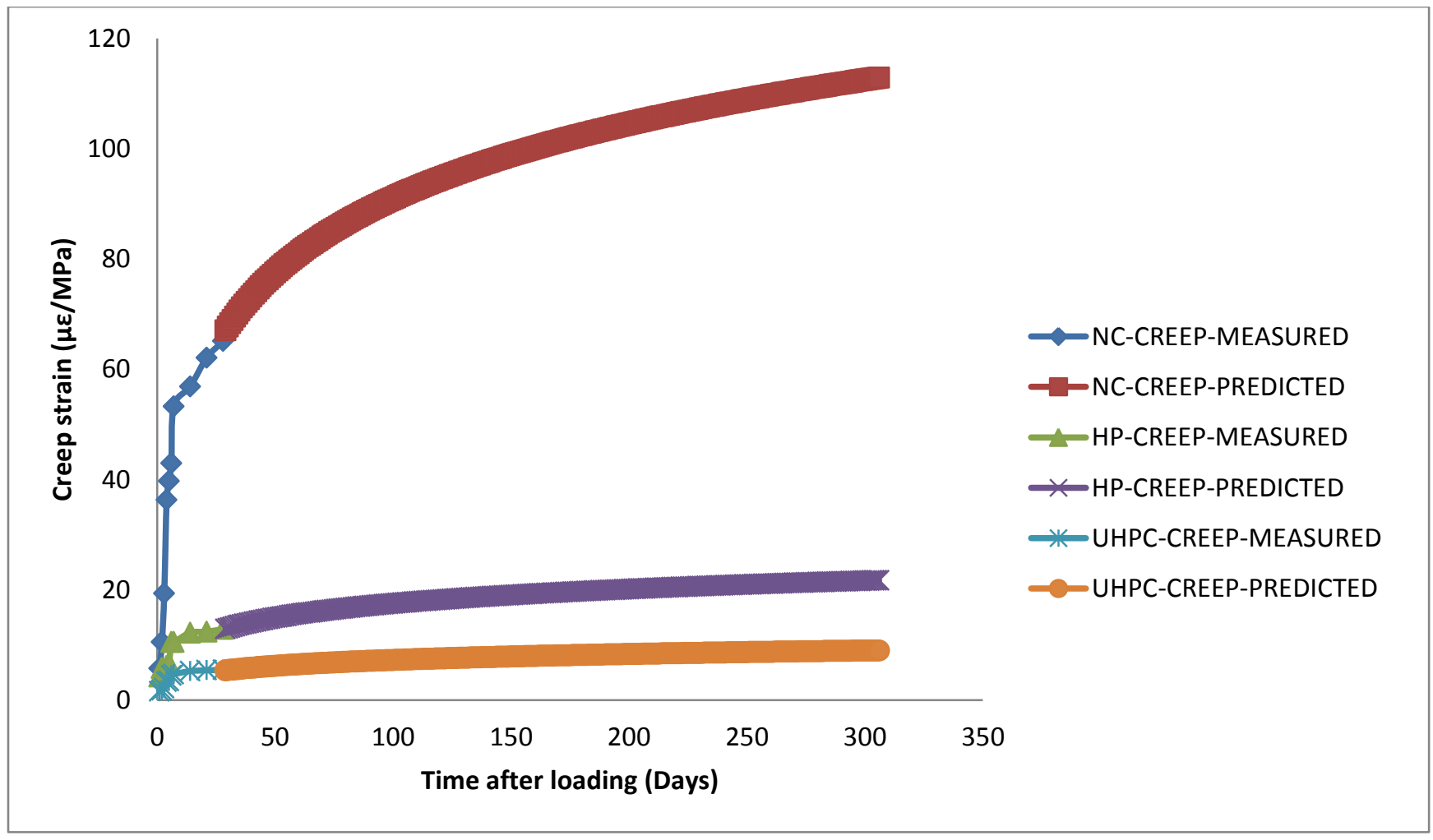

Figure 6-15 Prediction model results based on 28 days experiment results for, NC, HPC, UHPC 


\subsection{Prediction models for creep and shrinkage}

Figure 6-16 through Figure 6-23 presents the total shrinkage and creep strain predicted by models for each type of NC, HPC and UHPC. The predicted strains were calculated using the measured concrete parameters for each type of concrete. The following models were considered:

- $\quad$ ACI 209R-92(ACI209)

- Bazant's B3 Model (B3)

- Comite Euro-International Du Beton Model Code 1990( CEB90)

- $\quad$ Modified CEB90(CEB90-99)

- Gardner and Lockman’s GL2000 Model (GL2000)

The summary of creep and shrinkage strain predictions are summarized in tables 6-2 and 6-3.

\subsubsection{Creep Prediction}

The experimental results almost matched most prediction models for NC. However, prediction models are not designed to predict very first days of loading. Thus, the predictions for the first 7 days were over predicted and after 28 days experimental results and predictions gradually converged. The models over predicted creep strain of HPC and UHPC due to stress level applied for creep test. The different type of measurement and experimental condition would be another reason for over predication.

\subsubsection{Shrinkage Prediction}

Most prediction models and experimental models achieved good agreement for drying shrinkage strain measurement. The ACI 209 model over predicted the shrinkage in all three types of concrete. GL200 and CEB 90 predictions for HPC and UHPC were in the same range as experiments. 
Table 6-2 Creep strain prediction

\begin{tabular}{|l|l|l|l|}
\hline Prediction models & NC & HPC & UHPC \\
\hline ACI & In range & Over prediction & Over prediction \\
\hline B3 & In range & Over prediction & Over prediction \\
\hline CEB90 & In range & Over prediction & Over prediction \\
\hline CEB90-99 & In range & Over prediction & Over prediction \\
\hline GL200 & In range & Over prediction & Over prediction \\
\hline
\end{tabular}

Table 6-3 Shrinkage strain predictions

\begin{tabular}{|l|l|l|l|}
\hline Prediction models & NC & HPC & UHPC \\
\hline ACI & In range & Over prediction & Over prediction \\
\hline B3 & In range & Over prediction & Over prediction \\
\hline CEB90 & Under prediction & In range & In range \\
\hline CEB90-99 & Under prediction & In range & In range \\
\hline GL200 & Under prediction & Under prediction & Under prediction \\
\hline
\end{tabular}




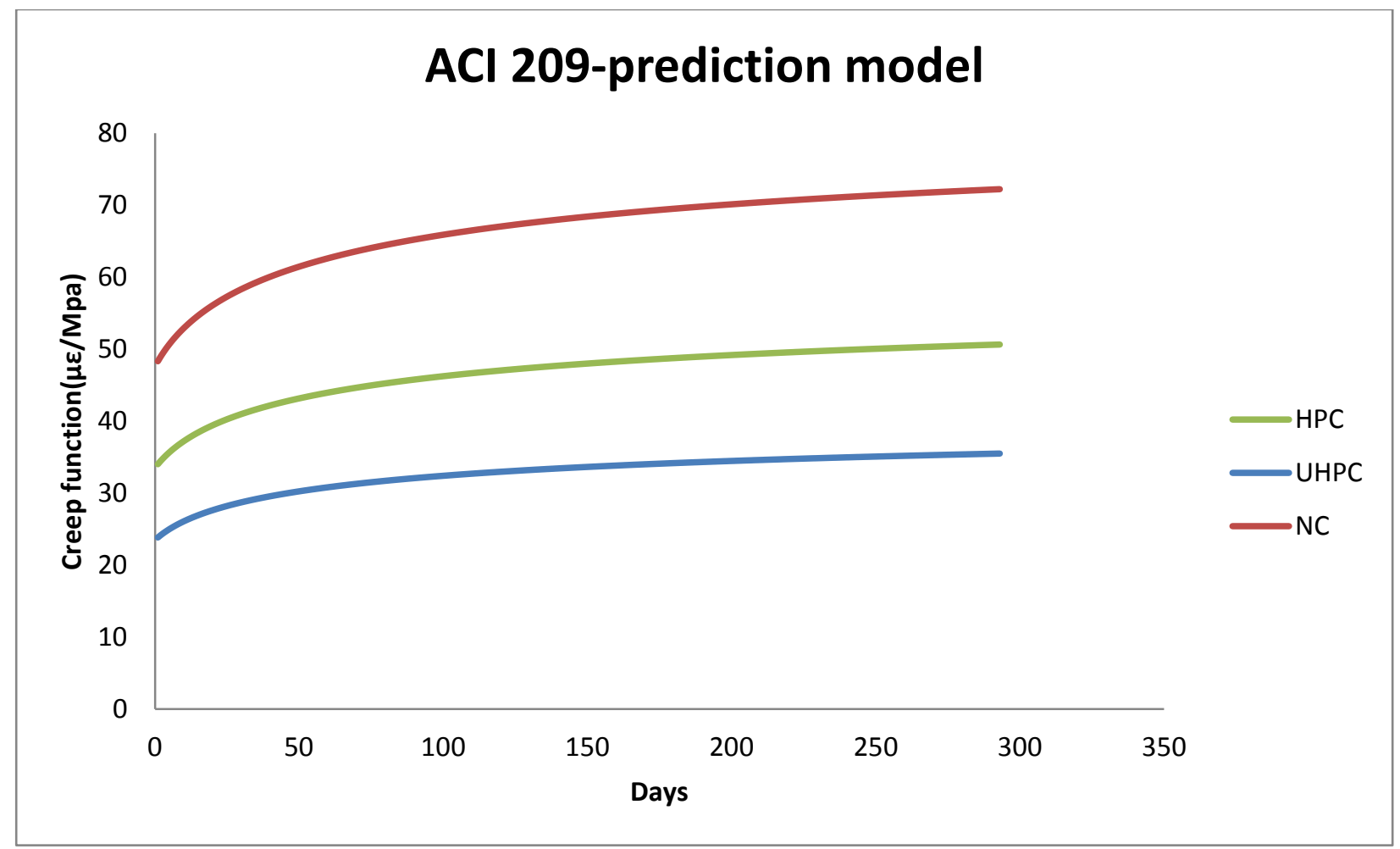

Figure 6-16 ACI209 Prediction Model

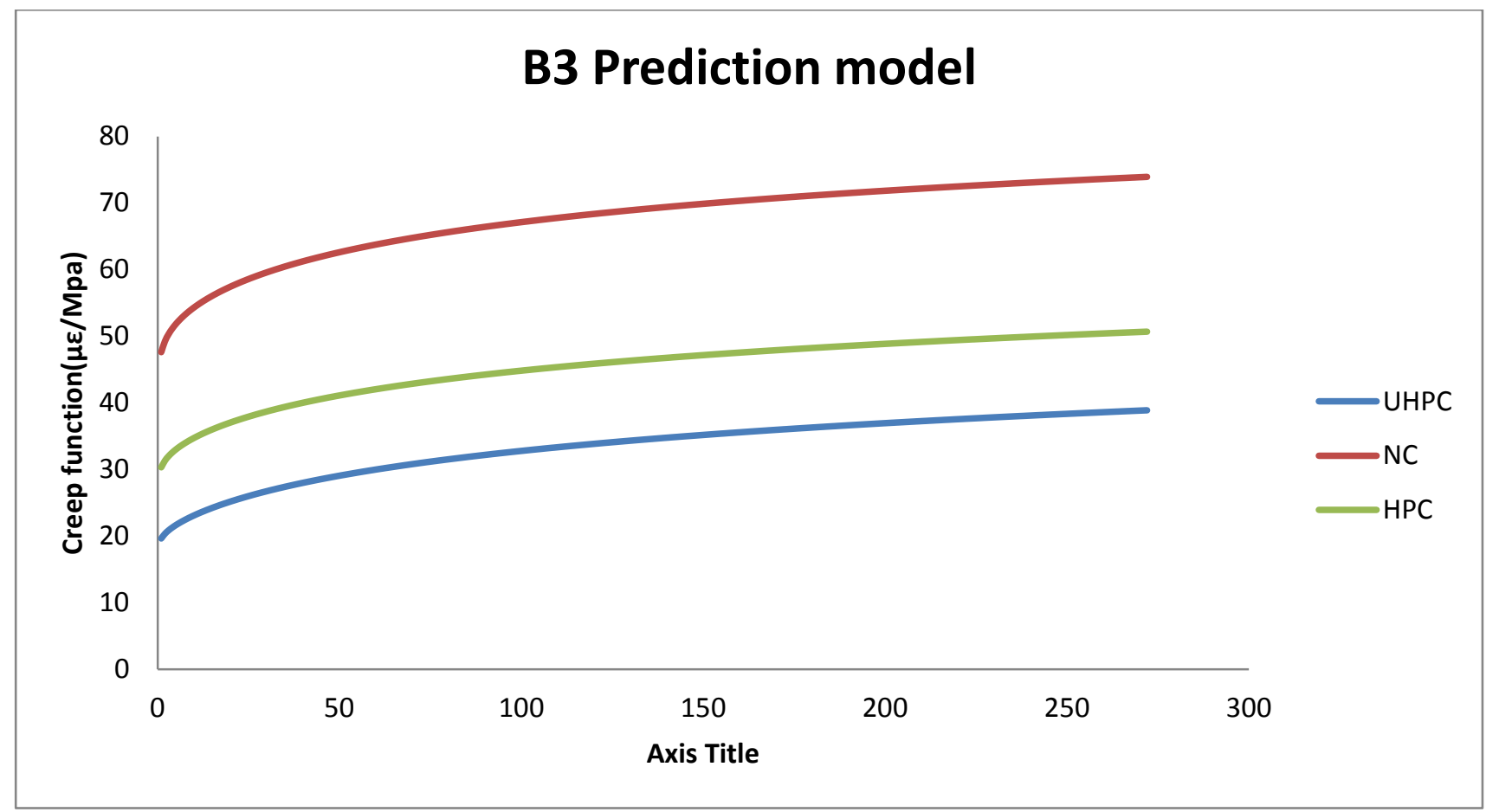

Figure 6-17 B3 Prediction Model 


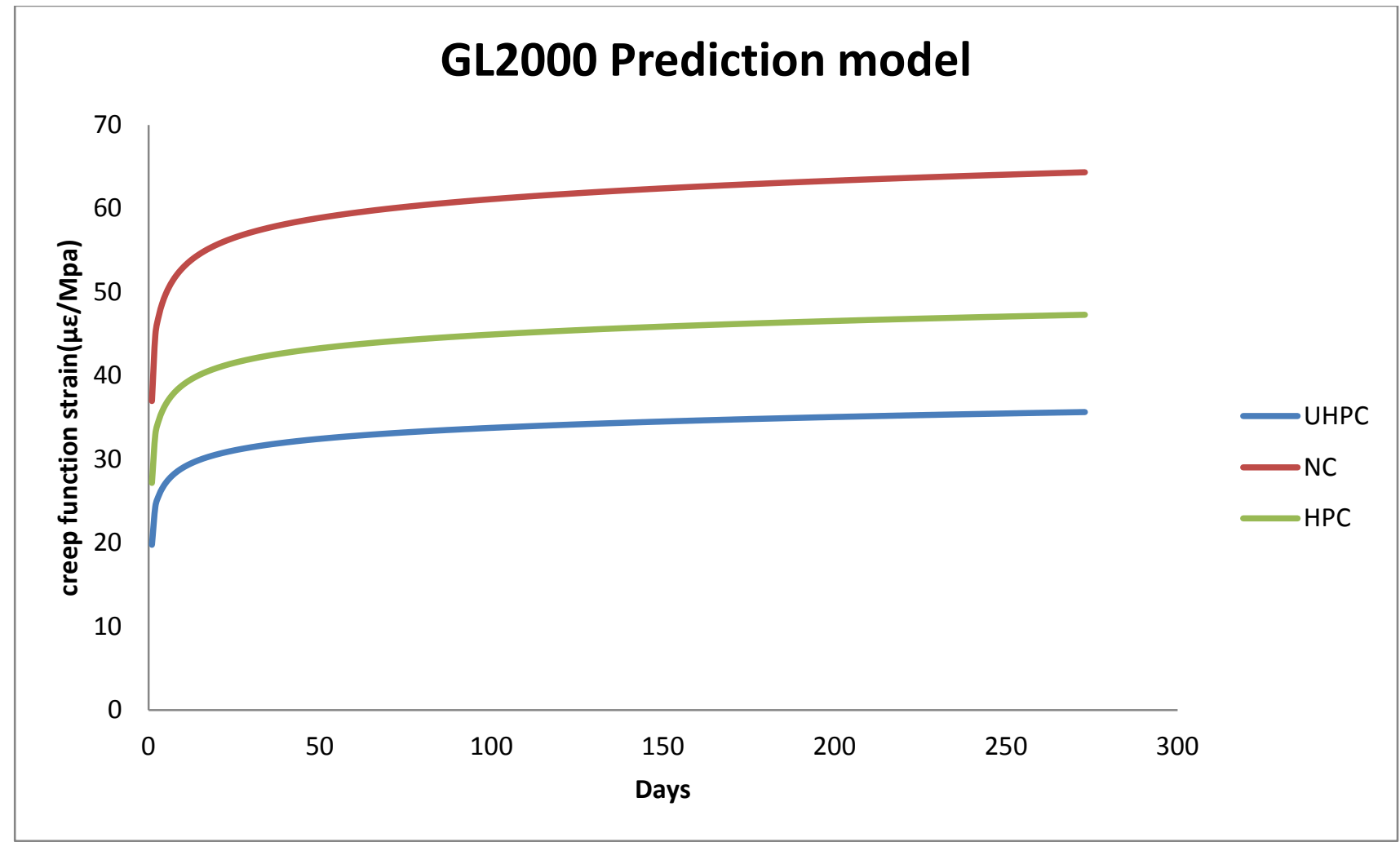

Figure 6-18 GL2000 Prediction Model

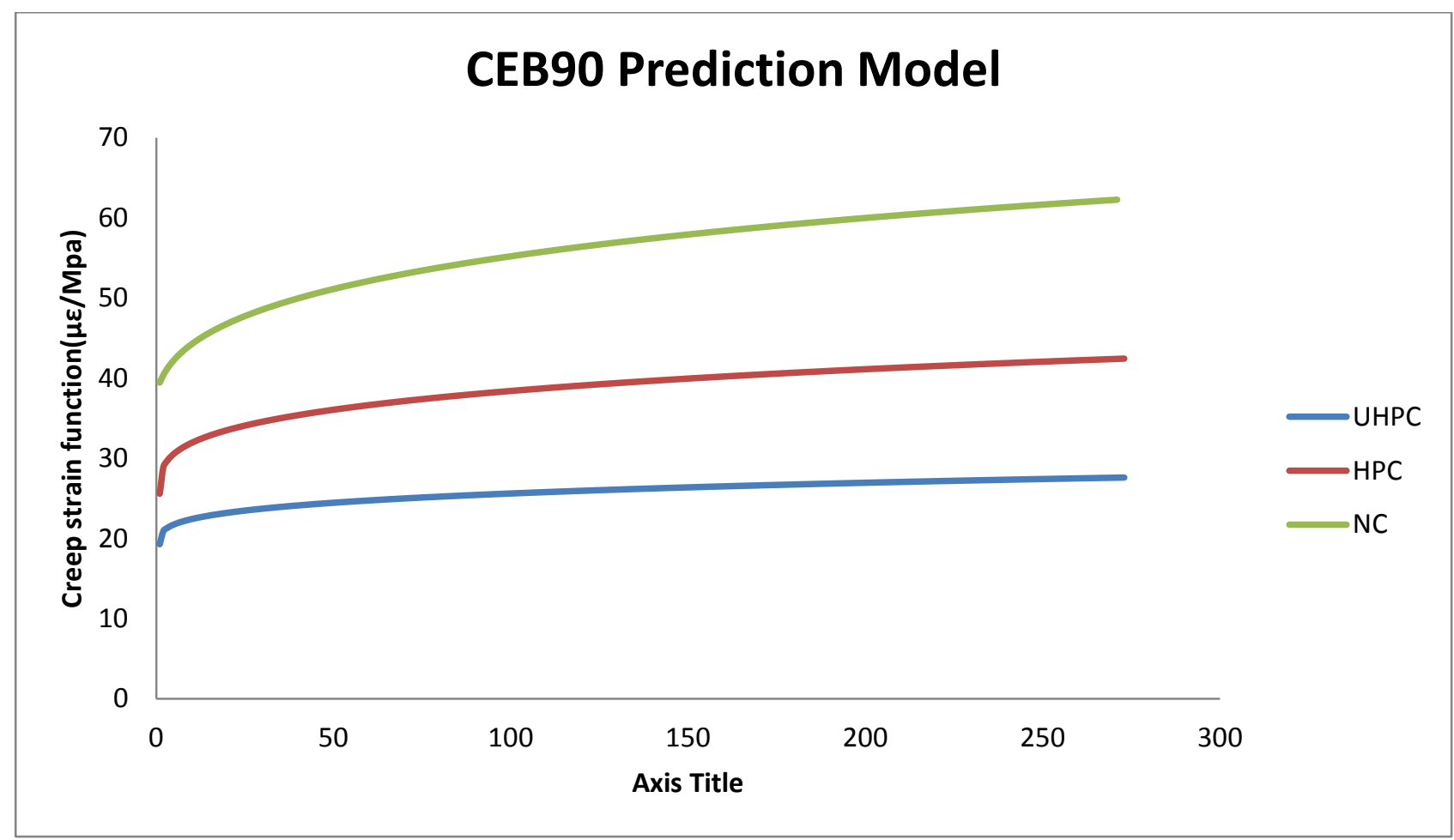

Figure 6-19 CEB90 Prediction Model 


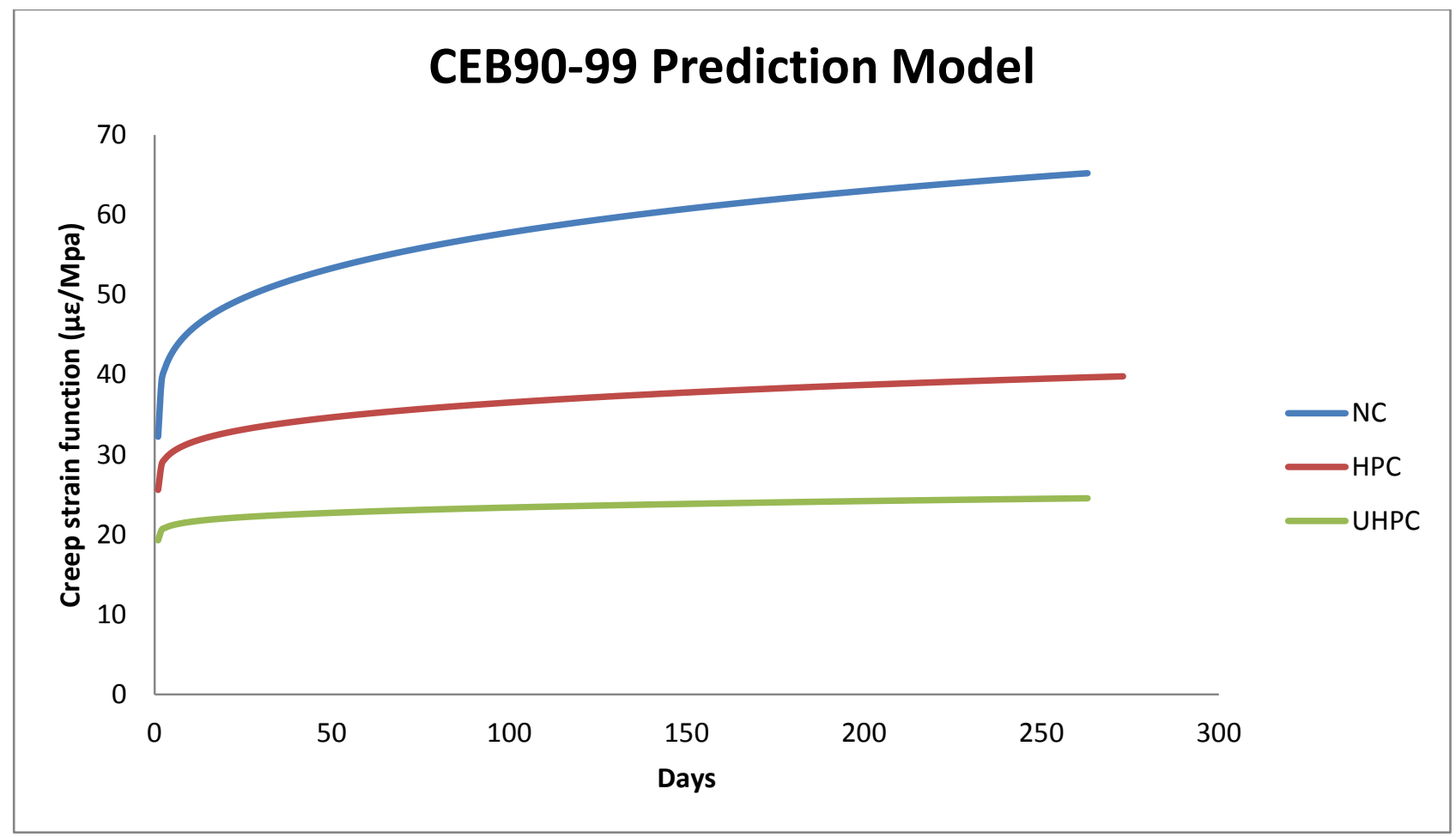

Figure 6-20 CEB90-99 Prediction Model

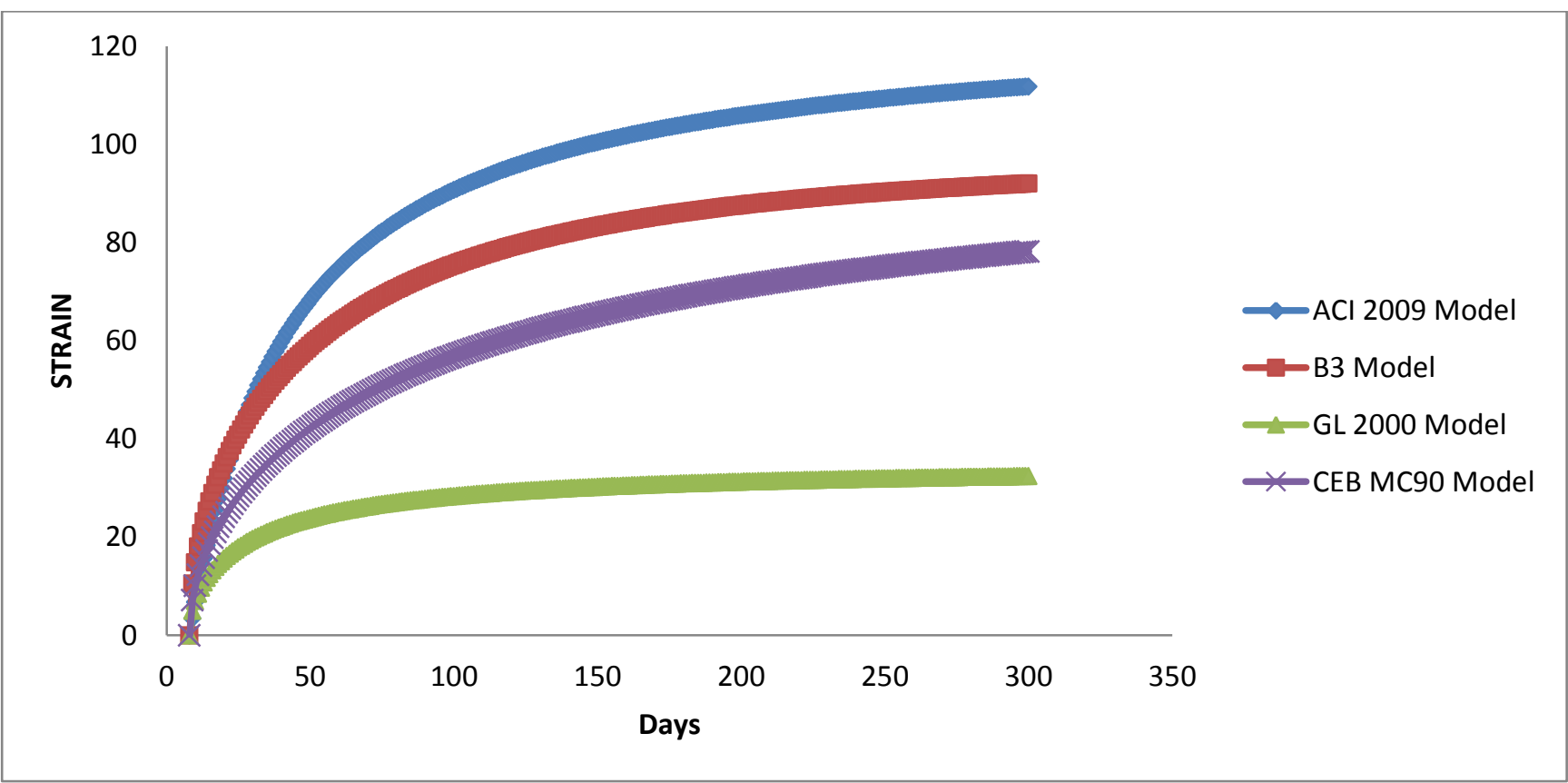

Figure 6-21 Shrinkage Prediction Model of NC 


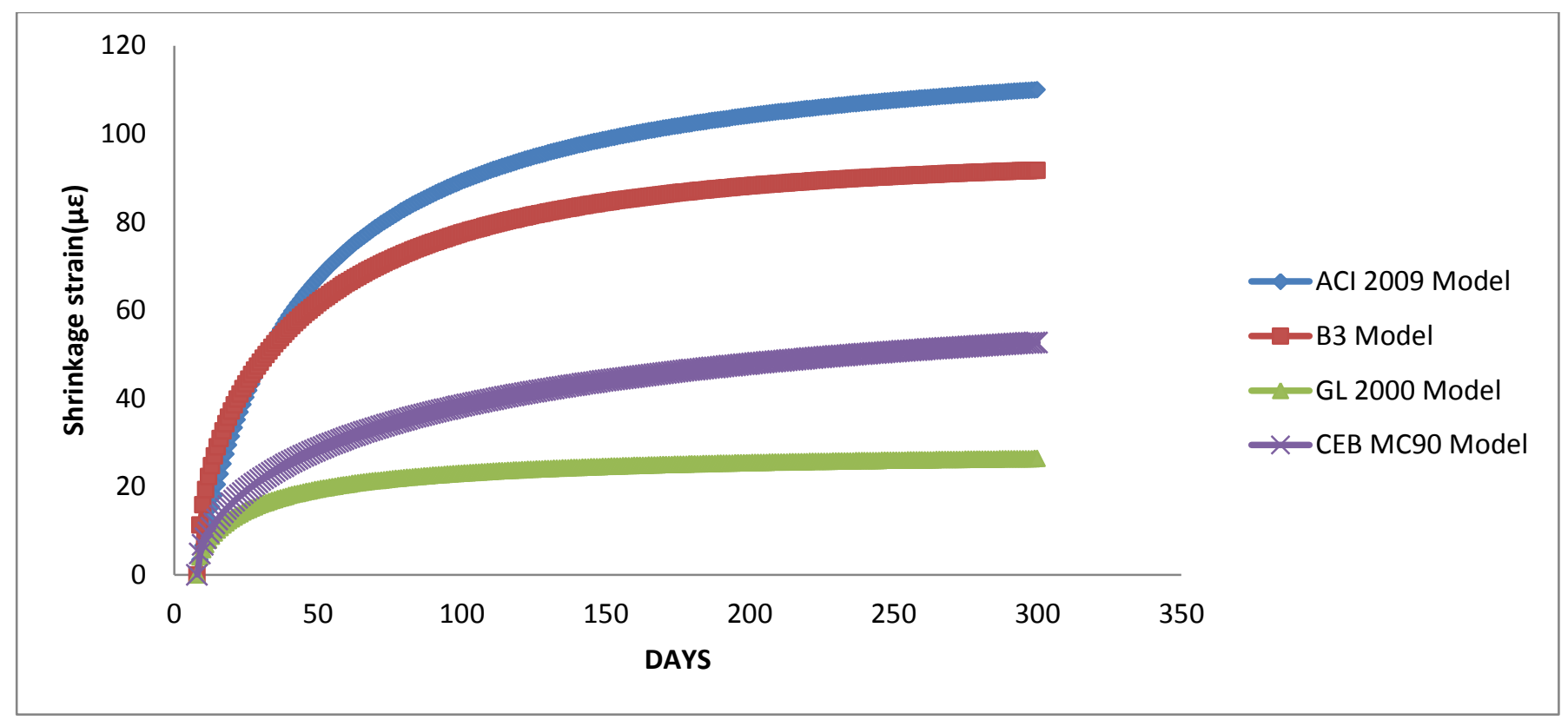

Figure 6-22 Shrinkage Prediction Models of HPC

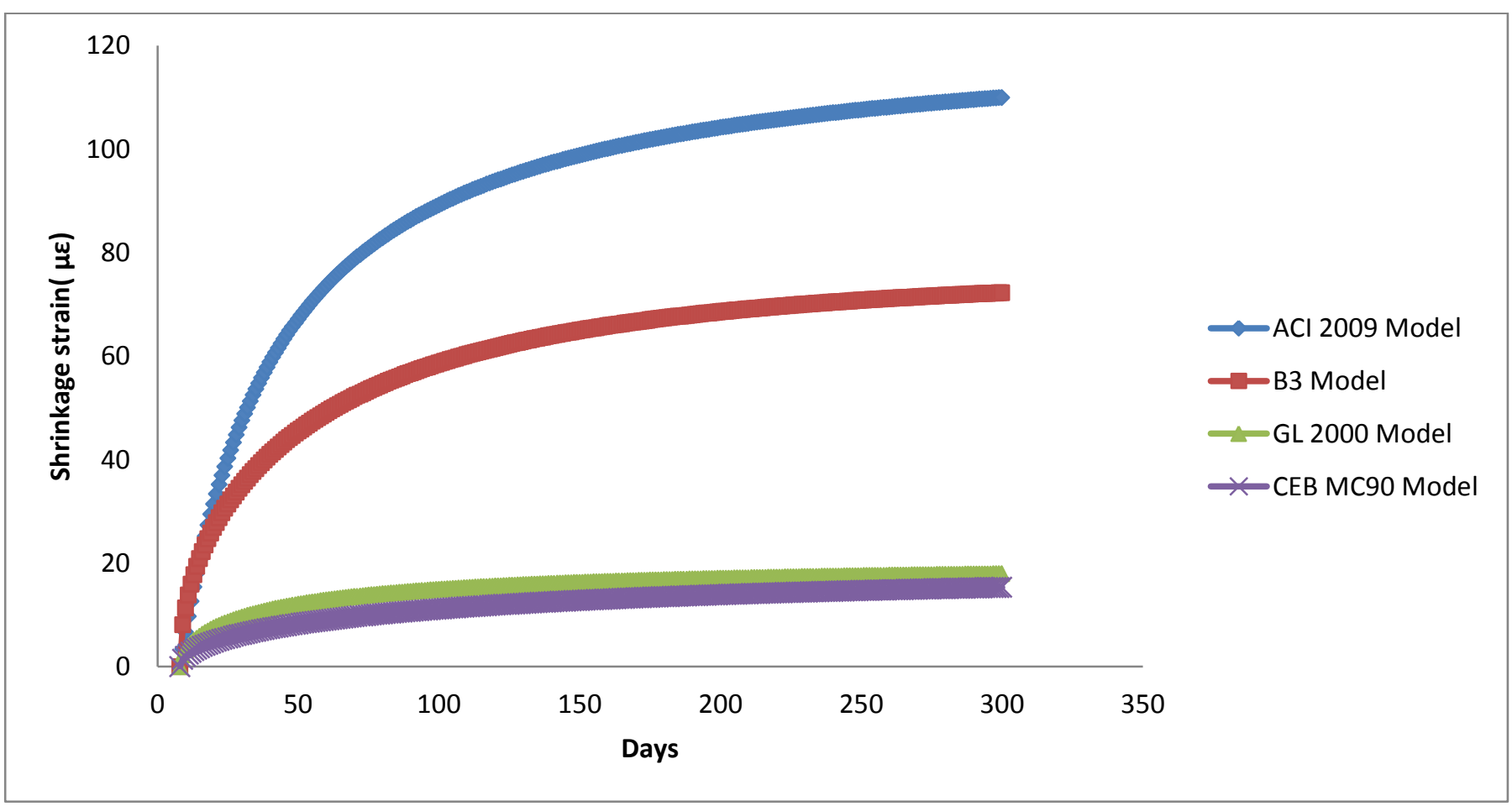

Figure 6-23 Shrinkage Prediction Models of UHPC 


\subsection{Summary}

In this phase of research the FBG sensors were used to investigate, shrinkage and creep of three different grades of concrete. The results were compared with displacement recorded with MTS machine as well as some prediction models. Also, the accuracy of prediction models based on experimental results was discussed. Therefore, it can be concluded all prediction models over predicted for HPC and UHPC, since all models have compressive limit of less than $65 \mathrm{MPa}$. Therefore, for HPC and UHPC creep prediction it is recommended to conduct creep testing for 28 days in order to get accurate concrete creep prediction properties, then use prediction models to predict creep for later ages.

Creep and shrinkage of concrete are complicated phenomenon which is difficult to model. But, measurement of creep and shrinkage is necessary to deign safe and economical structures. The fiber-optic technique is a good alternative to the conventional strain gauge for the studies of time-dependent properties of concrete such as strain in different application of civil structures. 


\section{References}

ACl Committe 209, 2004. Prediction of Creep, Shrinkage and Temperature Effects in Concrete Structures(209R-92), Detroit,Michigan: American Concrete Institute.

ACl committee 209, 2004. Guide for Modeling and Calculation Shrinkage and Creep in Hardend Concrete, s.I.: American Concrete Institute.

$\mathrm{ACl}, 1957$. symposium on shrinkage and creep of concrete. ACl journal 53.

Allan C.L, W., Paual A, C., Willam, T. \& Nadarajah, G., 2006. MONITORING OF SHRINKAGE AND CREEP OF CONCRETES USING FIBER BRAGG GRATING SENSORS. advances in structural engineering, 10(3), p. 219.

Al-Manasser, A. \& Lam, J., 2005. Statistical Evaluation of Shrinkage and Creep and Shrinkage. Revue Francaise de Genie Civil,special issue:Creep and Shrinkage of Concrete, pp. 170-176.

Ansari, F. \& Sture, S., 1992. Nondestractive testing of concrete elements and structure.

ASTM, C., 2009. Standard Test Method for Creep of Concrete in Compression.

ASTMC469, 2002. ASTM C469-02 Standard Test Method for Static Modulus of Elasticity and Poisson's Ratio of Concrete in Compression, s.I.: s.n.

Bazan, Z. \& OH, H., 1982. Strain-rate effect in rapid triaxial loading of concrete. Engineering Mechanics, Volume 108, pp. 764-782.

Branko, G. \& Daniele, I., 2007. FIBER OPTIC METHODS FOR STRUCTURAL HEALTH MONITORING. England: Wiley\&Sons, Ltd.

Branson, D. \& Christiason, M., 1971. Time Dependent Concrete Properties Related to Design-Strength and Elastic Properties, Creep and Shrinkage. Amrican Concrete Institute, Farmington Hills.

Brzev, S. \& Pao, J., 2006. Reinforced Concrete Desgin, A practical approch. Toronto: Prentic Hall.

BS, 1983. Testing concrete method for determination of static modulus of elasticity in compression, s.l.: British Standards Institution.

CEB, 1999. Structural Concrete-Textbook on Behaviour,Desgin and Performance.Updated Knowledge of the CEB/FIP Model Code 1990. Lausanne Switzerland: Federation Internationale due Beton.

Domone, P. \& Illston, J., 2010. Construction Materials: Their Nature and Behaviour. New York: Spon Press.

Federal Highway Adminstration, 2006. Material Property Characterization of Ultra-High Performance Concerte, s.I.: U.S. Department of transpotation. 
Friebele, E., 1998. Fiber Bragg grating strain sensors: present and future applications in smart structures. Optic Photon News, pp. 33-38.

Gardner, N. \& Lockman, M., 2001. Design Provisions for Drying Shrinkage and Creep of Normal Strength Concrete. ACl Matreials Journal, pp. 159-167.

Gilbert, R., 1983. Time effects in concrete Stuctures. Amseterdam: Elsevier.

Gilbert, R., 1988. Time effects in concrete structures. Amsterdam: Elsevier.

Glisic, B. \& Inaudi, D., 2007. Fibre optic methods for structural health monitoring. New York: Wiley.

Hassoun, M. \& AL-Maraseer, A., 2005. Structural Concrete :Theory and Desgin. 5th ed. s.I.:JOHAN WILEY \& SONS INC.

Hong-Nan, L., Dong-Sheng, L. \& Gang-Bing, s., 2004. RECENT APPLICATION OF FIBER OPTIC SENSORS TO HEALTH MONITORING. ELSEVER, p. 11.

Jianyong, L. \& Yan, Y., 2001. A study on creep and drying shrinkage of high performance concrete. Pergamon-Cement and Concrete Research, Volume 31, pp. 1203-1206.

Kin-tak, L., Chi-Chiu, C., Li-min, Z. \& Wei, J., 2001. Strain Monitoring in composite-strengthed concrete structure using optical fiber sensors. ELSEVER.

Marzouk, H., 1991. Creep of high-strength concrte and normal-strength concrete. Magazine of Concrete Resreach, p. 43.

McDonald, D. \& Roper, H., 1993. Accurancy of Prediction Models for Shrinkage of Concrete. ACI Materials Journal , pp. 265-271.

Mohammed, A., Fraid B.J, A. \& Al-janabi, A., 1990. Stress-Strain Relationship for concrte in compression made of loacal materials. Engineering Science, 2(183-194), pp. 183-104.

Mokhtarzadeh, A. \& French, C., 2000. Time-Dependent Properties of Hih-Strength Concrete with Consideration of Precast Applications. ACI Materials Journal, 97(3), pp. 263-271.

Neville, A., 1999. Properties of Concrete. s.l.:Longman.

Neville, A., 1970. Creep of Concrete:Plan, Reinforced, and Prestressed. AMSETERDAM: NORTH-HOLAND PUBLISHING COMPANY.

Neville, A., 2002. Propreties of Concrete. fourth ed. s.I.:Longman.

Neville \& Brooks, 1983. Creep of Plan and Structural concrete. London: Longman Group.

Oh, B., 1990. Fracture-Behavior of concrete under High-Rates of Loading ,. Eng Fract Mech, Volume 35, pp. 327-332. 
Pickett, G., 1956. Effect of Aggregate on shrinkage of concrete and Hypothesis Concerning Shrinkage. ACl Journal 52.

Pu, 2010. Fiber Bragg Grating Manual, s.I.: s.n.

Rizk, E., Marzouk, H., Hussein, A. \& Gu, X., 2012. Structural health monitoring of slab column connection using FBG. Civil Struct Health Monitoring.

Ruiz, G. et al., 2009. Effect of laoding rate on the fracture enrgy of high-strength concrete.

Smadi, M. M., Slate, F. O. \& Nilson, A. H., 1996. shrinkage and creep of high,medium ,and low strength concretes, including overloads. ACI Materials Journal, 93(5), pp. 409-415.

Soliman, A. M. \& Nehid, M. L., 2013. Self-Restraining Shrinkage Ultra-High Performance Concrete :Mechanisims and Evidance. ACI Materials Journal, p. 355.

Teng, J., 2007. Advance in Structural Engineering. An International Journal.

Tennyson, R. et al., 2001. Structural health Montoring of innovation bridges in Canada with fiber optic sensors. Smart Mater Struct, pp. 10(3):560-573.

Wiegrink, K., Marikunte, S. \& Shah, S., 1996. Prediction of high strength concrete. ACl Materials Journal, pp. 409-415.

Yan, D. \& Lin, G., 2006. Dynamic Properties of concrete in direct tenstion. ELESEVIER, March, pp. 13761338.

Zdenek, Bazant \& Sandeep, 2001. Creep and Shrinakge Prediction Model for Analysis and Desgin of Concrete Structures: Model B3, s.I.: ACI Concrete Interntional ACI23.

Zhi, Z. \& Jinping, O., 2005. Development of FBG sensors for structural health monitoring in civil infrastructure. pp. 1997-207. 